\title{
Ethics support in elderly care : developments and specific needs for ethics support, and an evaluation of Moral Case Deliberation in two Dutch elderly care organizations
}

Citation for published version (APA):

van der Dam, S. (2012). Ethics support in elderly care : developments and specific needs for ethics support, and an evaluation of Moral Case Deliberation in two Dutch elderly care organizations. [Doctoral Thesis, Maastricht University]. Datawyse / Universitaire Pers Maastricht.

https://doi.org/10.26481/dis.20121205sd

Document status and date:

Published: 01/01/2012

DOI:

10.26481/dis.20121205sd

Document Version:

Publisher's PDF, also known as Version of record

Please check the document version of this publication:

- A submitted manuscript is the version of the article upon submission and before peer-review. There can be important differences between the submitted version and the official published version of record. People interested in the research are advised to contact the author for the final version of the publication, or visit the DOI to the publisher's website.

- The final author version and the galley proof are versions of the publication after peer review.

- The final published version features the final layout of the paper including the volume, issue and page numbers.

Link to publication

\footnotetext{
General rights rights.

- You may freely distribute the URL identifying the publication in the public portal. please follow below link for the End User Agreement:

www.umlib.nl/taverne-license

Take down policy

If you believe that this document breaches copyright please contact us at:

repository@maastrichtuniversity.nl

providing details and we will investigate your claim.
}

Copyright and moral rights for the publications made accessible in the public portal are retained by the authors and/or other copyright owners and it is a condition of accessing publications that users recognise and abide by the legal requirements associated with these

- Users may download and print one copy of any publication from the public portal for the purpose of private study or research.

- You may not further distribute the material or use it for any profit-making activity or commercial gain

If the publication is distributed under the terms of Article $25 \mathrm{fa}$ of the Dutch Copyright Act, indicated by the "Taverne" license above, 


\section{Ethics support in elderly care}

Developments and specific needs for ethics support, and an evaluation of Moral Case Deliberation in two

Dutch elderly care organizations

Sandra van der Dam 
(C) Copyright Sandra van der Dam ISBN 9789461591975

Printed by Datawyse | Universitaire Pers Maastricht

Het schilderij op de cover is gemaakt door Nanne Schlukebir. 


\title{
Ethics support in elderly care
}

Developments and specific needs for ethics support, and an evaluation of Moral Case Deliberation in two

Dutch elderly care organizations

\author{
PROEFSCHRIFT \\ Ter verkrijging van de graad van doctor aan de Universiteit Maastricht, \\ op gezag van de Rector Magnificus, \\ Prof dr. L.L.G. Soete \\ volgens het besluit van het College van Decanen, \\ in het openbaar te verdedigen \\ op woensdag 5 december 2012 om 12.00 uur \\ door
}

Sandra van der Dam

Geboren op 26 april 1974 te Oudehorne

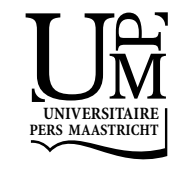




\section{Promotores:}

Prof. dr. T.A. Abma, VUMC Amsterdam

Prof. dr. G.A.M. Widdershoven, UM / VUMC Amsterdam

Prof. dr. M.J.M. Kardol, VU Brussel

\section{Beoordelingscommissie:}

Prof. dr. G.M.W.R. de Wert (voorzitter)

Prof. dr. J.P.H. Hamers

Prof. dr. K. Horstman

Dr. M.J.P.A. Janssens (VUMC, Amsterdam)

The research presented in this thesis was conducted at the School for Public Health and Primary Care: CAPHRI, Department HES, of Maastricht University, with financial support of Vughterstede and Vivre. CAPHRI participates in the Netherlands School of Primary Care Research CaRe. CAPHRI was classified as 'excellent' by the external evaluation committee of leading international experts that reviewed CAPHRI in December 2010. 


\section{Contents}

CHAPTER 1 General introduction 7

CHAPTER 2 Ethics support in elderly care: a review of the literature 19

S. van der Dam, B. Molewijk, G. Widdershoven, T. Abma.

Submitted

CHAPTER 3 Morality in the mundane. Specific needs for ethics support in elderly care

L. Dawwerse, S. van der Dam, T. Abma. Nursing Ethics, 2012, 19(1), 91-103.

CHAPTER 4 "Here's my dilemma". Moral Case Deliberation as a platform for discussing everyday ethics in elderly care

S. van der Dam, T. Abma, M. Kardol, G. Widdershoven.

Health Care Analysis, 2012, 20(3), 250-267

CHAPTER 5 Organizing Moral Case Deliberation. Experiences in two

Dutch nursing homes

S. van der Dam, T. Abma, B. Molewijk, M. Kardol, J. Schols, G.

Widdershoven. Nursing Ethics, 2011, 18(3), 327-340.

CHAPTER 6 The Discovery of Deliberation. From ambiguity to appreciation through the learning process of doing Moral Case Deliberation in Dutch elderly care

S. van der Dam, J. Schols, M. Kardol, B. Molewijk, G. Widdershoven, T. Abma.

Re-submitted after review

CHAPTER 7 General discussion

Summary

Samenvatting

Dankwoord

Curriculum Vitae 



\section{Chapter 1}

General introduction 
The first part of this thesis (chapters 2 and 3) explores the field of ethics support in elderly care from an international perspective and investigates the specific needs for ethics support in elderly care in the Dutch context. The second part (chapters 4 to 6) focuses on one form of ethics support, moral case deliberation (MCD), based on the evaluation of an MCD project in two Dutch elderly care organizations. The thesis combines several empirical research methods. The first chapter provides background information and explains the theoretical foundations of MCD. A description of the research methods and the setting of the implementation project will be given. The chapter ends with an outline of the thesis.

\section{ETHICS SUPPORT IN INSTITUTIONAL ELDERLY CARE}

Ethics support, often delivered through clinical ethics support services (CESS), aims to support health care professionals in their provision of high quality care and in dealing with ethical problems in daily practice. The field of bioethics, in which clinical ethics and ethics support services are rooted, is relatively young. Since the term 'bioethics' was coined in the 1970's, there has been discussion about whether bioethics should be regarded as a discipline of its own. ${ }^{1,2}$ Over the past decades several issues have gained the attention of bioethicists, for example: advances in biological sciences and medical technology (such as organ transplant, reproductive technologies), the use of human beings in medical experiments, the unraveling of DNA structures and developments in genetics. From the beginning, bioethics has aimed at practical guidance of practices and policies and in this sense bioethics is both a discipline, based on methods and theory, and a form of discourse, promoting public debate and consensus building on substantial questions. ${ }^{1}$ This practical orientation is particularly strong in the field of clinical ethics, aiming to improve the quality of patient care by identifying, analyzing, and attempting to resolve the ethical problems that arise in practice. ${ }^{3,4}$ According to Agich, clinical ethics is an activity that is deeply engaged in the clinical setting. ${ }^{4}$

When it comes to dealing with ethical issues in the context of elderly care we need to take into account the specific nature of care and care receivers. Unlike hospitalized patients, residents in elderly care stay for a longer period, they often suffer from chronic or complex physical problems, and when mental capacities decrease, residents' autonomy may become threatened. Residents live in the institution; most of their life takes place in the institutional setting and to a certain extent they have to adjust to the institutional routines and share their lives with fellow-residents they did not choose themselves. ${ }^{5}$ In recent years, more attention has been paid to less easily recognized everyday ethical issues, in addition to more obvious dilemmas that come for example with endof-life-care. ${ }^{6}$

The importance of ethics support in elderly care has been stressed in the literature. Professionals in elderly care have to deal with conflicting interests, ${ }^{7}$ difficult behavior, limited resources ${ }^{8}$ and social problems between residents who did not choose to live together, ${ }^{5,} 9$ causing feelings of moral distress. ${ }^{10}, 11$ Rees et al emphasize the role that elderly care institutions should play in offering ethics support: "Nursing management must recognize the emotional stress on nurses as they endeavor to resolve ethical issues 
in the care of older people, and offer appropriate support. Organizations can and should develop more effective dialogue between professional groups in relation to these ethical issues" (p.449). ${ }^{11}$

In order to deal with these ethical issues within institutional elderly care, clinical ethics supports services have started in the 1970s. Following the example of acute care, nursing homes began to install clinical ethics committees (CECs). In the decades that followed, committees became widespread, but also alternative or complementary support services were developed to respond to specific needs in institutional elderly care, different from those in acute care. ${ }^{6}$ In the first place, ethics support forms have been developed that are more outreaching. Examples are ethics rounds, retrospective ethics discussions on real cases that are easily accessible for a large and diverse audience, or consult teams, that are more flexible than the CEC. ${ }^{12,}{ }^{13}$ Secondly, more recent forms of ethics support have been developed with a stronger focus on the development of the health care professional, for example various frameworks, which serve as analytical tools, or educational programs and MCD. ${ }^{6}$ Thirdly, instead of focusing on extraordinary cases, ethics support has become more contextual and inclusive towards both organizational ethical issues and the more mundane ethical issues. These developments have made ethics support better adjusted to the types of professionals, mostly relatively low educated staff with concrete learning styles, and the types of ethical issues in elderly care, which are different from those in hospitals. ${ }^{6}$

\section{Clinical ETHICS IN THE NETHERLANDS}

In the Netherlands, the most popular type of ethics support is the EC. Although most widespread in general hospitals, in institutional elderly care over the past decade a catch-up in the development of institutional bodies for ethics support has taken place. ${ }^{14}$ Other forms of ethics support, e.g. policies and educational programs, have also been developed. In institutions without a committee, protocols and codes are widely used. ${ }^{14}$ In Dutch elderly care, about $15 \%$ of the institutions do not have any form of ethics support.

Traditional forms of ethics support have become criticized both internationally and in the Netherlands for being bureaucratic and too distanced from practice. ${ }^{15-19}$ A new approach to ethics support was initiated by an influential Dutch discussion paper ${ }^{20}$ published in 1998, aiming to inspire administrators to develop institutional policies for improving the moral quality in the organization, as a modernization of the traditional EC. It suggested to transform ECs, which are situated far from the heart of the organization and the regular care processes, into steering committees that focus on integration of ethics within quality management, in order to enhance reflection and deliberation on moral issues where they arise. This approach distanced itself from the common concept of ethics support, where the EC is the place where moral reflection and deliberation is concentrated, and protocols are used as instruments to provide 'watertight' solutions to ethical problems. ${ }^{20}$ Instead, the author recommended implementation of moral deliberation at all levels of the organization; from the work-floor to the boardroom, using a phased approach. It was expected that in the first phase, ad hoc policy interventions 
that address the ethical issues that come to the surface first, will increase the sensibility for ethical issues and the willingness to reflect and deliberate on these issues. The second phase consists of a more programmatic approach, aiming at the integration of ethics with quality policy. The third phase focuses on mainstreaming ethics, and incorporating ethics in the regular policy cycle.

The idea of integrating ethics at all levels of health care institutions was endorsed by the Dutch government, and in 2002 clinical ethics support was put on the political agenda. The Ministry of Health, Welfare and Sport acknowledged that 'making explicit the ethical aspects of working in health care - from nursing assistant to manager - will make an important contribution to the quality of care and a respectful treatment of patients or clients'. ${ }^{21}$ A year later, media coverage of the introduction of a 'pyjamas day' in a nursing home, ${ }^{22}$ stressed the importance of ethical reflection and deliberation, stirring up the public and political debate on what should be done to improve the quality of (elderly) care. Moral case deliberation $(\mathrm{MCD})^{1}$ was presented by the Ministry as an 'instrument that can be used to recognize dilemmas and to notice the underlying values', ${ }^{23}$ in order to improve the quality of care. The further development of MCD was stimulated by the Ministry through the facilitation of and participation in a National Platform on Moral Deliberation. The platform offers both scholars in clinical ethics and representatives of ethics support initiatives in the field a forum to share their experiences and knowledge. A central theme is the implementation of MCD in health care institutions.

\section{THEORETICAL FOUNDATIONS OF MCD}

In MCD, health care professionals meet to reflect and deliberate on ethical questions and dilemmas they confront in their own work. Starting point for the deliberation is a concrete case, in which at least the case-presenter, but sometimes the whole group, is involved. In a dialogue, structured by a conversation method and under the guidance of a facilitator, participants analyze the case by exploring the perspectives, values and norms of the stakeholders involved in the case. In the Netherlands and Belgium, several academic and more practical research groups play an important role in the development of MCD in several health care settings, including elderly care. Between these research groups there are subtle differences concerning the theoretical perspectives of MCD.

Principlism is most clearly present in the Nijmegen method, which uses a standard framework (called protocol) of question to investigate a clear-cut moral question. The basic protocol has been adjusted to several different settings including nursing homes. ${ }^{19}$ The Nijmegen method is used for prospective ethical case deliberation by health care professionals in which the ethicist serves as a facilitator, not as an expert. ${ }^{19} \mathrm{~A}$ careethical approach, inspired by the work of Tronto and Walker, underlies the development of MCD from the academic (but practically orientated) ethics centers of Groningen, Tilburg and Leuven (Belgium). A care ethical approach is specifically sensitive to the

\footnotetext{
${ }^{1}$ Moral case deliberation is also referred to as moral deliberation or ethical deliberation.
} 
context of moral questions, interpersonal relations, responsibilities, power differences and narratives. ${ }^{24}$

Dialogue is important in all approaches to MCD, but it forms the heart of the dialogical-hermeneutic approach of our university research group (Vumc Amsterdam). This approach regards dialogue not only as a means but also as a basic requirement for good reflection and deliberation. Inspired by the work of Hans-Georg Gadamer (19002002), dialogue is seen as a vehicle for a learning process in which the participants listen to one another, aiming at mutual understanding. Understanding in this sense means taking on an open attitude towards the other and investigating the other's perspective. The exchange of perspectives ideally leads to reconsidering of perspectives, which may result in new perspectives replacing the old ones. Gadamer calls this a fusion of horizons. ${ }^{25}$ Hermeneutic ethics focuses on concrete experiences and is based on the assumption that ethics and morality start with actual experience, not with theories or concepts. ${ }^{26,27}$ This approach to ethics goes back to Aristotle who underlined that (moral) wisdom and (moral) knowledge originate from reflection on and within concrete situations. Dialogical ethics takes this Aristotelian approach to ethics a step further, emphasizing the interrelatedness and dialogical nature of human beings and the necessity of intersubjective reflection; moral judgements arise out of dialogue among openminded people in practice. $^{28}$

Depending on the goal of the deliberation, a conversation method is chosen to structure the dialogue. When the emphasis is on finding a resolution in a concrete case, for example the Dilemma method ${ }^{29}$ is used, which explicitly explores the various perspectives of both the stakeholders involved in the case and the participants present in the deliberation. When the emphasis is more on developing of professional's competence or a more conceptual moral question is explored (e.g. 'what constitutes good intercollegial collaboration?'), other conversation methods, for example the Socratic dialogue, are more suitable. ${ }^{28,29}$

The role of the ethicist or trained moderator in MCD is that of a facilitator, not an expert or consultant. This facilitator can be a formally trained ethicist but can also be an employee of a health care institution, who is especially trained as a facilitator in MCD. The dialogical-hermeneutical orientated facilitator is especially sensitive to the particularity of meanings and meaning-making ${ }^{27}$ and invites MCD participants to exemplify their perspective, and make explicit and reflect on the concepts they use. The participants are invited to go beyond looking for the only possible answer, meaning, decision or solution. ${ }^{27}$ When they let go of the drive to convince the other, they can become interested and open to the perspectives and meanings of other participants (including the perspectives that are not present in the MCD session) and begin to learn through actively listening and engaging in a joint moral inquiry. ${ }^{27}$ The facilitator should have expertise in guiding group processes but also needs to have moral knowledge and expertise. Being familiar with the practice under consideration enables the facilitator to help making explicit the moral considerations of participants. The facilitator will critically examine what is expressed by the group, not as an expert giving advice, but as an element of the dialogical learning process in which both the health care professionals and the facilitator participate. ${ }^{27}$ 


\section{INSTITUTIONAL ELDERLY CARE IN THE NETHERLANDS}

Currently, 2,6 million people over the age of 65 live in the Netherlands. About 4,5\% of them live in a residential institution for elderly care, the majority being over 80 years old. As the greying of the Dutch population will continue the coming decades, the numbers of elderly citizens that will be dependent on residential care will rise. It is expected and stimulated by the government that elderly people, dependent on care, stay in their own homes as long as possible. ${ }^{30}$ New developments, for example in the field of domotica, may make this possible for elderly with somatic problems, but it is expected that homecare is not sufficient for elderly suffering from dementia, they probably will stay dependent on institutional care.

Institutional elderly care evolved from the care for the old and poor as it was organized before the Second world war, financed by the church and charity organizations, ${ }^{31}$, 32 into professional institutional elderly care financed by the government. Nowadays, two types of elderly care institutions can be distinguished in the Netherlands: the care home and the nursing home. Care homes and nursing homes differ in the degree of intensity and complexity of the care and treatment offered to the residents. The care home is meant for elderly who are no longer able to live independently, who need assistance with cleaning, personal care and (social) activities. In a care home, a resident has his or her own front door, and receives (para)medical care from his or her own general practitioner and other professionals (e.g. a physiotherapist). A nursing home provides more intensive care and treatment for residents who suffer from a chronic disease, severe physical impairments or dementia. Nursing homes employ their own paramedical and psychosocial staff and medical care is provided by a specially trained nursing home physician (specialist ouderengeneeskunde). ${ }^{33}$ Sometimes nursing home care is provided to residents who live in a care home, for example in specialized psychogeriatric units. Often care homes and nursing homes provide day care for their own residents (in a care home) and for extramural clients. In most nursing homes, a difference is made between units for psychogeriatric care, somatic care and rehabilitation (temporary, aimed at returning to the former living situation).

Daily care in care homes and nursing homes is provided by nurses and nursing aides. In the Dutch educational system five different levels of (pre)vocational and higher education for caring professionals are distinguished. Level one refers to orderlies (zorghulp) who have a certificate which is not considered a sufficient qualification to enter the labor market. Most students continue with secondary vocational education, at level two, to become a nursing aide (belpende), at level three, to become an advanced nursing aide (verzorgende/IG), or at level four, to become a licensed practical nurse (verpleegkundige). The majority of the professionals who deliver the daily care are (advanced) nursing aides educated at level three. The highest level in nursing education, the level five registered nurse (HBO verpleegkundige) is not found regularly in care homes and nursing homes. Over the past decades the educational level in institutional elderly care has decreased, but recently initiatives have been developed to (re)introduce higher educated nurses. ${ }^{34}$ 


\section{STUDY DESIGN}

AIM OF THE PROJECT

Over the past decades the interest in ethics in elderly care has increased, fuelled by societal concern for the quality of elderly care and media attention for wrongs such as the earlier mentioned 'pyamas days'. Clinical ethics, focusing on ethical issues within the context of the care for older residents is developing fast, however, scientific research on this subject is still in its infancy. A full overview of the available types of ethics support in the international context is missing. Also, the specific needs for ethics support in elderly care are unclear. In the Netherlands only very recently initiatives to implement clinical ethics support in elderly care have been undertaken. A recent and popular format for clinical ethics support in the Dutch context is MCD. Institutions that are currently implementing MCD can be considered pioneers, whose experiences are of great value for institutions that plan to implement MCD or to those that might in the future. The main research question is:

What are the needs for ethics support in residential elderly care, and how can MCD meet those needs and provide a space for care workers to address ethical issues and emotional challenges to realize good care?

\section{DESIGN, METHODS AND SETTTING}

Since each research question required a particular approach of data collection and analysis, a mix of different research designs was used. The study consisted of three major components: a systematic review of the international literature (chapter 2), a national survey among Dutch elderly care organizations (chapter 3) and a naturalistic evaluation ${ }^{35,36}$ of implementing MCD in two Dutch elderly care institutions (chapter 4, 5 and 6). The setting and methods of the first two studies are explained in the chapters dealing with them. The setting and methods used in the naturalistic evaluation are explained below.

The research setting was formed by the MCD projects in both institutions, between 2006 and 2010. The MCD projects started simultaneously in 2006, at three different locations: in two nursing homes of institution one (a consortium of nursing homes and care homes) and in institution two, a care home organization. At the time of the research, nursing home A consisted of eight wards in which 270 residents lived and 150 staff members worked. Nursing home B consisted of seven wards in which 180 residents lived and 75 staff members worked. Institution two, the care home organization, consisted of three locations and several assisted-living units. The locations varied from one to three wards in which (altogether) 250 residents lived and 150 staff members worked. Two of the wards were specialized in psychogeriatric care, making use of the expertise and staff of a nearby nursing home.

The implementation trajectory consisted of four, partly overlapping phases. The first, introductory phase aimed at gaining support from the (middle) management and giving general publicity to the MCD project. The second phase aimed at gaining experience with MCD, starting with a mixed group of motivated participants in order to both create an atmosphere of safety and openness and to foster dissemination through the 
institution. The third phase aimed at expanding MCD into the institution through implementation of MCD on the wards. The fourth phase was directed at taking over the organization of MCD by the institution by means of the training of their own professionals to become facilitators. This phased approach was chosen in order to gain both top-down and bottom-up support for MCD and to gradually hand-over the responsibilities for organizing MCD to the institution.

In 2006 MCD was introduced to the institutions by organizing (separate) meetings for both managers and interested staff members. Following the introduction, in 2007, mixed MCD groups were created, with employees from different wards and disciplines, in both organizations. Participants were asked to each provide a case description for every MCD session. In nursing home A, one group with 13 participants started, the group met eight times and generated 48 case descriptions. After the first year, nursing home A withdrew from the project, because of changed organizational priorities.

In nursing home B, two mixed MCD groups started simultaneously, in one group nursing aides from three somatic wards participated, and the other group consisted of nursing aides from three psychogeriatric wards. The first group had 12 participants, met four times and generated 18 case descriptions, and the second group met three times and generated 13 case descriptions. In the second year (2008) one mixed group continued with participants from both groups (nine meetings, 39 cases).

In the care home organization two MCD groups started consecutively. The first group had 12 participants, met 13 times and generated 60 case descriptions and the second group had 12 participants (six from the secondary process), met six times and generated 20 case descriptions. In the second and third year (2008/2009) both groups merged into one group (four meetings, four cases).

In the third phase (2008-2009), MCD was implemented on various wards in nursing home B and in the care home organization (six in total). The MCD sessions on the wards were preceded by a clinical work visit to make the team aware of issues and investigate what issues needed to be put on the agenda for a team deliberation. The fourth phase consisted of the training of seven professionals from nursing home $\mathrm{B}$ and the care home organization, with prior MCD experience, to become MCD facilitators. In nursing home B the continuation of the project was put on hold in 2011 due to budget cuts. In the care home organization MCD has been further embedded.

The MCD projects were a cooperation of the elderly care institutions and the university research team. The projects were accompanied by research activities following a naturalistic and responsive approach. The design combined naturalistic inquiry ${ }^{35,36}$ with the drive to improve practices through the active engagement of stakeholders in a dialogical process ${ }^{28}$. From the onset of the projects, the researcher adopted and combined a number of roles: facilitator in MCD sessions, implementer of the MCD projects, and researcher. The role of the researcher was continuous, in other words, part of the researcher was always in the 'inquiry mode', not only during clearly recognizable research activities, e.g. taking interviews, but also when facilitating an MCD session or participating in a project meeting. Several research methods were combined in the evaluation study. Individual semi-structured interviews were held with stakeholders, including directors, middle managers, (para)medics and nursing assistants. The MCD groups were 
evaluated with the participants in focus groups (nursing home A and B) or during the MCD sessions (care home). Throughout the project, participant observation was performed by the researcher, resulting in field notes and a reflexive journal ${ }^{36}$. All MCD sessions were recorded. Listening to the tapes was helpful when writing the report for the MCD group, but also provided material to reflect on the role of facilitator and made it possible to learn from this. In addition, fragments of the sessions and the evaluative comments of participants were used as data. All written material (case descriptions, MCD reports, interview or focus group transcriptions, field notes and reflexive notes) was analyzed in an inductive way, using content analysis techniques such as reading and re-reading, coding and categorizing.

\section{OUTLINE OF THE THESIS}

This thesis contains two parts: the first two chapters give an overview of provision of and needs in institutional elderly care; the second part (chapters 4, 5 and 6) deals with the implementation of one specific form of ethics support, moral case deliberation, in Dutch institutional elderly care.

Chapter 2 provides an overview of types of ethics support that have been developed internationally, based on a review of the literature. Chapter 3 describes the specific needs of ethics support in elderly care, based on a survey and interviews among Dutch elderly care organizations. Chapter 4 provides an overview of issues that were presented in the MCD sessions of mixed groups in our MCD projects. In Chapter 5 the pros and cons of these mixed MCD groups are explored. In addition, the thoughts of participants on the further embedding of MCD in the institution are described. Chapter 6 elaborates on the learning process that took place during the implementation of MCD, and focuses on the role of practical experience with MCD in becoming motivated for reflection and deliberation. Finally, in Chapter 7 we will provide an overall discussion and conclusion. 


\section{REFERENCES}

1. Jonsen AR. A history of bioethics as discipline and discourse. In: Jecker NS, Jonsen AR and Pearlman RA, (eds.). Bioethics An introduction to the history, methods and practice. second ed. Sudbury MA: Jones and Bartlett publishers, 2007, p. 3-16.

2. Callahan D. Bioethics as a discipline. In: Jecker NS, Jonsen AR and Pearlman RA, (eds.). Bioethics: an introduction to the history, methods and practice. Second ed. Sudbury MA: Jones and Bartlett publishers, 2007, p. 17-22.

3. Singer PA, Pellegrino ED and Siegler M. Clinical ethics revisited. BMC Med Ethics. 2001; 2: E1.

4. Agich GJ. What kind of doing is clinical ethics? Theor Med Bioeth. 2005; 26: 7-24.

5. Collopy B, Boyle P and Jennings B. New directions in nursing home ethics. Hastings Cent Rep. 1991; 21: S1-15.

6. Dam van der S, Molewijk AC, Widdershoven GAM and Abma TA. Ethics support in institutional elderly care: a review of the literature. SUBMITTED. 2012.

7. Elander G, Drechsler K and Persson KW. Ethical dilemmas in long-term care settings; interviews with nurses in Sweden and England. Int J Nurs Stud. 1993; 30: 91-7.

8. Hasselkus BR. Everyday ethics in dementia day care: narratives of crossing the line. Gerontologist. 1997; 37: 640-9.

9. Rosen T, Pillemer K and Lachs M. Resident-to-Resident Aggression in Long-Term Care Facilities: An Understudied Problem. Aggress Violent Behav. 2008; 13: 77-87.

10. Jakobsen R and Sorlie V. Dignity of older people in a nursing home: narratives of care providers. Nursing ethics. 2010; 17: 289-300.

11. Rees J, King L and Schmitz K. Nurses' perceptions of ethical issues in the care of older people. Nursing ethics. 2009; 16: 436-52.

12. Chichin ER and Olson E. An ethics consult team in geriatric long-term care. Camb Q Healthc Ethics. 1995; 4: 178-84.

13. Libow LS, Olson E, Neufeld RR, et al. Ethics rounds at the nursing home: an alternative to an ethics committee. Journal of the American Geriatrics Society. 1992; 40: 95-7.

14. Dartel van JN. De evolutie van ethische commissie naar stuurgroep ethiek-ervaringen uit Nederland. In: Roelandt M, Stiennon JA and Schotsmans P, (eds.). Lokale commissies voor ethiek en medische praktijk. Leuven: Lannoo Campus, 2006, p. 47-61.

15. Glasser G, Zweibel NR and Cassel CK. The ethics committee in the nursing home. Results of a national survey. J Am Geriatr Soc. 1988; 36: 150-6.

16. Olson E, Chichin E, Meyers H, Schulman E and Brennan F. Early experiences of an ethics consult team. J Am Geriatr Soc. 1994; 42: 437-41.

17. Piette M, Ellis JL, St Denis P and Sarauer J. Integrating ethics and quality improvement: practical implementation in the transitional/ extended care setting. J Nurs Care Qual. 2002; 17: 35-42.

18. Thompson MA and Thompson JM. Ethics committees in nursing homes: a qualitative research study. HEC Forum. 1990; 2: 315-27.

19. Steinkamp $\mathrm{N}$ and Gordijn B. Ethical case deliberation on the ward. A comparison of four methods. Med Health Care Philos. 2003; 6: 235-46.

20. Dartel van JN. Van ethische commissie naar stuurgroep ethiek? [From ethics committee to steering committee]. Utrecht: CELAZ/Nederlandse Zorgfederatie, 1998.

21. VWS M. Agenda Ethiek en Gezondheid 2003 [Agenda Ethics and Health Care 2003]. In: Ministry of Health Care Was, (ed.). The Hague2002.

22. Onderzoek naar pyamadag ouderen [investigation after pyjamas day elderly]. NRC Handelsblad. PCM Uitgevers B.V., 2003.

23. VWS M. Agenda Ethiek en Gezondheid 2006 [Agenda Ethics and Health Care 2006]. In: Ministry of Health Care Was, (ed.). The Hague2005.

24. Verkerk M, Lindemann H, Maeckelberghe E, Feenstra E, Hartoungh R and De Bree M. Enhancing reflection: an interpersonal exercise in ethics education. Hastings Cent Rep. 2004; 34: 31-8.

25. Gadamer H-G. Wahrheit und Methode; Grundzüge einer philosophischen Hermeneutik. Tübingen, Mohr, 1960, p.xvii, 486 p.

26. Porz R, Landeweer E and Widdershoven G. Theory and practice of clinical ethics support services: narrative and hermeneutical perspectives. Bioethics. 2011; 25: 354-60.

27. Widdershoven GAM and Molewijk AC. Philosophical foundations of clinical ethics. A hermeneutic perspective. In: Schildmann J, Gordon JS and Vollmann J, (eds.). Clinical ethics consultation Theories and methods, implementation, evaluation. Surrey: Ashgate, 2010, p. 37-52.

28. Abma TA, Molewijk B and Widdershoven GA. Good care in ongoing dialogue. Improving the quality of care through moral deliberation and responsive evaluation. Health Care Anal. 2009; 17: 217-35. 
29. Molewijk AC, Abma T, Stolper M and Widdershoven G. Teaching ethics in the clinic. The theory and practice of moral case deliberation. J Med Ethics. 2008; 34: 120-4.

30. Preventie bij ouderen: focus op zelfredzaamheid. Publicatienr. 2009/07 [Prevention in the elderly: focus on functioning in daily life. Publication no. 2009/07]. Den Haag [The Hague]: Gezondheidsraad [Health Council of the Netherlands], 2009.

31. Kardol MJM. Zorg voor zelfstandigheid [Care for independency]. Maastricht: Maastricht University, 2004.

32. Pijper de NF, Ribbe MW and Stoop JA. Verpleeghuisgeneeskunde, een nieuw vakgebied [Nursing home medicine, a new discipline]. Nederlands Tijdschrift voor Geneeskunde. 1995; 139: 1820-3.

33. Schols JM, Crebolder HF and van Weel C. Nursing home and nursing home physician: the Dutch experience. J Am Med Dir Assoc. 2004; 5: 207-12.

34. State Secretary of Health Care WaS. Letter to House of Representatives, MEVA/BO-3102550. In: Ministry of Health Care Was, (ed.). The Hague2012.

35. Lincoln Y and Guba E. Naturalistic inquiry. New York: Sage, 1985.

36. Erlandson DA. Doing naturalistic inquiry : a guide to methods. Newbury Park, Calif.: Sage, 1993, p.xxi, 198 p. 



\section{Chapter 2}

\section{Ethics support in institutional elderly care: a review of the literature}

S. van der Dam

A.C. Molewijk G.A.M. Widdershoven T.A. Abma 


\begin{abstract}
A B S T R A C T
The aim of this paper is to present an overview of the ethics support mechanisms that have been developed internationally, to assist health care professionals in institutional elderly care in dealing with ethical issues. A review of the literature was performed in three electronic databases (Pubmed, CINAHL/PsycINFO, Ethxweb). Sixty papers were included in the review. The ethics support mechanisms are classified in four categories: 'institutional bodies' (ethics committee and consultation team); 'frameworks'; 'educational programs and moral case deliberation'; and, 'written documents and policies'. For each category the goals, methods and ways of organizing are described. Ethics support often serves several goals and can be targeted at more than one level: the case, the professional or the organization. Over the past decades a number of changes have taken place in the development of ethics support in elderly care. Considering the goals, ethics support has become more outreaching and pro-active, aiming to qualify professionals to integrate ethics in daily decision making processes. The spectrum of methods has become more diverse and better adapted to the concrete learning style of the nursing staff and more focused on everyday ethical issues. Ethics support has become less centrally organized and more connected to the organizational context. Clarity on the theoretical underpinnings of ethics support and transparency about design, data collection and analysis of empirical research are needed in the future in order to assess and compare the actual contribution of each kind of ethics support service to the quality of care in elderly care.
\end{abstract}




\section{INTRODUCTION}

In 1985, Eileen and Don Curl ${ }^{1}$ expressed their hope that one day long term care, which includes residential elderly care, would not be the 'forgotten' setting of ethical dilemmas. Since then a lot has changed. Nowadays it is widely recognized that ethical issues in elderly care exist and that its context differs from acute care. Both the care-receiver, the organizational context (including staff characteristics) and the kind of ethical issues that arise are different. Care receivers in residential elderly are residents; being a resident is quite different from being a patient in a hospital., 3 Residency usually lasts for a longer period; mostly the nursing home is the residents' home until death. Admission is often decided in a state of crisis or stress and is in many cases a group decision of the family instead of the older person's own choice. ${ }^{4}$ Physical handicaps make residents dependent on others and decreasing cognitive abilities make it less easy to respect resident's autonomy when $\mathrm{s} /$ he cannot make clear what his or her values and preferences are..$^{5-7}$ Elderly care institutions, as compared to hospitals, tend to have both limited access to resources and professional expertise, and higher staff turnover rates and shortages. ${ }^{5}$ Staff is not only confronted with end-of-life-issues, but also with the ethical issues that are hidden in everyday life in the institution. ${ }^{8-10}$

It is generally acknowledged that ethical issues in elderly care need to be addressed. Elsewhere, we have reported on the specific needs for ethics support in elderly care in the Dutch context. ${ }^{11}$ Internationally, several ethics support mechanisms have been developed in order to support health care professionals in dealing with the ethical issues they face in their daily practice. However, a systematic overview of the types of ethics support that have emerged over time specifically in elderly care is not available yet. This paper aims to fill this gap by presenting an overview of the ethics support forms in residential (nursing homes and care homes) and semi-residential (day care) elderly care, that have been developed and described in international scientific journals over the past three decades. Our main research question was: 'What types of ethics support are described in the literature and what are the goals, methods and ways of organizing?' The ethics support types are classified into four categories that emerged from the review of the literature. Next, for every category the described goals, methods and ways of organizing are reported.

Institutions and staff members of ethics support services that are planning to develop or review their current ethics support may benefit from this overview. This paper makes it possible for these institutions to (re)consider the type(s) of ethics support that serve(s) their goals best. Furthermore, this overview also reveals some historical developments in ethics support in elderly care which makes it possible to learn from the past. 


\section{METHOD}

\section{SEARCH PROCEDURE}

To identify studies on ethics support in elderly care a systematic search in three different electronic databases was performed: Pubmed, CINAHL/PsycINFO, Ethxweb. The search was limited to English and Dutch publications from January 1980 until October 2011. Related to the two key concepts, '(semi) residential elderly care' and 'ethics support', a list of equivalent search terms (see table 1) was formed, using both subject headings (Mesh terms, Cinahl headings) and free search terms.

Table 1: Search terms

\begin{tabular}{|c|c|}
\hline Key concept 1: (semi) residential elderly care & Key concept 2: ethics support \\
\hline $\begin{array}{l}\text { MeSH/Cinahl: } \\
\text { - home(s) for the aged OR } \\
\text { - nursing home(s) OR } \\
\text { - long-term care OR } \\
\text { - residential facilities OR } \\
\text { - day care/age-specific care/Long term care OR } \\
\text { Free search terms: } \\
\text { - care home OR } \\
\text { - day care OR } \\
\text { - assisted living OR } \\
\text { - elderly care OR }\end{array}$ & $\begin{array}{l}\text { MeSH/Cinahl: } \\
\text { - clinical ethics OR } \\
\text { - medical ethics OR } \\
\text { - nursing ethics OR } \\
\text { - decision making/ethics OR } \\
\text { - decision making/ethical OR } \\
\text { - decision support techniqrues OR } \\
\text { - gerontologic nursing/ED/EI* } \\
\text { - ethical analysis/methods OR } \\
\text { - geriatric nursing/ethics OR } \\
\text { - nursing staff/education OR } \\
\text { - nursing staff/ethics OR } \\
\text { - problem solving/ethics OR } \\
\text { - attitude of health personnel OR } \\
\text { - ethics consultation OR } \\
\text { - Ethics, Institutional OR } \\
\text { - Organizational ethics OR } \\
\text { Free search terms: } \\
\text { - ethics support OR } \\
\text { - ethical reflection OR } \\
\text { - ethical deliberation OR } \\
\text { - moral deliberation OR } \\
\text { - moral case deliberation OR } \\
\text { - ethics committee OR } \\
\text { - reflection groups OR } \\
\text { - ethics rounds OR } \\
\text { - reflection/ED/EI } \\
\text { * ED= education; EI=ethical issues }\end{array}$ \\
\hline
\end{tabular}

\section{SELECTION PROCESS}

The selection of relevant articles took place in several steps (see figure 1). The search in the three selected databases yielded 3.936 publications (including overlap). The high number of hits was a consequence of the broadness of our research question and 
search procedure. We deliberately chose a wide lens since 'ethics support' is not a standard search term. Furthermore, we wanted to look at ethics activities and products that were not directly archived or recognized as being 'ethics support service'. On the basis of inclusion and exclusion criteria, authors SD and BM screened titles and abstracts (when available) which resulted in 158 potentially relevant publications for further reading. After close-reading of the potentially relevant articles, using the same inclusion and exclusion criteria, 60 publications were included for the final review (see appendix 1 for a categorization of the references).

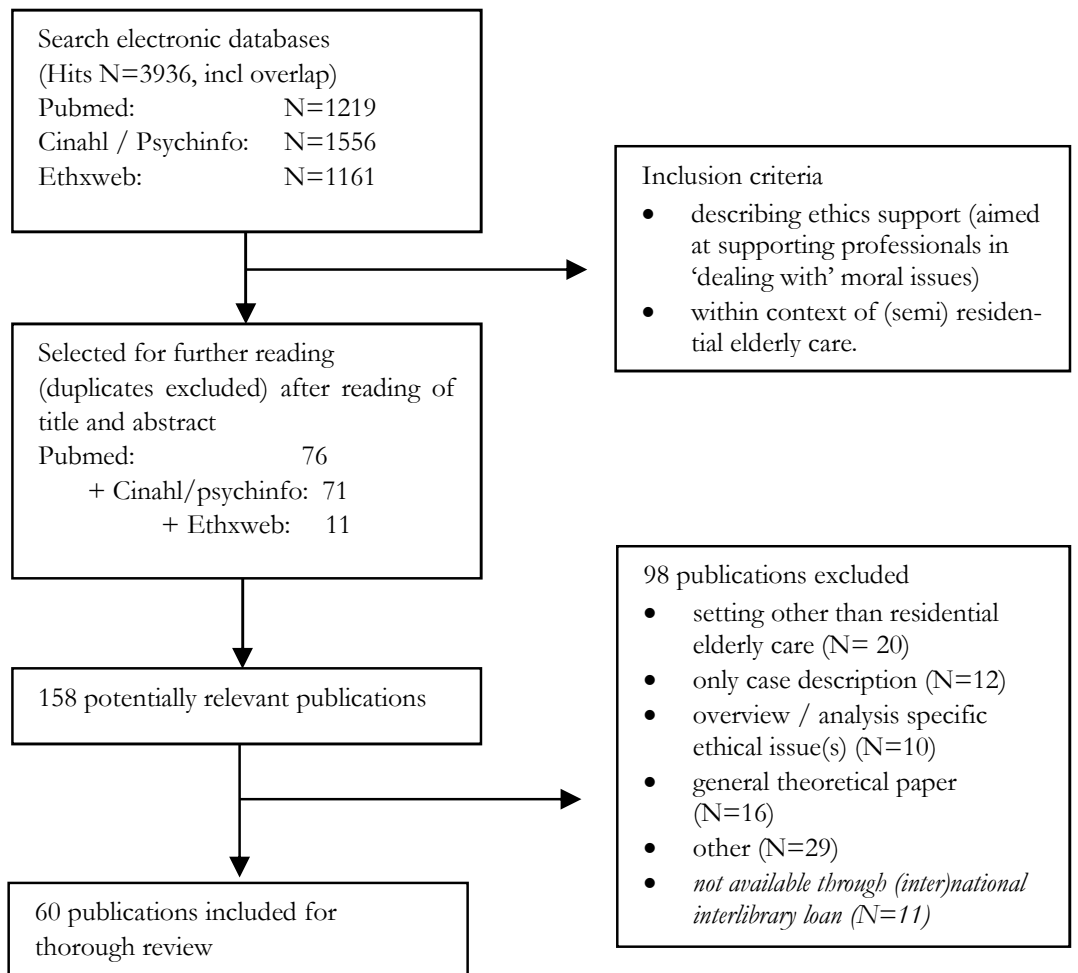

Figure 1: Flow chart of the publication search

\section{ANALYSIS}

The included articles $(\mathrm{N}=60)$ cover a palette of ethics support. Analyzing the papers and subsequent discussions in the research team resulted in a categorization consisting of four categories representing different types of ethics support: 'institutional bodies: ethics committees and consultation'; 'frameworks'; 'written policies and documents'; 
and 'educational programs and moral case deliberation'. Frameworks are analytical tools to assist care professionals in dealing with and solving ethical problems. ${ }^{2}$

The four categories were empirically constructed, based on the literature search, and reflect the 'landscape' of ethics support as it has developed and exists today in residential elderly care. The purpose of our category system is to elucidate specific characteristics, differences and similarities of the different types of ethics support. Further analysis of the four categories concentrated on the following dimensions: goals, methods, and ways of organizing. The goal refers to the specific focus of ethics support (e.g. the ethical issue or the health care professional) and to the intended outcomes (e.g. sound ethical decision making or raising moral awareness). The second dimension ('method') refers to the technique that is applied in order to reach the goal (e.g. team conversations or experiential learning). The third dimension refers to how the ethics support is organized (e.g. as a committee).

\section{RESULTS}

The majority of the 60 included papers is situated in North America (USA / Canada) and was published in the 1980's and '90's. From 2000 also publications from other countries (i.e. Australia, Belgium, Sweden, Norway, The Netherlands) were found.

The most documented type of ethics support are institutional bodies, mainly the clinical ethics committee (CEC) and a smaller amount of publications on ethics consult teams. All 32 publications on 'institutional bodies' are from North America, 75\% was published before 2000. Five out of those 32 articles report on the prevalence and design of CECs; six articles are programmatic (describing the CEC in general terms or serving as a guide to establish an CEC); the other publications (21) describe concrete CECs, or similar bodies, in one institution or a (regional) network of institutions. The second largest category consists of 17 publications, describing 12 different frameworks. Two smaller categories are 'educational programs and moral case deliberation' ( 7 publications) and 'written documents and policies' (4 publications).

The included publications vary considerably concerning the size, scope and profundity. Among the publications there was quite a lot of cross-referencing. An overview of the included articles per category is presented in Appendix 1.

\section{TYPES OF ETHICS SUPPORT}

Below we will present the four categories of ethics support and describe their goals, methods and ways of organizing.

\footnotetext{
2 The term 'framework' is borrowed from Pompei ${ }^{33}$. Examples of other terms that are used are: process (Hamilton), model (Miedema) or template(Kirsch).
} 


\section{INSTITUTIONAL BODIES: ETHICS COMMITTEE AND CONSULTATION TEAM}

We included 32 publications on institutional bodies: 24 on ethics committees and similar ethics groups and four on ethics consultation and mediation. Research indicated that although the number of CECs has increased since the 1970 's, ${ }^{12}, 13$ in the late eighties CECs are still an uncommonly used tool of nursing homes for handling ethical dilemmas. ${ }^{14}$ The relatively high number of publications on CECs and the increasing percentages of institutions that have established an CEC, seems to indicate a slow but steady increase of CECs.

\section{Goals}

Most CECs serve multiple purposes, varying from a narrow focus on assisting in the decision-making process ${ }^{1,15,16}$ to a broader scope of fostering an institutional milieu that is sensitive to ethical priorities. ${ }^{12}$ Early publications also refer to a legal base, pointing at developments in the 1980's (e.g. the passage of the Natural Death Act in 1983) which motivated institutions to establish a CEC.2, 17, 18 The goal of these CECs was to minimize the possibility of litigation and liability ${ }^{15}$ or to raise issues with residents and their families and give them the opportunity to exercise their rights. ${ }^{19}$ The most common goals of CECs are: education of staff (and sometimes also residents, their family and the community); development of policies and guidelines; and case review (prospective or retrospective)..$^{12}$ Although research indicates that $25-30 \%$ of the CECs have decision making authority, ${ }^{14}$ all articles in our review agree on the advisory role of CECs. Case review should not discharge health care professionals, resident and family of their decision making responsibilities ${ }^{18}$ and is therefore considered consultative ${ }^{2}$ and supplementary to customary decision making. ${ }^{12}$

\section{Methods}

Before they take on other activities, most CECs start with self-education, ${ }^{14,}{ }^{17}$ i.e. following courses, using reading material and discussing cases, and some CECs hire an ethicist. ${ }^{20-22}$ Education of staff and others is done by, for example, organizing conferences, ethics rounds, case discussions or conducting specific educational programs. Some CECs have scheduled (monthly) meetings, set their own agenda and only discuss hypothetical cases, ${ }^{20}$ while other CECs generate requests from the staff, resident and family or administrators. ${ }^{14}$ Most CECs will consider the more dramatic or striking issues like DNR orders, patient competence, the use of feeding tubes or the use of restraints. ${ }^{14}$ A number of CECs pay explicit attention to everyday ethical issues. $5,21,23$ One article pictures the shift that the particular ethics study group made from a focus on end-of-life, medical decision issues to the ordinary, everyday events of resident life. This "opened up myriad issues (...) that usually deemed too mundane to consider seriously or outside the purview of ethics"5(p. 42). The majority of the 32 publications do not go into the method or framework that is applied in reviewing cases, with the exception of the decision making trees developed for case managers, ${ }^{22}$ the framework proposed by Hogstel ${ }^{16}$ and the mediation model presented by Wood. ${ }^{24}$ 


\section{Ways of organizing}

Two-third of the publications on CECs describe committees that are organized in a traditional fashion: regular meetings of a multi-disciplinary group (10-15 members) representing the professionals, administrators and sometimes patients, family members and/or representatives of the community. ${ }^{14}$ The way CECs are organized has been criticized over the past decades. It is said that CECs may create undesirable bureaucracy, are not close enough to the clinical situation and too passive, ${ }^{25}$ and may diffuse responsibilities. ${ }^{14,}$ 26, 27 Alternatives for the traditional CEC have been presented in the literature, which reflect a number of changes. In the first place a liaison with quality assurance is made 2 28. According to Piette (2002) a 'next generation CEC', which integrates ethics in quality improvement, makes "ethics and values become a part of what every person does every day, rather than being present only in formal ethics decisions" ${ }^{\prime 2}$ (p. 42). In the second place a more outreaching form of ethics support is provided by the ethics consult team, smaller and more flexible than the typical CEC, it has the ability to assemble with relative ease and go to the bedside when needed. ${ }^{26,}{ }^{29}$ This consult team is part of a center on ethics, which illustrates a third development in the way CECs are organized: decentralization and specialization of CEC functions, which is also found in the Capital Health Ethics Support (CHES) model, described by Simpson. ${ }^{30} \mathrm{~A}$ fourth development that is visible in both integration with quality assurance and the centers on ethics is a broadening of the scope from resident care issues to organizational ethics, as "the place of ethics will be found equally at the bedside and in the boardroom". ${ }^{30}$ Overall, with these developments the role of traditional centrally organized CECs has transformed more into a network organization.

\section{FRAMEWORKS}

We found 12 different examples (in 17 publications), which provide practical analytical tools to guide reflection and deliberation when confronted with ethical problems in elderly care. Typically, a step-by-step approach is used.

\section{Goals}

The focus of frameworks is on the case level. Most frameworks are illustrated with apparent problems that surround end-of-life care, use of restraints, tube-feeding, informed consent and decision-making capacity. ${ }^{31-33}$ One framework is applied to problems in processes of admission, relocation and transfer., 34 Three frameworks pay explicit attention to the less dramatic everyday ethical issues that arise in the context of everyday nursing home life. ${ }^{7-9,35-37}$

The main goal of using a framework, especially a step-by-step approach, is to resolve ethical problems that arise in practice. Several authors point out that the process of coming to a decision is just as important as the resulting decision. A framework serves to "find moral agreement in the midst of differing moral beliefs and traditions"31(p. 384). Pompei stresses the importance of 'dialogue' and 'working through the dilemma"33 and Schneider concludes that "dilemmas do not disappear simply because this model is employed; however, it will provide a framework for stimulating critical 
thinking and ethical reflection" (p. 45). ${ }^{4}$ The use of a systematic approach helps to safeguard against personal biases ${ }^{38}$ and increases the likelihood that health care professionals explore the most important aspects of the case. ${ }^{33}$ Thoughtful deliberation of ethical issues warrant the trust of patients and society in healthcare providers. ${ }^{39}$ In addition, using a framework reduces complexity and uncertainty 34 as decisions that are well-considered and well-founded likely will reduce moral stress by giving good reasons for what to do. ${ }^{7}$ Two frameworks, Sansone's values profile and Power's folk taxonomy, do not follow a step-by-step-approach and focus less on decision making but rather on mapping out resident's values ${ }^{37}$ or raising awareness of the ethical implications of common everyday situations. ${ }^{9}$

\section{Methods}

The step-by-step frameworks roughly follow the same sequence of elements: 1) recognition and definition of the ethical issue, 2) consideration of the relevant facts, 3) assessment of stakeholders and value judgments, 4) assessment of alternatives and consequences, 5) decision and implementation and 6) evaluation. Some frameworks are explicitly shaped by an underlying ethical theory, e.g. the teleological model described by Bolmsjö ${ }^{7,8}$ or the casuistic framework suggested by Slettebø. Most frameworks are not directly derived from one ethical theory. The authors discuss different ethical theories as a basis for moral reasoning; they present their framework as a practical tool for guiding reflection and deliberation. Ethical principles are not a standard component: in seven frameworks they are absent. To some authors, ethical principles are indispensable as 'guideposts in the decision making process'. 4, 34, 40 Other authors regard a principlebased approach too rationalistic or too abstract and therefore not very helpful to professionals when dealing with everyday ethical problems. ${ }^{7}, 40$ Slettebø and Horner both present their framework as supplementary to a principle-based approach. ${ }^{40,41}$

Evaluation of a decision is important in order to see whether the solution has in fact improved the good lives of the involved parties on the whole, ${ }^{7}$ to prevent or reduce the effects of collateral damages ${ }^{39}$ and to be able to adjust the decision to changed circumstances. ${ }^{31,32}$

\section{Ways of organizing}

In general, the frameworks are meant to be used by health care professionals when deliberating on ethical problems that they confront. Although most publications leave it open by whom the framework can be used, some authors indicate users, for example social workers, ${ }^{41}$ physicians, ${ }^{33}$ nursing students, ${ }^{42}$ a nursing team, $7,32,38,40$ a multidisciplinary team ${ }^{31,43}$ or a CEC. ${ }^{35}$ Bolmsjö and Scheider both stress the importance of implementing the presented framework together with education, taking care of time and supervision. 4, 7, 34 According to Fleming his framework requires no formal training in ethics, making it cost-effective and available for a broad range of learners: providers, managers and administrators. ${ }^{31,43}$ Both Fleming and Schneider regard their framework as a (temporary) stopgap, when other formal kinds of ethics support are not (yet) available. ${ }^{4,31,34,43}$ 


\section{EDUCATIONAL PROGRAMS AND MORAL CASE DELIBERATION}

Educational programs can be initiated by a CEC but may also derive from a separate institutional program or project without any institutional body. In our review seven publications with an emphasis on education were included: five on four different educational programs (seminars; ethics rounds; the 'Decisions near the end of life program' and the sTimul 'Care ethics lab') and two on moral case deliberation (MCD).

\section{Goals}

The main target of educational programs is the health care professional. The aims are broader than solely the development of ethical reasoning. First, professionals need to become aware of the ethical dimension of care. ${ }^{44}$ Then, ethical reasoning is linked to everyday practice, where behavioral skills and decision-making process employed by clinicians are important. ${ }^{45}$ Generally this is done by using a case-driven approach. Most educational programs emphasize the institutional context in which the professional operates. In addition, most programs aim to foster multi-disciplinary exchange and open communication. This focus on the institutional context and inter-collegial cooperation also serves to contribute to an ethical climate with attention and openness for values and norms. MCD has a strong educational focus, but it can also be applied for solving cases.

\section{Methods}

Most educational programs focus on real, experienced ethical problems, either actual cases or cases from the past. They make use of the professional's experiences in caring for residents. Some programs start with one or more introductory meeting(s) explaining ethical concepts and principles ${ }^{44}, 45$ before cases from practice are discussed. Ethics rounds and MCD are based on actual cases, but they are different considering the method and setting. Ethics rounds are open to all staff and attract a large and diverse audience. After the clinical case presentation, the resident and/or family is interviewed, followed by an ethical comment (by a staff member or ethicist). Then the full staff discussion takes place, concluding with a formal presentation of an ethicist, usually an outside expert. ${ }^{46}$ In MCD deliberations take place in smaller groups. A trained facilitator structures the deliberation, using a conversation method in order to foster joint reflection and dialogue among participants. The facilitator does not present his/her own ethical analysis to the group. ${ }^{47}$ The Care-ethics lab takes the focus on professionals' embodied experience a step further, making the professional step in to the resident's shoes. For one day and night they receive care from students and afterwards both groups reflect on their experiences together. ${ }^{48}$

\section{Ways of organizing}

Most programs have a strong connection with the institutional context. The focus is on the institution as a whole, both for fundamental and strategic reasons. A program involving multi-disciplinary groups is better suited for contributing to an ethical climate than teaching individual professionals. In addition, being part of a larger movement and 
commitment of administrators makes professionals more likely to change their attitudes and behaviors. ${ }^{45}$ The 'decisions program' and the 'ethics rounds' are part of an overarching center of ethics. MCD is strongly organized bottom-up, but commitment of the management is essential to secure preconditions and stimulate a working environment in which dialogue can flourish. ${ }^{10}$ MCD can be organized both in existing teams or in mixed groups. ${ }^{47}$ The educational program described by Paier ${ }^{44}$ offers a two-pronged approach, with seminars for professionals and a separate trajectory for residents and their family. The care ethics lab forms an exception with its laboratory-like context outside of the institution, although the follow-up meeting is focused on participants' experiences in their own practice.

\section{WRITTEN DOCUMENTS AND POLICIES}

Many of the publications on CECs and frameworks mention written documents and policies, sometimes as a product of a CEC. However, surveys showed that $40 \%-60 \%$ of the institutions without a CEC still rely on written documents (such as institutional policies or guidelines) in order to offer support when ethical problems arise. ${ }^{12}, 14 \mathrm{We}$ found four publications that focus on written documents and policies. Three publications describe a policy and one publication describes both a code of ethics and a guide.

\section{Goals}

The policies described by Feinsod and Levenson ${ }^{49,50}$ and Uhlmann et al ${ }^{6}$ aim to standardize and systematize the decision-making process in order make ethical decisionmaking more effective, reflecting patient's wishes or best interests ${ }^{49}$ and helping to reduce civil liability. ${ }^{50}$ Principles and practices are presented to guide physicians and other health care providers. Patient-directive forms and practical suggestions are given for opening a conversation with the patient on his/her preferences, since "the autonomy and best interests of patients are best served if medical management plans and decision-making mechanisms are considered in advance" (p. 884). ${ }^{6}$ One publication, from the Australian government, concerns a code of ethics and a guide to ethical conduct for providers in the Australian 'aged care sector' in order to protect the rights of residents. In addition, it provides a basis for individual organizations to develop their own written protocols. ${ }^{51}$

\section{Methods and ways of organizing}

Written policies and documents are support mechanisms that provide basic guidance for ethical decision-making. Codes of ethics are generally formulated in an abstract, general way and are not meant to serve as a methodology for decision making in concrete situations. ${ }^{39}$ A code therefore serves as a background document. Protocols or forms serve as practical instruments in standardizing procedures and are used to document preferences. 
Our review of the literature demonstrates a great variety of types of ethics support in elderly care. We ordered the types into four main categories. Figure 2 visualizes these categories. It displays the different accents of the distinguished types of ethics support but also shows their interconnectedness. Ethics support often serves several goals and can be targeted at more than one level. Various ethics support mechanisms can exist together in one institution.

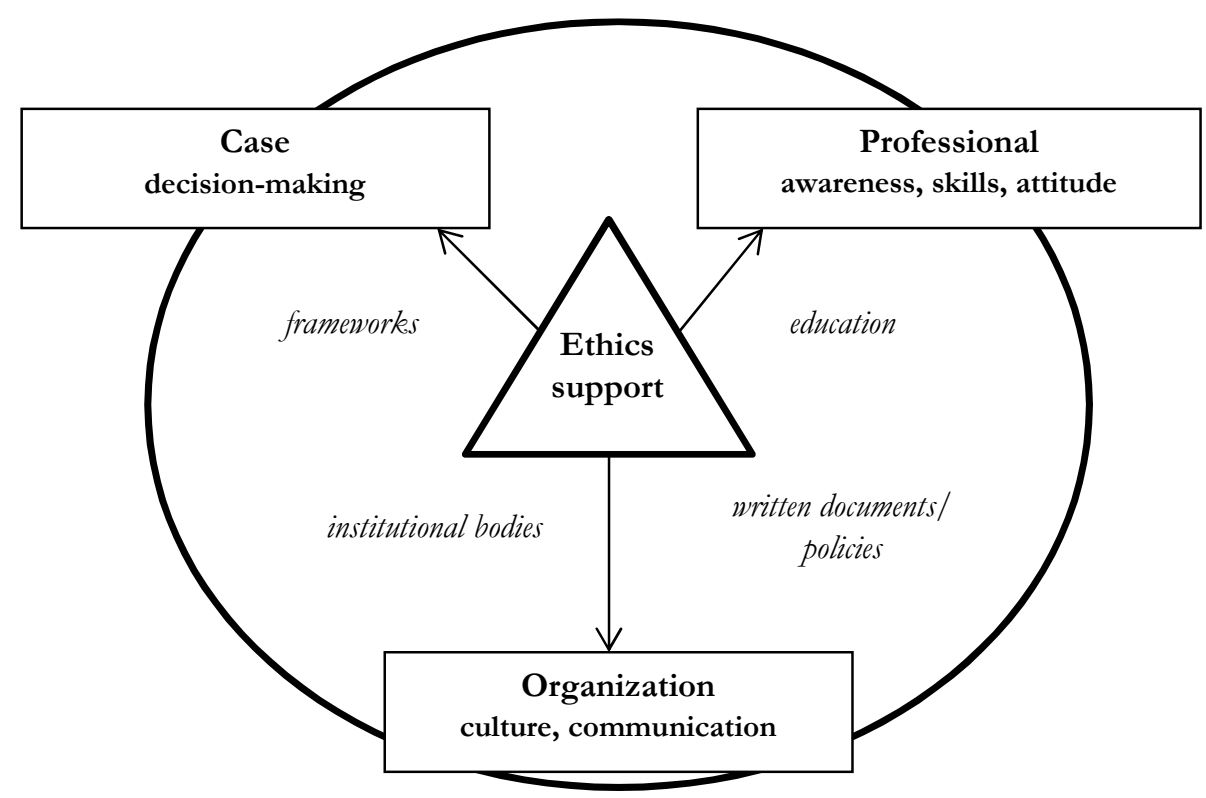

Figure 2: Interrelated elements in ethics support

The size of the four categories does not necessarily correspond to the degrees of usage in practice. The large number of publications on CECs in the 1980's and 1990's, in combination with relatively low prevalence figures, ${ }^{14}$ presumably is a consequence of the CEC being a novelty at that time. The large number of publications from the USA suggests that ethics support started as an American phenomenon. Nowadays this is not the case, in view of the more recent and diverse European publications.

When we do not restrict ourselves to numbers, some qualitative developments over the past decades of ethics support in elderly care can be identified. These changes have taken place within the category of CECs, but also within new types of ethics support. Considering the goals, the focus has broadened from the classical CEC functions of analyzing exceptional cases and providing general guidelines, towards supporting health care professionals to integrate ethics in their own decision making processes. Ethics support has become more outreaching and pro-active. Alternatives for a passive CEC 
(waiting for issues to be brought to the committee ${ }^{27}$ ) have been developed: easily accessible ethics rounds, which attract a large and diverse audience, ${ }^{46}$ and consult teams, which are more flexible and outreaching. ${ }^{29}$ As compared to CECs the categories 'frameworks' and 'educational programs' are even more strongly focused on the health care professional, providing them with tools and competence. Written documents, e.g. a code of ethics, may provide a baseline, but knowledge and skills in the art of ethical decision making are still needed to recognize ethical problems and act upon them. ${ }^{39}$ Health care professionals can become qualified to integrate ethics in their clinical decision making, provided that they get methodological support, e.g. through the use of a framework, and that they are trained in engaging in a dialogue, 52 for example through participation in MCD sessions. ${ }^{10}$ Overall, there seems to be a change in focus from a more traditional ethics support service (performed as a technocratic, analytical and expert based specialty) towards a more deliberative and contextual approach to ethics, placed at the daily level of the professional within his work place.

The spectrum of methods has become larger and more diverse, probably based on a growing diversity of needs for ethics support in elderly care organizations and a different understanding of what counts as appropriate ethics support. Most publications included in our review emphasize the ways in which elderly care is different from acute care. Yet, institutions which introduce ethics support in the 1970's followed the example of acute care, copying the types of ethics support that previously had been introduced in hospitals. More recent types of ethics support, often combining several methods, seem to match better with the kinds of workers in elderly care and the kind of ethical issues they face. In addition to stimulating multi-disciplinary dialogue, 45, 47, 53 methods and programs have been developed that better meet the needs and experiences of nurses and nursing aides $7,40,48,54,55$ who constitute a large part of the elderly care workforce. Given the concrete learning style of (lower educated) nursing staff, ${ }^{11}$ it is essential that ethics support takes their own experiences as a starting point. This is the case in many frameworks, educational programs and MCD but most explicit in the care-ethics lab, where nurses experience what it means to be a care-receiver. ${ }^{48}$ Furthermore, ethics support has become more open to ordinary problems and therefore better adapted to the context of elderly care, where everyday ethical issues are common but not always recognized. $5,7,9,10,35,36,44$

Diversity in methods and goals and more outreaching approaches are also reflected in three changes in the ways ethics support organized. Firstly, ethics support has become more decentralized. Our review included publications from three so called 'centers for ethics', a label we borrowed from the Jewish Home and Hospital for the aged. ${ }^{55}$ These centers offer a whole range of ethics support types. Some centers have developed from the traditional CEC, incorporating its functions in separate specialist bodies that are interrelated through a network structure. ${ }^{30,53}$ Secondly, ethics is more integrated with quality assurance. Both publications on this subject reveal pragmatic reasons for this integrative approach. Integration with quality activities may be less threatening for physicians who misunderstand ethics support as a sign that their clinical practice is not already ethical. ${ }^{2}$ Also, it may improve the scores on medical outcome indicators in surveys. ${ }^{27}$ When these indirect goals become a goal in itself, however, there is a risk of 
losing sight of the inherent values of ethics support (see below). Thirdly, a more holistic perception of ethics is displayed in recent ethics support initiatives that include all levels in the institution, from aides to board-members ${ }^{30}$ and broaden the scope from resident care issues to organizational ethical issues. ${ }^{27}, 30,45$ This should go further than solely a supportive attitude from the management, but also include active participation of management and clients/patients, for example in MCD sessions. ${ }^{56}$

Although the theoretical underpinnings and the effectiveness of ethics support were not the focus in our review, we will go into these two subjects briefly. Many of the publications briefly describe well-known ethical theories, e.g. utilitarianism, rule-ethics or principles-approach without indicating why these theories have been chosen and what the consequences are for the methods and the moral expertise of both staff of ethics support services and health care professionals themselves. Some recent publications, presenting ethics support models based on less common theories, e.g. casuistry, ${ }^{40}$ dialogical ethics ${ }^{10,47}$ and care-ethics, ${ }^{41,} 48$ explicitly address the theoretical assumptions of their ethics support mechanism and the practical consequences. This involves both clarity on normative ethics theories (e.g. 'How should we reason?') and on epistemological claims (e.g. 'What constitutes a moral problem?' or 'What is moral expertise here?'). We think that more clarity on the relationship between ethics theories and the practice of ethics support is important for health care institutions and ethics support services in order to make the right choices for the goal, method and even the goal of ethics support. Furthermore, more clarity will contribute to the reliability, transparency and evaluation of the ethics support service.

With regard to the effectiveness, feasibility and quality of ethics support most publications are merely programmatic and descriptive. Only $25 \%$ of the papers describe empirical results related to effects of ethics support. Two publications provide some quantitative results: a survey ${ }^{23}$ and a quasi-experimental design. ${ }^{57}$ Other studies made use of qualitative methods in which effects are described in a detailed and rich way. In general, for both quantitative and qualitative research on evaluation of ethics support, the design and research methods are not well explained which makes it difficult to assess the quality of the research (and subsequently the results that are presented). Exceptions include the publications on $\mathrm{MCD}^{47}$ and the program that uses critical thinking and structured controversy in teaching nursing students. ${ }^{42}$ More empirical evaluation research and transparency about theory, design, data collection and analysis are needed in order to assess and compare the quality of the ethics support itself and the actual contribution of each kind of ethics support service to the quality of care in elderly care. Research should concentrate more on upcoming types of ethics support (such as experiential learning and $\mathrm{MCD}$ ) and the different kinds of outcomes that these types generate since there is still little information available on these types as compared to the larger body of literature on CECs and frameworks. Finally, future research on ethics support in elderly care should focus on the specific needs for ethics support in elderly care from various stakeholders (health care professionals, patient and families, management and housing staff). 


\section{REFERENCES}

1. Curl E and Curl D. The "forgotten" setting of ethical dilemmas: long-term care. Kansas Nurse. 1985; 60: $2-4$.

2. Whiteneck MR. Integrating ethics with quality assurance in long term care. QRB Qual Rev Bull. 1988; 14: 138-43.

3. Collopy BT, Boyle P and Jennings B. New directions in nursing home ethics. The Hastings Center Report. 1991; 21: 1-15.

4. Schneider RL and Kropf NP. The admission process in nursing homes: a clinical model for ethical decision-making. Journal of Long Term Home Health Care. 1996; 15: 39-46.

5. Kelly $\mathrm{C}$ and Lazaroff $\mathrm{A}$. Learning to pay attention. An ethics study group refocuses on issues affecting long-term care residents' daily lives. Health Prog. 1993; 74: 40-3, 52.

6. Uhlmann RF, Clark H, Pearlman RA, Downs JC, Addison JH and Haining RG. Medical management decisions in nursing home patients. Principles and policy recommendations. Ann Intern Med. 1987; 106: 879-85.

7. Bolmsjo IA, Edberg AK and Sandman L. Everyday ethical problems in dementia care: a teleological model. Nurs Ethics. 2006; 13: 340-59.

8. Bolmsjo IA, Sandman L and Andersson E. Everyday ethics in the care of elderly people. Nurs Ethics. 2006; 13: 249-63.

9. Powers BA. Ethnographic analysis of everyday ethics in the care of nursing home residents with dementia: a taxonomy. Nurs Res. 2001; 50: 332-9.

10. van der Dam S, Abma TA, Kardol MJ and Widdershoven GA. "Here's My Dilemma". Moral Case Deliberation as a Platform for Discussing Everyday Ethics in Elderly Care. Health Care Anal. 2011.

11. Dauwerse L, van der Dam S and Abma T. Morality in the mundane: specific needs for ethics support in elderly care. Nursing Ethics. 2012; 19: 91-103.

12. Brown BA, Miles SH and Aroskar MA. The prevalence and design of ethics committees in nursing homes. I Am Geriatr Soc. 1987; 35: 1028-33.

13. Crawford KF. How ethical dilemmas are resolved. Journal of Long-Term Care Administration. 1994; 22: 25 8.

14. Glasser G, Zweibel NR and Cassel CK. The ethics committee in the nursing home. Results of a national survey. J Am Geriatr Soc. 1988; 36: 150-6.

15. Harris S. Ethics committees: an inside look at how they function. Provider. 1986; 12: 34-5.

16. Hogstel MO, Curry LC, Walker CA and Burns PG. NGNA: ethics committees in long-term care facilities. Geriatric Nursing. 2004; 25: 364-9.

17. Hiller MD. A look at long term care ethics: dilemmas and decisions. Provider. 1990; 16: 12-7.

18. Winn $\mathrm{P}$ and Cook J. Ethics committees in long-term care: a user's guide to getting started. Annals of Long Term Care. 2000; 8: 35-42.

19. Dunn H. Ethics committee protects individual rights. J Am Health Care Assoc. 1986; 12: 52-3.

20. Cox B and Roy MM. Nursing ethics can improve quality long term care... forming an Ethics Committee. American Health Care Association Journal. 1985; 11: 48-51.

21. Sansone P. The evolution of a long-term care ethics committee. HEC Forum. 1996; 8: 44-51.

22. Storl H, DuBois B and Seline J. Ethical decision-making made easier: the use of decision trees in case management. Care Management Journals. 1999; 1: 163-9.

23. Weston CM, O'Brien LA, Goldfarb NI, Roumm AR, Isele WP and Hirschfeld K. The NJ SEED project: evaluation of an innovative initiative for ethics training in nursing homes. J Am Med Dir Assoc. 2005; 6: 68-75.

24. Wood E and Karp N. Mediation: reframing care conflicts in nursing homes. Generations. 1994; 18: 54-7.

25. Thompson MA and Thompson JM. Ethics committees in nursing homes: a qualitative research study. HEC Forum. 1990; 2: 315-27.

26. Olson E, Chichin E, Meyers H, Schulman E and Brennan F. Early experiences of an ethics consult team. J Am Geriatr Soc. 1994; 42: 437-41.

27. Piette M, Ellis JL, St Denis P and Sarauer J. Integrating ethics and quality improvement: practical implementation in the transitional/ extended care setting. J Nurs Care Qual. 2002; 17: 35-42.

28. Whiteneck MR. Forum allows LTC facilities to face ethical issues together. Health Prog. 1988; 69: 82-4.

29. Chichin ER and Olson E. An ethics consult team in geriatric long-term care. Camb Q Healthc Ethics. 1995; 4: 178-84.

30. Simpson C, Kirby J and Davies M. Building a culture of ethics: the Capital Health Ethics Support model. Healthc Manage Forum. 2004; 17: 14-7.

31. Fleming D. Addressing ethical issues in the nursing home. Mo Med. 2007; 104: 387-91. 
32. Miedema F. A practical approach to ethical decisions. American Journal of Nursing. 1991; 91: 20.

33. Pompei P. How do we decide? Ethical dilemmas in the nursing facility. Annals of Long Term Care. 1999; 7: 19-22.

34. Schneider RL and Sar BK. The relocation and transfer of older persons: when decision-making combines with ethics. Journal of Gerontological Social Work. 1998; 30: 101-15.

35. Powers BA. Everyday ethics of dementia care in nursing homes: a definition and taxonomy. American Journal of Alzheimer's Disease. 2000; 15: 143-51.

36. Powers BA. Everyday ethics in assisted living facilitites: a framework for assessing resident-focused issues. J Gerontol Nurs. 2005; 31: 31-7.

37. Sansone P and Schmitt L. Assessing values: the neglected dimension in long-term care. HEC Forum. 1997; 9: 264-75.

38. Hamilton L, Bourret E and Doyle D. Application of a decision-making model for resolving ethical problems. Perspectives: The Journal of the Gerontological Nursing Association. 1988; 12: 5-8.

39. Kirsch NR. Ethical decision making: application of a problem-solving model. Topics in Geriatric Rehabilitation. 2009; 25: 282-91.

40. Slettebo A and Haugen Bunch E. Ethics in nursing homes: experience and casuistry. Int J Nurs Pract. 2004; 10: 159-65.

41. Horner R and Kelly TB. Ethical decision-making in the helping profession: a contextual and caring approach. Journal of Religion \& Spirituality in Social Work. 2007; 26: 71-88.

42. Mysak S. Strategies for promoting ethical decision-making. Journal of Gerontological Nursing. 1997; 23: 2531.

43. Fleming DA. Responding to ethical dilemmas in nursing homes: do we always need an "ethicist"? HEC forum : an interdisciplinary journal on hospitals' ethical and legal issues. 2007; 19: 245-59.

44. Paier $G$ and Miller P. The development of ethical thought in long-term care. Journal of Gerontological Nursing. 1991; 17: 28-31.

45. Solomon MZ, Jennings B, Guilfoy V, et al. Toward an expanded vision of clinical ethics education: from the individual to the institution. Kennedy Inst Ethics J. 1991; 1: 225-45.

46. Libow LS, Olson E, Neufeld RR, et al. Ethics rounds at the nursing home: an alternative to an ethics committee. J Am Geriatr Soc. 1992; 40: 95-7.

47. Dam van der S, Abma T, Molewijk A, Kardol M, Schols J and Widdershoven G. Organizing moral case deliberation Experiences in two Dutch nursing homes. Nursing Ethics. 2011; 18: 327-40.

48. Vanlaere L, Coucke T and Gastmans C. Experiential learning of empathy in a care-ethics lab. Nurs Ethics. 2010; 17: 325-36.

49. Feinsod FM and Levenson SA. Procedures for managing ethical issues and medical decision making. Annals of Long Term Care. 1998; 6: 63-5.

50. Levenson SA and Feinsod FM. Implementing effective ethics decision-making programs. Annals of Long Term Care. 1999; 7: 232-7.

51. Codes and declarations. Guide to ethical conduct for providers of residential aged care. Nursing Ethics. 2003; 10: 89-94.

52. Doucet H. Ethical deliberation in multiprofessional health care teams. Ottawa: University of Ottawa Press, 2001.

53. Gordon M, Turner L and Bourret E. Addressing ethical issues in geriatrics and long-term care: ethics education at the Baycrest Centre for Geriatric Care. Med Law. 2000; 19: 475-91.

54. Olson E, Martico-Greenfield T, Carlos A, Jackson R, Guilfoy V and Jennings B. Ethics education in long-term care: the Decisions Near the End of Life program. J Health Adm Educ. 1992; 10: 611-22.

55. Olson E, Chichin ER, Libow LS, Martico-Greenfield T, Neufeld RR and Mulvihill M. A center on ethics in long-term care. Gerontologist. 1993; 33: 269-74.

56. Weidema FC, Abma TA, Widdershoven GA and Molewijk AC. Client participation in moral case deliberation: a precarious relational balance. HEC forum : an interdisciplinary journal on hospitals' ethical and legal issues. 2011; 23: 207-24.

57. Dunbar B, Sink P, Alsobrook D, Bailey B, Lonczak T and Starnes R. Ethical perspectives of sustaining residents' autonomy: a cultural transformation best practice. Nurs Adm Q. 2011; 35: 126-33. 


\section{Appendix 1: Overview of references in four categories}

Institutional bodies: Ethics committee and consultation $[\mathrm{N}=32]$

Brown, B. A., Miles, S. H., \& Aroskar, M. A. [1987]. The prevalence and design of ethics committees in nursing homes. J Am Geriatr Soc, 35[11], 1028-1033.

Cox, B., \& Roy, M. M. [1985]. Nursing ethics can improve quality long term care... forming an Ethics Committee. American Health Care Association Journal, 11[6], 48-51.

Curl, E., \& Curl, D. [1985]. The "forgotten" setting of ethical dilemmas: long-term care. Kansas Nurse, 60[10], 2-4.

Dunbar, B., Sink, P., Alsobrook, D., Bailey, B., Lonczak, T., \& Starnes, R. [2011]. Ethical perspectives of sustaining residents' autonomy: a cultural transformation best practice. Nurs Adm Q, 35[2], 126-133.

Dunn, H. [1986]. Ethics committee protects individual rights. J Am Health Care Assoc, 12[2], 52-53.

Glasser, G., Zweibel, N. R., \& Cassel, C. K. [1988]. The ethics committee in the nursing home. Results of a national survey. J Am Geriatr Soc, 36[2], 150-156.

Gordon, M., Turner, L., \& Bourret, E. [2000]. Addressing ethical issues in geriatrics and long-term care: ethics education at the Baycrest Centre for Geriatric Care. Med Law, 19[3], 475-491.

Harris, S. [1986]. Ethics committees: an inside look at how they function. Provider, 12[7], 34-35.

Hirsh, H. L. [1987]. Nursing home ethics committees: to be or not to be. Nurs Homes Sr Citiz Care, 36[3], 12 15.

Weisman, S. [1980]. A nursing home's experience with an ethics committee. Nurs Homes, 29[5], 2-4.

Whiteneck, M. R. [1988]. Forum allows LTC facilities to face ethical issues together. Health Prog, 69[2], 82-84.

Whiteneck, M. R. [1988]. Integrating ethics with quality assurance in long term care. QRB Qual Rev Bull, $14[5], 138-143$.

Chichin, E. R., \& Olson, E. [1995]. An ethics consult team in geriatric long-term care. Camb Q Healthc Ethics, $4[2], 178-184$.

Crawford, K. F. [1994]. How ethical dilemmas are resolved. Journal of Long-Term Care Administration, 22[3], 2528.

Hiller, M. D. [1990]. A look at long term care ethics: dilemmas and decisions. Provider, 16[5], 12-17.

Hogstel, M. O., Curry, L. C., Walker, C. A., \& Burns, P. G. [2004]. NGNA: ethics committees in long-term care facilities. Geriatric Nursing, 25[6], 364-369.

Kaufmann, A. [1994]. Long-Term Care Coalition of the Orange County Bioethics Network [California]. HEC Forum, 6[3], 183-186.

Kelly, C., \& Lazaroff, A. [1993]. Learning to pay attention. An ethics study group refocuses on issues affecting long-term care residents' daily lives. Health Prog, 74[9], 40-43, 52.

Kimboko, P., \& Jewell, E. [1994]. A beginner's guide to ethical awareness in long-term care services. Activities, Adaptation \& Aging, 18[3-4], 5-26. 
Institutional bodies [continued]

Meece, K. S. [1990]. Long-term care bioethics committees: a cooperative model. HEC Forum, 2[2], 127-131.

O'Brien, L. A. [2005]. Establishing and educating a long-term care regional ethics committee: the NJ model. Journal of the American Medical Directors Association, 6[1], 66-67.

Olson, E., Chichin, E. R., Libow, L. S., Martico-Greenfield, T., Neufeld, R. R., \& Mulvihill, M. [1993]. A center on ethics in long-term care. Gerontologist, 33[2], 269-274.

Olson, E., Chichin, E., Meyers, H., Schulman, E., \& Brennan, F. [1994]. Early experiences of an ethics consult team. J Am Geriatr Soc, 42[4], 437-441.

Piette, M., Ellis, J. L., St Denis, P., \& Sarauer, J. [2002]. Integrating ethics and quality improvement: practical implementation in the transitional/ extended care setting. J Nurs Care Qual, 17[1], 35-42.

Sansone, P. [1996]. The evolution of a long-term care ethics committee. HEC Forum, 8[1], 44-51.

Simpson, C., Kirby, J., \& Davies, M. [2004]. Building a culture of ethics: the Capital Health Ethics Support model. Healthcare management forum / Canadian College of Health Service Executives = Forum gestion des soins de sante / College canadien des directeurs de services de sante, 17[3], 14-17.

Storl, H., DuBois, B., \& Seline, J. [1999]. Ethical decision-making made easier: the use of decision trees in case management. Care Management Journals, 1[3], 163-169.

Thompson, M. A., \& Thompson, J. M. [1990]. Ethics committees in nursing homes: a qualitative research study. HEC Forum, 2[5], 315-327.

Welch, R. M. [1992]. Ethics committees provide decision-making support. Provider, 18[11], 49-49.

Weston, C. M., O'Brien, L. A., Goldfarb, N. I., Roumm, A. R., Isele, W. P., \& Hirschfeld, K. [2005]. The NJ SEED project: evaluation of an innovative initiative for ethics training in nursing homes. J Am Med Dir Assoc, 6[1], 68-75.

Winn, P., \& Cook, J. [2000]. Ethics committees in long-term care: a user's guide to getting started. Annals of Long Term Care, 8[1], 35-42.

Wood, E., \& Karp, N. [1994]. Mediation: reframing care conflicts in nursing homes. Generations, 18[4], 54-57.

Frameworks [N=17]

Bolmsjo, I. A., Edberg, A. K., \& Sandman, L. [2006]. Everyday ethical problems in dementia care: a teleological model. Nurs Ethics, 13[4], 340-359.

Bolmsjo, I. A., Sandman, L., \& Andersson, E. [2006]. Everyday ethics in the care of elderly people. Nurs Ethics, 13[3], 249-263.

Fleming, D. [2007]. Addressing ethical issues in the nursing home. Mo Med, 104[5], 387-391.

Fleming, D. A. [2007]. Responding to ethical dilemmas in nursing homes: do we always need an "ethicist"? HEC forum : an interdisciplinary journal on hospitals' ethical and legal issues, 19[3], 245-259.

Hamilton, L., Bourret, E., \& Doyle, D. [1988]. Application of a decision-making model for resolving ethical problems. Perspectives: The Journal of the Gerontological Nursing Association, 12[1], 5-8. 
Frameworks [continued]

Horner, R., \& Kelly, T. B. [2007]. Ethical decision-making in the helping profession: a contextual and caring approach. Journal of Religion \& Spirituality in Social Work, 26[1], 71-88.

Kirsch, N. R. [2009]. Ethical decision making: application of a problem-solving model. Topics in Geriatric Rehabilitation, 25[4], 282-291.

Miedema, F. [1991]. A practical approach to ethical decisions. American Journal of Nursing, 91[12], 20.

Mysak, S. [1997]. Strategies for promoting ethical decision-making. Journal of Gerontological Nursing, 23[1], 2531 .

Pompei, P. [1999]. How do we decide? Ethical dilemmas in the nursing facility. Annals of Long Term Care, 7 , 19-22.

Powers, B. A. [2000]. Everyday ethics of dementia care in nursing homes: a definition and taxonomy. American Journal of Alzheimer's Disease, 15[3], 143-151.

Powers, B. A. [2001]. Ethnographic analysis of everyday ethics in the care of nursing home residents with dementia: a taxonomy. Nurs Res, 50[6], 332-339.

Powers, B. A. [2005]. Everyday ethics in assisted living facilitites: a framework for assessing resident-focused issues. J Gerontol Nurs, 31[1], 31-37.

Sansone, P., \& Schmitt, L. [1997]. Assessing values: the neglected dimension in long-term care. HEC Forum, $9[3], 264-275$.

Schneider, R. L., \& Kropf, N. P. [1996]. The admission process in nursing homes: a clinical model for ethical decision-making. Journal of Long Term Home Health Care, 15[3], 39-46.

Schneider, R. L., \& Sar, B. K. [1998]. The relocation and transfer of older persons: when decision-making combines with ethics. Journal of Gerontological Social Work, 30[3/4], 101-115.

Slettebo, A., \& Haugen Bunch, E. [2004]. Ethics in nursing homes: experience and casuistry. Int J Nurs Pract, $10[4], 159-165$.

\section{Educational programs and MCD $[\mathrm{N}=7]$}

Dam van der, S., Abma, T., Molewijk, A., Kardol, M., Schols, J., \& Widdershoven, G. [2011]. Organizing moral case deliberation Experiences in two Dutch nursing homes. Nursing Ethics, 18[3], 327-340.

van der Dam, S., Abma, T. A., Kardol, M. J., \& Widdershoven, G. A. [2011]. "Here's My Dilemma". Moral Case Deliberation as a Platform for Discussing Everyday Ethics in Elderly Care. Health Care Anal. 2012; 20: 250-67.

Libow, L. S., Olson, E., Neufeld, R. R., Martico-Greenfield, T., Meyers, H., Gordon, N., et al. [1992]. Ethics rounds at the nursing home: an alternative to an ethics committee. J Am Geriatr Soc, 40[1], 95-97.

Olson, E., Martico-Greenfield, T., Carlos, A., Jackson, R., Guilfoy, V., \& Jennings, B. [1992]. Ethics education in long-term care: the Decisions Near the End of Life program. J Health Adm Educ, 10[4], 611-622.

Paier, G., \& Miller, P. [1991]. The development of ethical thought in long-term care. Journal of Gerontological Nursing, 17[10], 28-31. 
Educational programs and MCD [continued]

Solomon, M. Z., Jennings, B., Guilfoy, V., Jackson, R., O'Donnell, L., Wolf, S. M., et al. [1991]. Toward an expanded vision of clinical ethics education: from the individual to the institution. Kennedy Inst Ethics J, 1[3], 225-245.

Vanlaere, L., Coucke, T., \& Gastmans, C. [2010]. Experiential learning of empathy in a care-ethics lab. Nurs Ethics, 17[3], 325-336.

Written document and policies [N=4]

Codes and declarations. Guide to ethical conduct for providers of residential aged care. [2003]. Nursing Ethics, $10[1], 89-94$.

Feinsod, F. M., \& Levenson, S. A. [1998]. Procedures for managing ethical issues and medical decision making. Annals of Long Term Care, 6[2], 63-65.

Levenson, S. A., \& Feinsod, F. M. [1999]. Implementing effective ethics decision-making programs. Annals of Long Term Care, 7[6], 232-237.

Uhlmann, R. F., Clark, H., Pearlman, R. A., Downs, J. C., Addison, J. H., \& Haining, R. G. [1987]. Medical management decisions in nursing home patients. Principles and policy recommendations. [Research Support, U.S. Gov't, P.H.S.]. Annals of internal medicine, 106[6], 879-885. 


\section{Chapter 3}

\section{Morality in the mundane: Specific needs for ethics support in elderly care}

L.Dauwerse

S. van der Dam

T.A. Abma

Published in: Nursing Ethics, 2012, 19(1), 91-103. 


\begin{abstract}
A B S T R A C T
Ethics support is called for to improve the quality of care in elderly institutions. Various forms of ethics support are presented, but the needs for ethics support remain unknown. Using a mixed-methods design, this article systematically investigates the specific needs for ethics support in elderly care. The findings of two surveys, two focus groups and 17 interviews demonstrate that the availability of ethics support is limited. There is a need for ethics support, albeit not unconditionally. Advice-based forms of ethics support are less appropriate as they are removed from practice. Ethics support should be tailored to the often mundane and easily overlooked moral issues that arise in long-term care. Attention should also be given to the learning styles of nurses who favour experiential learning. Raising awareness and developing a climateof openness and dialogue are the most suitable ways to deal with the mundane moral issues in elderly care.
\end{abstract}




\section{INTRODUCTION}

There is increasing international awareness that attention should be given to the further development of elderly care to maintain or improve the quality of care. ${ }^{1-4}$ The volume of elderly care is increasing as a consequence of the growing number of clients resulting from the increasing numbers of older citizens in the population. Cost cuts, the sector's negative image, care standardization, an ever increasing workload, and understaffing all impose a heavy burden on elderly care. ${ }^{5-8}$

Nurses and care assistants in elderly care are confronted with various ethical issues. $^{7,}$,-12 Ideally, a nursing home should provide a living context where residents can live in accordance with their own standards. However, life in an institution is seldom a continuation of life as it was at home. Living in an institution inevitably means that personal preferences and autonomy are curtailed by the necessary routines, the presence of fellow residents, family members, dependency on professional caregivers and limited resources. ${ }^{13,14}$ Nursing homes still resemble the 'total institution' depicted by Goffman in the $1960 \mathrm{~s}^{15}$, in spite of recent developments such as person-centred care, hospitality care, and small-scale living. Nurses must deal with conflicting interests ${ }^{16}$, difficult behaviour ${ }^{17}$, limited resources, and social problems stemming from a community of residents who did not choose to live together. ${ }^{13,18}$

A seemingly easy situation, such as the routine of washing older adults involves a set of complex values such as dignity, autonomy, bodily integrity and wellbeing. ${ }^{9}$ However, the complexity of such a situation is easily overlooked as working routines and habits lend structure to daily care. ${ }^{9,19}$ Moreover, given the relatively low formal education and training of most nurses, reflection in long-term care and enduring clientprofessional relations are challenging. ${ }^{13,20}$

Several forms of ethics support have been introduced to help nurses deal with moral issues. $9111,12,21,22$ The most common form of support is the clinical ethics committee. ${ }^{23}$ Some authors have observed that a traditional ethics committee tends to be far removed from practice ${ }^{24-26}$ and some studies promote alternative forms of ethics support for long-term care, i.e. moral case deliberation, ${ }^{27}$ ethics rounds ${ }^{28}$ and a care-ethics lab. ${ }^{9}$ To date, no systematic studies have investigated the extent to which the range of ethics support currently on offer actually meets the needs of ethics support in elderly care.

This article systematically assesses the specific needs for ethics support in elderly care. The research question is: 'What are the specific needs for ethics support in elderly care?' The data are based on a mixed methods study conducted among elderly care organizations in the Netherlands. This study focused on the ethics support currently available, on evaluating these forms of ethics support, and on the needs for ethics support in elderly care. The argument is that the specific moral issues that arise in elderly care and the learning styles of nurses have implications for the kind of ethics support that best fits with institutionalized elderly care. Here, the term nurses also includes care assistants. 


\section{METHOD}

\section{DES I G N}

An integrated mixed methods design was used i.e. quantitative and qualitative methods were intentionally mingled during the research process. ${ }^{29}$ Two surveys were prepared using qualitative instruments. Survey data were used as input and validated in two focus groups and in face-to-face interviews $(\mathrm{N}=17)$. Table 1 presents a detailed description of the procedures followed. Data were derived from a larger study that included all healthcare sectors. This article first describes the methods used in the larger study and then focuses on our findings regarding elderly care, which is, in fact, the largest care sector in the Netherlands.

Table 1: Data collection procedures

\begin{tabular}{|c|c|c|c|c|}
\hline Activity & $\begin{array}{l}\text { Survey question- } \\
\text { naire } 1\end{array}$ & $\begin{array}{l}\text { Survey question- } \\
\text { naire } 2\end{array}$ & $\begin{array}{l}2 \text { Focus groups } \\
(n=22)\end{array}$ & 17 Interviews \\
\hline Preparation & $\begin{array}{l}\text { Literature research } \\
7 \text { expert conversa- } \\
\text { tions } \\
\text { Pilot: } 9 \text { people }\end{array}$ & $\begin{array}{l}\text { Literature research } \\
12 \text { expert conversa- } \\
\text { tions } \\
\text { Pilot: } 12 \text { people }\end{array}$ & $\begin{array}{l}\text { Contact to inform } \\
\text { PowerPoint to present } \\
\text { results } \\
\text { Preparation of } \\
\text { handouts }\end{array}$ & $\begin{array}{l}\text { Contact to inform } \\
\text { Topic list }\end{array}$ \\
\hline $\begin{array}{l}\text { Target } \\
\text { group }\end{array}$ & Board members & Ethics support staff & $\begin{array}{l}\text { Respondents ques- } \\
\text { tionnaires }\end{array}$ & $\begin{array}{l}\text { Participants research } \\
\& \text { network } \\
\text { Diversity of sectors }\end{array}$ \\
\hline Procedures & $\begin{array}{l}\text { Addresses (2137) } \\
\text { from Dutch gov- } \\
\text { ernment } \\
2 \text { reminders, phone } \\
\text { follow-up }\end{array}$ & $\begin{array}{l}\text { Contact information } \\
\text { (515) from respond- } \\
\text { ents Q1 } \\
2 \text { reminders, phone } \\
\text { follow-up }\end{array}$ & $\begin{array}{l}2 \text { days, each day } 11 \\
\text { people } \\
\text { Dialogue in } 2 \text { separate } \\
\text { groups } \\
\text { Member check }\end{array}$ & $\begin{array}{l}\text { Recording and } \\
\text { transcription } \\
\text { Member check }\end{array}$ \\
\hline
\end{tabular}

\section{DATA COLLECTION, ANALYSES AND QUALITY PROCEDURES}

The need for ethics support was investigated using two survey questionnaires, prepared by reading the literature and talking to experts from different fields. Both questionnaires focused on the needs for ethics support, the goals of ethics support, and the different forms of ethics support.

Questionnaire 1 was directed at the board members of healthcare institutions. It was developed by reading the literature, talking to experts $(N=7)$ from different sectors and testing the questionnaire with board members and experts $(\mathrm{N}=9)$ from various sectors. The participants found our questionnaire too long, and board members were not the right people to answer some of the questions. We searched for ways to get 
as much information as possible in a short questionnaire. The main topics we wanted to ask the board members about were included in the short questionnaire based on Slowther. ${ }^{23}$ We added open-ended questions on the goals of ethics support, the desirability of ethics support, and on existing forms of ethics support. An additional advantage of using Slowther's questionnaire was that we were able to place the results in an international context.

Questionnaire 1 was sent (postal) to all intramural healthcare institutions $(\mathrm{N}=$ 2137) registered with the Netherlands Ministry of Health, Welfare and Sports (Table 2), and included elderly care establishments, hospitals, mental healthcare and institutions for the mentally disabled. The data collection (April-July 2008) included two reminders and a telephone follow-up. The 2137 individual healthcare institutions turned out to be members of 864 legal bodies, i.e. umbrella organizations with a legal status. Hence, there are two response rates for this first questionnaire, namely $30 \%(638 / 2137)$ at the individual institution level, and 56\% (485 / 864) at the legal body level.

Questionnaire 2 was distributed to ethics support staff, who are, generally speaking, professionals involved in organizing, implementing and executing ethics support in their institutions, such as the chairs of ethical committees, or spiritual caregivers. The questionnaire was also developed by reading the literature and by holding discussions with experts $(\mathrm{N}=12)$ from different sectors, for example, people with methodological experience in (digital) surveys and people with substantial knowledge of ethics support. This questionnaire was first tested among 12 experts from different fields, who completed the questionnaire and gave feedback by email. Questionnaire 2 included the questions that the board members were unable to answer in the pilot e.g. on content, participants, integration and evaluation of ethics support.

Questionnaire 2 was sent (digitally) to all the ethics support staff members $(\mathrm{N}=$ 515) designated by the respondents in questionnaire 1 . The number of ethics support staff members was less than the number of respondents for questionnaire $1 \quad(N=638)$ because not all respondents in questionnaire 1 designated a best informant. The data collection (April 2009-July 2009) included 2 reminders and a telephone follow-up. The response rate was $48 \%$ (247 / 515).

Elderly care (care homes, nursing homes and sometimes home care) is the largest group $(78 \%)$ in the research population of the original study (see Table 2), and it is also the group with the highest response rate in the dataset. More than half the respondents $(62 \%$ for questionnaire 1 , and $55 \%$ for questionnaire 2$)$ are from elderly care (see Table 2).

The data provided by the questionnaires were analyzed separately and transformed for further analysis and comparison (crossover track analysis). ${ }^{29}$ The closed questions were first analyzed using MS Excel and SPSS 15. Subsequently, the answers to the open-ended questions were labelled and clustered into (sub)themes following an inductive qualitative analysis. Relations were visualized in a mind map and discussed in the research team and validated in the advisory committee and the focus groups. 
Table 2: Research population and response to original study

\begin{tabular}{|c|c|c|c|c|c|c|c|c|}
\hline \multirow[b]{3}{*}{ Sector/respondents } & \multicolumn{4}{|c|}{ Questionnaire 1 board members } & \multicolumn{4}{|c|}{ Questionnaire 2 ethics support staff } \\
\hline & \multicolumn{2}{|c|}{ Population } & \multicolumn{2}{|c|}{ Response } & \multicolumn{2}{|c|}{ Population } & \multicolumn{2}{|c|}{ Response } \\
\hline & $\mathrm{N}$ & $\%$ & $\mathrm{n}$ & $\%$ & $\mathrm{~N}$ & $\%$ & $\mathrm{~N}$ & $\%$ \\
\hline Elderly care ${ }^{3}$ & 1660 & $78 \%$ & 397 & $62 \%$ & 308 & $60 \%$ & 135 & $55 \%$ \\
\hline Mentally disabled & 186 & $9 \%$ & 78 & $12 \%$ & 72 & $14 \%$ & 30 & $12 \%$ \\
\hline Hospital & 171 & $8 \%$ & 99 & $16 \%$ & 82 & $16 \%$ & 48 & $19 \%$ \\
\hline Psychiatric institute & 120 & $6 \%$ & 64 & $10 \%$ & 46 & $9 \%$ & 19 & $8 \%$ \\
\hline Other ${ }^{4}$ & - & - & - & - & 7 & $1 \%$ & 15 & $6 \%$ \\
\hline Total & 2137 & $100 \%$ & 638 & $100 \%$ & 515 & $100 \%$ & 247 & $100 \%$ \\
\hline
\end{tabular}

We organized two focus groups (summer 2009) which were attended by participants who had completed the questionnaires. The groups were a mix of board members/directors, ethics support staff, general staff members and a healthcare professional. There were 22 participants, including 7 participants from elderly care. The elderly care participants were 3 staff members (including 1 who was also head of the ethics committee), 1 head of the ethics committee, 1 spiritual caregiver, 1 director, and 1 nursing home doctor). The meeting itself was structured by the issues emerging from the surveys, and followed an agenda that left ample room for exploration and dialogue. Each two-hour session was moderated by an experienced senior researcher and the first author. Group dynamics were taken into account. The initial analysis of the data from both questionnaires was discussed. Furthermore, they also completed a handout about the preliminary findings. The conversations were analyzed and a summary sent to the participants for validation (member check). Any additional email and telephone responses were incorporated in the further analysis.

Semi-structured interviews $(\mathrm{N}=17)$ were conducted to establish corroboration and to gain a deeper understanding of the findings. The interviewees included three people from elderly care, 1 staff member and the head of an ethics committee, 1 staff member from an elderly care umbrella organization, and 1 staff member from a centre of expertise for long-term care. The interviews were conducted by the first author and lasted about 1.5 hours. Themes again included the need for developing goals for ethics support, and the forms of ethics support. The interviews were recorded, analyzed, returned for validation (member check), and used to establish corroboration and gain a deeper understanding. The analysis of the focus group and interview transcripts followed a thematic content analysis. Transcripts were read for recurring themes, which were labelled and clustered until a robust framework was developed. The analysis was completed by the first author together with a team of senior researchers. The combination

\footnotetext{
3 These are sometimes combined centres with assisted living facilities, including home care.

${ }^{4}$ For example: sensory disabled, youth care, social service, acquired brain injury, physically disabled.
} 
of methods (triangulation procedure) added breadth to the study, and the qualitative data helped provide explanations for the numeric data from the surveys.

\section{ETHICAL CONSIDERATIONS}

Informed consent was obtained by an explanatory introduction letter to respondents of Questionnaire 1 and 2. Prior to the meeting, participants of the focus groups and interviews received information by telephone and / or email about the focus group or interview. At the start of the meeting there was a short presentation of the preliminary findings and afterwards they received a member check for agreement. Respondents participated voluntarily. Anonymity was guaranteed by not using names in the analysis and reports.

\section{RESULTS}

\section{ETHICS SUPPORT IN ELDERLY CARE}

Currently, ethics support, as in the existence of ethics committees (56\% are without), moral case deliberation ( $64 \%$ are without), and ethics consultants ( $92 \%$ are without) is severely limited in elderly care in the Netherlands. When a moral question arises in elderly care, other forms such as pastoral care (78\% have this), group meetings in the form of multidisciplinary meetings ( $65 \%$ have them), or policy-like guidelines $(54 \%$ have them) are used (see Table 3). The findings in Table 3 also show that ethics support is not automatically considered to be important in elderly care institutions. For example, only $23 \%$ of the ethics committees are deemed to be important within the institution (see Table 3). Collaborative meetings, such as multidisciplinary team meetings, are the most highly esteemed (26\%).

\section{NEED FOR ETHICS SUPPORT}

The findings indicate that there is a very real need for ethics support. $67 \%$ of elderly care institutions experience a considerable need for ethics support. However, this need is not unconditional as 34\% of respondents (questionnaire 1) disagree with the statement that ethics support is desirable (see Table 4).

\section{CONDITIONAL NEED}

The answers to the open-ended questions in the first questionnaire (QI) illustrate that some elderly care institutions see no need for ethics support because they are satisfied with their existing forms of ethics support:

'Regular, informal deliberation is enough .'(Q1, director, nursing home) 
Respondents also indicate that the need for ethics support may not be evident or even espoused. They explain that the ethical dimension of care is implicit and therefore the need is hidden:

'T'm convinced there is a need, but what makes it complicated is that this need is hidden from view.' (interview staff member centre of expertise for long-term care)

Table 3: Assessment of ethics support in elderly care (Questionnaire 2, N=135)

\begin{tabular}{|c|c|c|c|c|c|c|c|c|}
\hline \multirow[b]{2}{*}{$N=135$} & \multicolumn{2}{|c|}{ Available } & \multicolumn{2}{|c|}{ Not available } & \multicolumn{2}{|c|}{ (Most) important } & \multicolumn{2}{|c|}{ Not (most) important } \\
\hline & Number & $\%$ & Number & $\%$ & Number & $\%$ & Number & $\%$ \\
\hline Individual $(\mathrm{s})^{5}$ & 105 & $78 \%$ & 30 & $22 \%$ & 20 & $15 \%$ & 115 & $85 \%$ \\
\hline Group meeting(s) ${ }^{6}$ & 88 & $65 \%$ & 47 & $35 \%$ & 35 & $26 \%$ & 100 & $74 \%$ \\
\hline Policy & 73 & $54 \%$ & 62 & $46 \%$ & 10 & $7 \%$ & 125 & $93 \%$ \\
\hline Ethics committee & 60 & $44 \%$ & 75 & $56 \%$ & 31 & $23 \%$ & 104 & $77 \%$ \\
\hline Other committee $(\mathrm{s})^{7}$ & 59 & $44 \%$ & 76 & $56 \%$ & 7 & $5 \%$ & 128 & $95 \%$ \\
\hline Ad hoc & 58 & $43 \%$ & 77 & $57 \%$ & 9 & $7 \%$ & 126 & $93 \%$ \\
\hline Education & 53 & $39 \%$ & 82 & $61 \%$ & 18 & $13 \%$ & 117 & $87 \%$ \\
\hline Moral Deliberation & 48 & $36 \%$ & 87 & $64 \%$ & 21 & $16 \%$ & 114 & $84 \%$ \\
\hline Peer assessment & 27 & $20 \%$ & 108 & $80 \%$ & 7 & $5 \%$ & 128 & $95 \%$ \\
\hline Ethics consultant & 11 & $8 \%$ & 124 & $92 \%$ & 3 & $2 \%$ & 132 & $98 \%$ \\
\hline
\end{tabular}

Some argue that moral issues in elderly care do not arise very often and if they do, they are not particularly complicated. For example, they compare their situation with hospitals where, given the complex and structural nature of medical ethical issues in that context, the need for ethics support would be more obvious. The following is from the chairman of a board who probably has a traditional view of ethics and is not aware of the mundane nature of many ethical issues:

Ethical issues in our care home generally tend to be incidental and less complex than those in, say, a hospital. (Q1, chairman of the board, health care centre with assisted living facilities)

Elderly care institutions may not give priority to ethics support for organizational reasons such as the size of the healthcare institution: It is important, but our care bome is too small' (Q1, care manager, health care centre with assisted living facilities); and the spiritual background: 'The Bible is the precept behind all our care and services.' (Q1, director, health care centre with assisted living facilities).

Some respondents have also noticed a discrepancy between what elderly care institutions want and what they actually have in place. They want to use ethics support to help

\footnotetext{
5 This individual is not an ethics consultant

${ }^{6}$ This group is not moral case deliberation

${ }^{7}$ This committee is not an ethics committee
} 
them deliver good care, yet they do not embark on ethics support because there are so many other priorities and because implementing ethics support would change the organization.

'All those organizations really have a lot on their plate. So, because there are so many other priorities, if they have to make a choice, they won't, out of the blue, just implement some kind of ethics support. It really is something that organizations do want to get up and running, but it's quite intensive because you actually shake the very core of your organization.' (interview staff member centre of expertise for long-term care)

\section{SPECIFIC NEEDS}

The data of this study as a whole indicate that elderly care has specific needs regarding ethics support. Most board members concur that ethics support is desirable (see Table 4) and the answers to the open ended questions explain the specific needs for ethics support in elderly care. Firstly, the moral issues in elderly care require ethics support. Secondly, given the characteristic moral issues and skills required of nurses working in elderly care, it is a very specific kind of support that is needed.

Table 4: Need for ethics support elderly care (questionnaire $1, \mathrm{~N}=397$ )

\begin{tabular}{|c|c|c|}
\hline & Number & Percentage \\
\hline Strongly agree there is a need & 73 & $19 \%$ \\
\hline Agree there is a need & 186 & $48 \%$ \\
\hline Disagree there is a need & 111 & $29 \%$ \\
\hline Strongly disagree there is a need & 19 & $5 \%$ \\
\hline Total & 389 & $100 \%$ \\
\hline
\end{tabular}

\section{MORAL ISSUES IN ELDERLY CARE}

The answers to the open-ended questions illustrate that the type of moral questions influence the specific need for ethics support in elderly care:

'Employees are confronted every day with questions from an ever increasing group of elderly, vulnerable clients.' (Q1, regional manager, healthcare centre).

The findings indicate there is some discrepancy as to the perceived number of moral issues in elderly care. A minority of respondents indicate that moral issues are uncommon in elderly care. Conversely, most respondents emphasize that there are many complex questions that require more structural and systematic attention. They point to care ethical questions, organizational constraints, and nurses' attitudes.

Several board members and ethics staff members emphasize that ethics is much broader than dilemmas about life and death.

Ethics support is absolutely essential when caring for frail and vulnerable people; it influences what you do, and it's a basis to belp you make decisions.' (Q1, spiritual caregiver, nursing bome) 
Ethics is an everyday issue, when are you doing the right thing, and for whom is it the best thing to do? Ethics is more than dilemmas about life and death.' $(Q 1$, head of the day-care unit, health care centre with assisted living facilities)

Table 5: Type of questions (Questionnaire 2: 'How often do the following ethical themes arise in your healthcare institution?')

\begin{tabular}{|c|c|c|c|c|c|c|c|c|c|}
\hline \multirow{2}{*}{$\begin{array}{l}\text { Question / } \\
\text { Number }\end{array}$} & \multicolumn{2}{|c|}{ Often } & \multicolumn{2}{|c|}{ Sometimes } & \multicolumn{2}{|c|}{ Seldom } & \multicolumn{2}{|c|}{ Total } & \multirow[b]{2}{*}{ Explanation } \\
\hline & $\%$ & $\mathrm{~N}$ & $\%$ & $\mathrm{~N}$ & $\%$ & $\mathrm{~N}$ & $\%$ & $\mathrm{~N}$ & \\
\hline Medical ethical & $26 \%$ & 35 & $34 \%$ & 46 & $40 \%$ & 54 & $100 \%$ & 135 & $\begin{array}{l}\text { Medical ethical themes in } \\
\text { relation to difficult } \\
\text { decisions (euthanasia, abor- } \\
\text { tion, drip feeding, coercive } \\
\text { admission, reproduction) }\end{array}$ \\
\hline Care ethical & $43 \%$ & 58 & $31 \%$ & 42 & $26 \%$ & 35 & $100 \%$ & 135 & $\begin{array}{l}\text { Care ethical themes (am I } \\
\text { allowed to wash a patient who } \\
\text { doesn't want me to? Am I } \\
\text { allowed to inform family } \\
\text { about the care policy when the } \\
\text { patients don't want this?) }\end{array}$ \\
\hline Organizational & $58 \%$ & 77 & $30 \%$ & 39 & $12 \%$ & 14 & $100 \%$ & 132 & $\begin{array}{l}\text { Organizational themes (for } \\
\text { example development of } \\
\text { organizational vision, savings, } \\
\text { waiting lists, scarcity) }\end{array}$ \\
\hline Attitude & $73 \%$ & 98 & $16 \%$ & 22 & $11 \%$ & 14 & $100 \%$ & 134 & $\begin{array}{l}\text { Attitudes (for example: how to } \\
\text { treat someone?) }\end{array}$ \\
\hline
\end{tabular}

The quantitative findings of Questionnaire 2 (see Table 5) confirm that there are not many medical ethical issues in elderly care $(40 \%$ indicate that these kinds of questions do not arise frequently).

However, moral questions about one's attitude as to how to treat someone do emerge frequently $(73 \%)$. These questions often generate a feeling of powerlessness:

'When you really have the idea that you can't do anything to make life more pleasant for the residents.' (interview with staff member of an umbrella organization for elderly care).

As a nurse it is obviously very difficult when you feel you cannot influence the situation:

When you really have the feeling that you can't do anything to make someone's life easier and more pleasant.' (interview staff member centre of expertise for long-term care).

Respondents point out that nurses in elderly care have less professional training in ethics than, for example, registered nurses in hospitals. Those respondents who understand ethics to encompass more than medical ethical issues such as end-of-life decisions are not satisfied with how nurses currently deal with the moral dimension in healthcare:

They are confronted with ethical questions, but they are not fully equipped to recognize or deal with them.'(Q1, board member, health care centre with assisted living facilities) 
Nurses tend to associate ethics with medical ethical issues such as respect for autonomy, tube feeding, resuscitation or euthanasia, while most ethical questions in elderly care actually different. For example:

'An old lady with dementia and diabetes who wants to eat cake every day. When you believe she's autonomous, then you should let her have cake every day, but then that doesn't feel like being a good caregiver.'(interview staff member centre of expertise for long term care).

Several respondents state that nurses do not have sufficient skills to identify and deal with ethical issues. They indicate that nurses in elderly care do feel when there is an ethical question, but they are unable to say what it is:

'They often experience a feeling of powerlessness without recognizing the ethical basis of the situation.'(focus group participant, staff member elderly care).

Nurses feel uncomfortable, but simply return to their routines in order to deal with the unpleasant feeling they experience since they see no alternatives. One interviewee comments that employees wrongly assume that giving attention takes time:

When serving food there was one caregiver who waited until the patient answered "thank you" after she had said "enjoy your meal." The others just got on with handing out food without waiting for an answer:... enjoy your meal, enjoy your meal, enjoy your meal...'(interview staff member centre of expertise for long-term care).

\section{SPECIFIC SUPPORT}

Given the type of moral issues to be found in elderly care, and the skills of the nurses involved, respondents postulate that specific ethics support is needed, which, they believe, is up to the organization to facilitate. In elderly care, particularly those people with an exemplary role can be very supportive for nurses, so that they learn how to deal with ethical questions:

It's all about how people learn. Most caregivers in elderly care don't learn from theory. They tend to learn from good examples, by copying the behaviour of role models. If there's a team with colleagues they respect and admire then they might think something like "I'd also like to do it the way they do". In these cases many beautiful things happen. They're often new people or students.' (interview staff member centre of expertise for long-term care)

Respondents suggest that elderly care might possibly require forms of ethics support that differ from what is found in other healthcare settings, particularly because nurses in elderly care lack confidence and do not feel appreciated for the effort and energy they put into their work. The broader political image in society at large of what elderly care entails actually exacerbates the situation and results in nurses being ashamed of working in elderly care. Ethics support should help get the work of these nurses recognized, rather than introducing yet another innovation or course that may again be perceived as criticism of their effort:

Elderly care is not really appreciated. Nurses should get more support, more recognition. It's only when they become aware that they really do make a difference that they'll start to appreciate themselves and again be proud of their profession. For example, if asked about their job at a party, 
they hardly dare say they are nurses. They are usually associated with urine and faeces instead of with wellbeing, whereas for me it is wellbeing that really counts.' (interview staff member centre of expertise for long-term care)

Respondents argue that implementing ethics support as 'yet another' course only serves to foster the feeling that nurses 'do not do enough', while in fact they actually give a lot of themselves. There is a tension here for elderly institutions because, on the one hand, they should not introduce 'yet another innovation,' but on the other hand they are assumed to be responsible for ethics support, as the following quote illustrates:

Employees who have to deal with difficult questions are entitled to get support for this in their work.' (Q1, spiritual caregiver \& member of ethics committee, care home)

Respondents prefer not to opt for a specific form of ethics support and advocate a combination of different forms: most often cited are - group deliberation (informal: $26 \%$; in a committee: $23 \%$; moral case deliberation: $16 \%$ ). Apparently there are advantages to group deliberations, as the following respondent illustrates:

'Ethical dilemmas are sometimes discussed during team or work meetings. Perhaps this isn't really official support, but in practice it is meaningful and useful to make an ethical decision in a short space of time.' (Q2, nursing home physician, nursing home)

Furthermore, many elderly care institutions reject isolated forms of ethics support. Respondents prefer integrated ethics support which blends in with daily activities i.e. it is not something new, and low threshold. Ethics should become a shared responsibility. Role models and leadership are essential:

Don't formalize it as a "service." That only involves extra money and leads to problems; easy accessibility would disappear. Rather define it as an integral responsibility.' (Q1, chairman of the board, health care centre with assisted living facilities)

Employees and management should feel and behave responsibly because otherwise they might think that "the ethics committee is responsible for this." (Q1, site director, care home)

Directors say it's important that the work floor is ethical, but they don't get involved themselves. And their involvement really is necessary if the goals of ethics support are to be achieved.' (Focusgroup, staff employee elderly care)

Therefore, elderly care institutions have a need for organized and integrated low threshold, familiar ethics support.

\section{IS C USS I O N}

Our findings illustrate that ethics support in elderly care institutions in the Netherlands is limited. There is a need for this kind of support, albeit not unconditionally. The data indicate that advice-based forms of ethics support transcend and do not match up with the nature of moral problems found in long-term care. The belief is that advice-based forms of ethics support are far removed from actual practice and that they are not in 
tune with the real issues in the workplace. Several authors describe the advantages and disadvantages of ethics committees, ${ }^{24-26}$ and they confirm that the extent to which a committee is appropriate for creating a communication platform for mundane issues is ambiguous.

Many moral issues in elderly care arise daily, and often involve seemingly 'trivial'

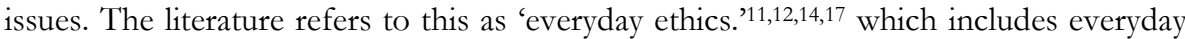
practice, the routines and encounters with clients and relatives. Everyday ethics looks beyond the extra-ordinary dilemmas, such as death and dying - the traditional focus of bio-ethics ${ }^{30}$ - and broadens the scope to the context in which ethical dilemmas arise. ${ }^{31}$ One problem observed in our study is that everyday ethical questions may be overlooked or found to be, as Caplan puts it, 'mundane' or 'banal'. ${ }^{14}$ Our respondents argue that ethics support should therefore first and foremost help nurses recognize and identify these problems as being moral problems. This corresponds with the literature that says that explicit attention should be given to the moral dimension of daily practice, as 'the challenge of recognizing everyday ethical issues lies in their ordinariness.' 32 Blind spots may easily arise in institutional settings that are regulated by a rigid regime and working routine.

Another emergent characteristic of everyday ethics is that many moral problems are continuous in nature. End-of-life decisions are irreversible: once a decision has been taken, nurses have to deal with the consequences. The majority of moral issues in elderly care are not irreversible decisions but problems that last much longer. This also implies that everyday ethical questions often create more space for experimentation and for trying out different options. Yet this space for creative interaction can only be used if there is ongoing evaluation of delivered care, underlying values and an analysis of the context. ${ }^{11}$ As Caplan rightly states: 'everyday questions are no less deserving of careful thought and deliberation.' ${ }^{14}$ This implies that ethics support should create space for reflection in order to encourage nurses to experiment in their dealings with elderly clients.

Our respondents indicate that specific needs for ethics support are also related to the nurses' education level. Daily care (e.g. personal care, leadership on the ward, assistance at mealtimes) is generally provided by lower educated and cheap nursing staff. ${ }^{13}$ They are task oriented ${ }^{33}$ and focus on practical work. ${ }^{2}$ These nurses also prefer to learn in concrete and active ways ${ }^{34}$ and can, as Kolb puts it, be typified as 'accommodators.' 35 In an empirical study in two nursing homes and six care homes in the Netherlands, Snoeren ${ }^{34}$ found that lower educated nursing staff were less capable of perceiving abstract problems, were reluctant to change, often did not analyze problems thoroughly and therefore found it difficult to evaluate solutions. Negative communication patterns within the team and a tendency for a quick evaluation or for no evaluation at all, and waiting for the manager to solve a problem can also obstruct learning processes. $34,36,37$ found that an important strategy for dealing with difficult situations is the use of former experience, by applying solutions that have proven successful in the past. One risk of this strategy, also known as casuistry, is that experience and solutions become private and are not discussed in the team. This means that dialogue and group learning cannot 
take place. Traditional ethics support does not match well with these learning styles and the need for collective learning.

We should not overlook the problems related to the context in which the nurses work. Our respondents draw attention to feelings of powerlessness as a human response to the chasm between their low educational level and the complex questions they encounter. Instead of being recognized for the difficult work they do, nurses are overloaded with new assignments and innovations which may, in turn, further increase their feeling of powerlessness. There is a need for empowerment rather than for just another form of ethics support.

\section{LIMITATIONS OF THE STUDY}

Our findings are somewhat limited because we only included the perspectives of board members and ethics support staff in the elderly care institutions. However, this is the first broad overview of ethics support, and it clearly forms the basis for further research into the needs for ethics support, also with other stakeholders in elderly care.

Furthermore, the empirical data were collected in the Netherlands, so therefore it remains unclear to what extent these findings can also be applied in an international context. However, because the international literature corresponds with many of our results, the findings might be relevant for other countries outside the Netherlands. Moreover, this article can serve as a starting point for a discussion about the need for ethics support in elderly care abroad.

\section{RECOMMENDATIONS}

Since many issues in elderly care are mundane and long term, it is important to focus ethics support on reflection and learning instead of on decision making. Reflection here refers to being able to get a handle on complex situations, understanding their complexity and the underlying values and duties.

Ethics support should also be adapted to the learning styles of nurses and focus on reinforcing learning. It is recommended that a developmental perspective be taken and that once formal education has been completed, learning should realistically be continued. Work-based learning is probably a good way to do this. Education is important and should be linked to explicit actions in a specific context. Experiential learning is more appropriate than frontal learning. For example, moral case deliberation (mcd) stimulates reflection and mutual learning. Another example of ethics support grounded in concrete experience is the recently developed sTimul care ethics lab. This is an educational setting where nurses take the role of a patient in order to experience what it means to be a care-receiver. After preparation and selection the participants join a so called 'empathy session' of two days in which they receive care from nursing students. During the session the simulation exercise is stopped twice to invite both groups to reflect on their experiences. After two months there is a follow-up including a returnday for the nurses and ethical reflection in lessons for the students. The personal and 
embodied simulation of the vulnerability of older care-dependent people leads to an enhanced insight into ethical intuitions and expression of ethical perceptions. ${ }^{9}$ What these approaches also share is that they build on the moral insights of participants as opposed to following the advice of an expert. This is not to say that traditional ethics support models, i.e. ethics committees and consultants, are no longer needed. These forms of ethics support can be complementary: e.g. an ethics committee may help introduce and coordinate mcd or alternatives.

Furthermore, we recommend the development of an ethical climate of reflectionin-action, openness and dialogue. Ethics support should empower nurses and encourage them to be creative. A cultural change might even be more important than simply another form of ethics support. As things stand, it would appear that ethical issues have reached a status quo, whereas what is really needed is a dynamic climate. Such an organizational culture is characterized by openness, it is a context in which something which might appear obvious is questioned. Creative and higher educated nurses may act as role models and foster cultural change in the workplace, if supported by leadership from top and middle management. Middle managers in particular might serve as role models and create the opportunity and space for reflection. We recommend that ethical competences become part of the criteria when recruiting middle managers.

This study was conducted among respondents in the higher echelons of elderly care organizations. We recommend that the need for ethics support also be investigated from the perspectives of practitioners and care receivers in elderly care, namely the residents and their families.

\section{ONCLUSION}

Elderly care generates specific needs for ethical support. Everyday ethics in elderly care requires mundane issues to be recognized as moral issues, otherwise they may all too easily be overlooked. The continuous nature of moral problems in long-term care requires methodical evaluation and reflection to be able to optimally use the room for creative experimentation. There should also be room for learning-by-doing and collective reflection to counter the tendency to focus on getting the work done and finding solutions to practical problems based on former experiences. In addition to an ethics committee or consultant, elderly care institutions might benefit from ethics support that focuses on reflection and learning among nurses. However, this starts with the development of a climate and culture of openness and dialogue, and the recognition of the valuable work done by nurses. 


\section{REFERENCES}

1. Gurnik M, Hollis-Sawyer L. Empowering assisted living front-line care staffs to better care for Alzheimer's and dementia residents. Ageing International 2003; 28(1): 82-97.

2. Solum EM, Slettebø A, Hauge S. Prevention of unethical actions in nursing homes, Nursing ethics, 2008; 15(4): 536-48.

3. Franklin LL, Ternestedt BM, Nordenfelt L. Views on dignity of elderly nursing home residents. Nursing Ethics 2006; 13(2): 130-146.

4. Pauly B, Varcoe C, Storch J, et al. Registered nurses'perceptions of moral distress and ethical climate. Nursing Ethics 2009; 16(5): 561-573.

5. Schaffer MA. Ethical problems in end-of-life decisions for elderly Norwegians. Nursing Ethics 2007; 14(2): 242-257.

6. Haggstrom E, Kihlgren A. Experiences of caregivers and relatives in public nursing homes. Nursing Ethics 2007; 14(5): 691-701.

7. Rees J, King L, Schmitz, K. Nurses' perceptions of ethical issues in the care of older people. Nursing Ethics 2009; 16(4): 436-452.

8. Chen Z, Yua J, Song Y, et al. Aging Beijing: Challenges and strategies of health care for the elderly. Ageing Research Reviews 2010; 9s: s2-s5

9. Vanlaere L, Coucke T, Gastmans G. Experiential learning of empathy in a care-ethics lab. Nursing Ethics 2010; 17(3): 325-336.

10. Gjerberg E, Førde R, Pedersen R, Böllig G. Ethical challenges in the provision of end-of-life care in Norwegian nursing homes. Social science \& medicine 2010; 71(4): 677-684.

11. Bolmsjö I $\AA$, Sandman L, Andersson E. Everyday Ethics in the care of elderly people. Nursing Ethics 2006; 13 (3) 249-263.

12. Bolmsjö I Å, Edberg AK, Sandman L. Everyday Ethical problems in dementia care: a teleological model. Nursing Ethics 2006; 13 (4): 340-359.

13. Collopy B, Boyle P, Jennings B. New Directions in Nursing Home Ethics. The Hastings Center Report 1991; 21(2): 1-15

14. Kane RA, Caplan AL (eds). Everyday ethics: resolving dilemmas in nursing home life. New York: Springer, 1990.

15. Goffman, E. Asylums: Essays on the social situation of mental patients and other inmates. New York: Doubleday, 1961.

16. Elander G, Drechsler RGN, Persson KW. Ethical dilemmas in long-term care settings; interviews with nurses in Sweden and England. Int J Nurs Stud 1993; 30(1): 91-97.

17. Hasselkus BR. Everyday Ethics in Dementia Day Care: Narratives of Crossing the Line. The Gerontologist 1997; 37(5): 640-649

18. Rosen T, Pillemer K, Lachs M. Resident-to-resident aggression in Long-term care facilities: an understudied problem. Aggress Violent Behav 2008; 13(2): 77-87

19. Jakobsen R, Sørlie V. Dignity of older people in a nursing home: narratives of care providers. Nursing Ethics 2010; 17(3): 289-300

20. Moyle W, Hsu MC, Lieff S, et al. Recommendations for staff education and training for older people with mental illness in long-term aged care. International Psychogeriatrics 2010; 22(7): 1097-1106.

21. Svantesson M, Löfmark R, Thorsén H. et al. Learning a way through ethical problems: Swedish nurses' and doctors' experiences from one model of ethics rounds. J Med Ethics 2008; 34: 399-406

22. Dam van der, S., Abma T.A., Molewijk, A.C., Kardol, M.J.M., Schols, J.M.G.A., \& Widdershoven, G.A.M. (2011). Organizing Moral Case Deliberation in mixed groups: experiences in two Dutch nursing homes. Nursing ethics, accepted July 2010

23. Slowther A. Ethics consultation and ethics committees. In: Ashcroft R, Dawson A, Draper H, et al., eds. Principles of health care ethics, John Wiley and Sons, 2007

24. Steinkamp N, Gordijn B. Ethical case deliberation on the ward. A comparison of four methods. Med Health Care and Philos 2003;6;235-246

25. Thompson MA, Milburn Thompson J. Ethics committees in nursing homes: a qualitative research study. HECFORUM, Vol 2, No. 5, pp. 315-327, 1990

26. Fox MD, McGee G, Caplan A. Paradigms for Clinical Ethics Consultation Practice. Cambridge Quarterly of Healthcare Ethics 1998;7;3008-3014.

27. Molewijk AC, Abma T, Stolper M. et al. Teaching ethics in the clinic. The theory and practice of moral case deliberation. J Med Ethics 2008; 34:120-124

28. Libow LS, Olson E, Neufeld RR, et al. Ethics rounds at the nursing home: an alternative to an ethics committee. J Am Geriatr Soc.1992; 40(1): 95-7.

29. Greene J C, Mixed Methods in Social Inquiry. Wiley \& Sons. San Francisco. 2007 
30. Moody HR. Ethics in an aging society. Baltimore: The John Hopkins University Press, 1992

31. Moon M., Taylor HA., McDonald EL, et al. Everyday ethics issues in the outpatient clinical practice of pediatric residents. Arch Pediatr Adolesc Med. 2009;163(9):838-843.

32. Powers BA. Ethnographic analysis of everyday ethics in the care of nursing home residents with dementia. Nursing research 2001; 50(6): 332-339

33. 'Tuckett AG. Residents' rights and nurses' ethics in the Australian nursing home. International nursing review 2005; 52: 219-224

34. Snoeren MWC \& Dekker-VanDoorn CM. Leren=veranderen. Een kwalitatief onderzoek naar de relatie tussen veranderingsprocessen en de leerstrategie van lageropgeleide medewerkers. [Learning=changing. A qualitative research of the relationship between changing processes and the learning strategy of lower educated practitioners.]. Verpleegkeunde 2007; 22(2): 86-97

35. Kolb DA. Experiential learning: experience as the source of learning and development. Englewood Cliffs, New Jersey: Prentice Hall, 1984

36. Dam, van der S, Abma TA, Molewijk et al. Organising moral case deliberation in mixed groups: experiences in two Dutch nursing homes. In press: Nursing Ethics.

37. Slettebø A \& Haugen Bunch E. Ethics in nursing homes: experience and casuistry. International journal of nursing practice 2004; 10: 159-16 



\title{
Chapter 4
}

\section{“Here's my dilemma”. Moral Case Deliberation as a platform for discussing everyday ethics in elderly}

care

\author{
S. van der Dam \\ T.A. Abma \\ M.J.M. Kardol \\ G.A.M. Widdershoven
}




\begin{abstract}
A B S T R A C T
Our study presents an overview of the issues that were brought forward by participants of a moral case deliberation (MCD) project in two elderly care organizations. The overview was inductively derived from all case descriptions $(\mathrm{N}=202)$ provided by participants of seven mixed MCD groups, consisting of care providers from various professional backgrounds, from nursing assistant to physician. The MCD groups were part of a larger MCD project within two care institutions (residential homes and nursing homes). Care providers are confronted with a wide variety of largely everyday ethical issues. We distinguished three main categories: 'resident's behavior', 'divergent perspectives on good care' and 'organizational context'. The overview can be used for agendasetting when institutions wish to stimulate reflection and deliberation. It is important that an agenda is constructed from the bottom-up and open to a variety of issues. In addition, organizing reflection and deliberation requires effort to identify moral questions in practice whilst at the same time maintaining the connection with the organizational context and existing communication structures. Once care providers are used to dealing with divergent perspectives, inviting different perspectives (e.g. family members) to take part in the deliberation, might help to identify and address ethical 'blind spots'.
\end{abstract}




\section{INTRODUCTION}

The literature on ethical issues in elderly care covers a wide range of topics, typically described against the background of demographic, socio-cultural, technological and political developments. The aging population in western societies presents ethical issues particularly in relation to the allocation of services and intergenerational justice, ${ }^{1}$ and to matters of life and death (such as euthanasia or resuscitation). These primary substantive issues are compounded by secondary issues: negative images of older people in society, not just amongst the general population but also among the care workers dealing with older people, for example nurses ${ }^{2,3}$ give rise to ageism and discrimination. ${ }^{4}$ These wide ethical issues, however, are traditionally the domain of academic ethicists, because of their controversial and often technical nature. They have become more prominent in recent years because of medical developments and life-sustaining technologies. ${ }^{1}$ The debates have branched out into more overt technology discussions, for example with the application of robots and sensor-augmented environments both at home and within institutions. .5

It has been argued that ethical issues in the context of long-term (elderly) care are different from those arising in acute care. ${ }^{4}$ Instead of temporarily getting treatment and being cured older people in nursing or care homes are living in an institution until their last day, facing deterioration rather than cure. ${ }^{7,8}$ This calls for a different ethical framework in which the emphasis shifts from upholding individual rights to meeting the residents' needs in congruence with their life story and sharing responsibilities between resident, family and staff. ${ }^{8}$ Instead of the extraordinary cases studied by ethicists, issues that arise in the context of daily life, care and diverse relationships, are of prime concern to professional caregivers. To help them deal with these issues better, new forms of ethics support in care organizations have been developed as an alternative or complementary to the more traditional ethics committee. One of these forms of ethics support is Moral Case Deliberation (MCD). ${ }^{9}, 10$

This paper reports on the content of MCD as part of a larger evaluation study on the introduction of MCD in two elderly care organizations in the Netherlands. The central question in this study is what the issues are that professional caregivers wish to discuss in MCD.

In the international literature ethical questions that arise on a day-to-day basis are captured in the concept of 'everyday ethics'. Since Kane \& Caplan ${ }^{11}$ published their book, Everyday Ethics, several papers have been published on different aspects of 'everyday ethics' in various care settings covering a range from home-care ${ }^{12}$ and day-care ${ }^{13}$ to assisted-living ${ }^{14}$ and nursing home care. ${ }^{15,16}$ Some publications focus on one perspective, for example that of the caregiver, ${ }^{17,18}$ other articles explore the differences and similarities of more than one perspective, e.g. the resident, family members and caregivers. ${ }^{19}$

Up to now very few studies have been published on the issues that are subject of ethical deliberation on the workfloor. Bolmsjö et al present their teleological model applying it to three different types of ethical problems in dementia care. ${ }^{15}$ The aim of 
our study is to demonstrate the great variety and richness of issues which are brought forward within the context of MCD.

\section{AS AN INTERVENTION FOR ETHICS SUPPORT}

Moral case deliberation fits within the recent shift to dialogical ethics. ${ }^{9}$ Instead of leaving the deliberation to an expert or a committee, in MCD the care-providers deliberate with peers on their own moral issues. The deliberation takes about two hours (although sessions can also be shorter or longer) and is facilitated by trained facilitator. This can be an ethicist but can also be a professional within the care organization, who is especially trained in clinical ethics and conversation methods. The facilitator's job is to foster a sincere and constructive dialogue among participants, to keep the focus on the moral dimension of the case and to help the group with planning actions in order to improve the quality of care. ${ }^{?}$

A special feature of the MCD groups in our study was their heterogeneous character. ${ }^{20}$ The participants came from different teams and had various professional backgrounds.

\section{DESIGN AND METHODS}

\section{SETTING: MCD PROJECT IN TWO ELDERLY CARE INSTITU- TIONS}

The data presented here were derived from a larger evaluation study on the implementation of MCD in residential elderly care (two nursing homes and a consortium of care homes in the Netherlands). One nursing home (A) consisted of eight wards in which 270 residents lived and 150 staff members worked. The other nursing home (B) consisted of seven wards in which 180 residents lived and 75 staff members worked. The care home organization consisted of three locations and several assisted-living units. The locations varied from 1 to 3 wards in which in total 250 residents lived and 150 staff members worked.

The project consisted of different phases. In 2006 both organizations started the MCD project with support from an MCD research team. After introducing MCD to the staff in a meeting accessible to all disciplines, in 2007 in each of the institutions mixed MCD groups were created, with participants from different wards and disciplines (see table 2 for composition)

Within each MCD group a series of two-hour MCD sessions was organized in which ethical issues that the participants experienced in their own daily practice were discussed using a structured conversation method. ${ }^{10}$ Over the course of the years 2008 2009 in one of the nursing homes (the other nursing home withdrew from the project) and in the care home organization MCD was implemented on six wards. In 2010 seven representatives from the institutions, with prior experience in one of the MCD groups, 
were trained to become MCD facilitators in order to structurally anchor MCD within their organization.

Table 1: Cases per MCD group

\begin{tabular}{|c|c|c|c|}
\hline Institution & Group / cases $\mathbf{N}$ & Participants & Remark \\
\hline $\begin{array}{l}\text { Nursing home } \\
\text { A }\end{array}$ & $\begin{array}{l}\text { A1 }(03-12 / ’ 07) \\
48 \text { cases }\end{array}$ & $\begin{array}{l}\text { - (auxiliary) nurses (5) } \\
\text { - nurses (2 \& } 1 \mathrm{RN}) \\
\text { - activity therapist } \\
\text { - speech therapist } \\
\text { - pastor } \\
\text { - occupational therapist } \\
\text { - nursing home physician }\end{array}$ & $\begin{array}{l}\text { Institution withdrew from project } \\
\text { in } 2008 \text {, cases from } 2007 \text { were } \\
\text { used. }\end{array}$ \\
\hline $\begin{array}{l}\text { Nursing home } \\
\text { B }\end{array}$ & $\begin{array}{l}\text { B1 (05-09 / '07) } \\
18 \text { cases }\end{array}$ & $\begin{array}{l}\text { - (auxiliary) nurses (6) } \\
\text { - team manager PG ward } \\
\text { - physiotherapist } \\
\text { - social worker } \\
\text { - activity therapist } \\
\text { - pastor } \\
\text { - nursing home physician }\end{array}$ & Aux. nurses from somatic wards \\
\hline & $\begin{array}{l}\text { B2 }(05-09 / ' 07) \\
13 \text { cases }\end{array}$ & $\begin{array}{l}\text { - (auxiliary) nurses }(7) \\
\text { - team manager somatic ward } \\
\text { - nurse }(\mathrm{RN}) \\
\text { - psychologist } \\
\text { - activity therapist } \\
\text { - nursing home physician }\end{array}$ & $\begin{array}{l}\text { Aux. nurses from psychogeriatric } \\
\text { wards }\end{array}$ \\
\hline & $\begin{array}{l}\text { B3 (01-11 / ’08) } \\
39 \text { cases }\end{array}$ & $\begin{array}{l}\text { - (auxiliary) nurses (6) } \\
\text { - nurse (RN) } \\
\text { - physiotherapist } \\
\text { - activity therapist } \\
\text { - pastor } \\
\text { - social worker } \\
\text { - nursing home physician }\end{array}$ & Merged from B1 \& B2 \\
\hline \multirow[t]{3}{*}{ Care home } & $\begin{array}{l}\mathrm{C} 1\left(01 /{ }^{\prime} 07-03\right. \\
/ \text { '08) } \\
60 \text { cases }\end{array}$ & $\begin{array}{l}\text { - (auxiliary) nurses (6) } \\
\text { - nurse (2) } \\
\text { - nursing student } \\
\text { - activity therapist } \\
\text { - social worker } \\
\text { - policy advisor }\end{array}$ & \\
\hline & $\begin{array}{l}\mathrm{C} 2\left(12 /{ }^{\prime} 07-04\right. \\
/ \text { '08) } \\
20 \text { cases }\end{array}$ & $\begin{array}{l}\text { - (auxiliary) nurses (3) } \\
\text { - admissions consultant } \\
\text { - receptionist } \\
\text { - resident administrator } \\
\text { - activity therapist } \\
\text { - nurse (2) } \\
\text { - student's mentor (2) } \\
\text { - policy advisor }\end{array}$ & $\begin{array}{l}\text { Some participants from secundary } \\
\text { process. One policy advisor partic- } \\
\text { ipated in all groups. }\end{array}$ \\
\hline & $\begin{array}{l}\text { C3 }(10 / ’ 08-02 \\
\text { / '09) } \\
4 \text { cases }\end{array}$ & $\begin{array}{l}\text { - (auxiliary) nurses (4) } \\
\text { - nurse } \\
\text { - policy advisor }\end{array}$ & $\begin{array}{l}\text { Merged from C1 \& C2, continued } \\
\text { from March } 2009 \text { with team } \\
\text { managers as future moderators }\end{array}$ \\
\hline
\end{tabular}




\section{DATA COLLECTION}

The evaluation project offered us the opportunity to analyze a large number of case descriptions $(\mathrm{N}=202)$ provided by the participants $(\mathrm{N}=60)$ of seven mixed MCD groups (47 MCD sessions between January 2007 and February 2009, see table 2).

Before the first meeting participants were asked to provide a description of a situation in which they experienced an ethical dilemma. The request was formulated in plain language: describe a situation that you were involved in, in which you (or you and your colleagues) struggled with the question 'what should we do'? Try to formulate a concrete question. The facilitator distributed all the cases this generated to all participants of the group, so that everyone could read the cases prior to the MCD session. At the meeting the person who had written the case, the 'case-owner', briefly presented his or her case orally. During the first meetings all cases that were generated for that meeting were presented and (briefly) discussed, focusing on how to make explicit the ethical question in each case. The discussion of the situations resulted in greater insight into what case descriptions could entail. For example, through the discussion it was concluded that the term case is not synonymous with resident and that more than one dilemma (case) can arise in caring for one resident. In order to encourage engagement in the deliberations and to increase awareness of ethical issues, participants were asked to present a case at every meeting. The group democratically selected one case and discussed it in depth.

All the case descriptions (written and oral) as well as all the conversations about the selected cases in the MCD sessions were collected by the research team. The conversations in the meetings were tape-recorded (after first gaining approval from the group), and these were used to make a meeting report which summarized the discussion and was sent to the participants to gain their approval. The first author acted as a participant observer, taking the role of moderator in all the MCD meetings, and made field notes focusing on the nature of the issues discussed during the meetings. These observations were also used when writing the meeting report.

\section{DATA ANALYSIS}

The overview of issues was developed from the analyses of the original case descriptions and the discussion in the MCD sessions. For a small number of cases $(N=23)$ we made use of the meeting report as these cases had only been presented verbally. For the other cases $(\mathrm{N}=179)$, the case description as provided by the participant was used. For nearly a third $(\mathrm{N}=63)$ of the cases this was the only source available. These cases were either not selected for discussion or there was no report available. We checked whether the definition of the moral issue changed during the meeting. In most cases the moral question stayed the same or was slightly adjusted. In a small number of cases $(N=6)$ the moral question finally turned out to be different from the one originally posed. For the analysis we focused on the adjusted dilemma. See figure 1 for the source of the case descriptions. 


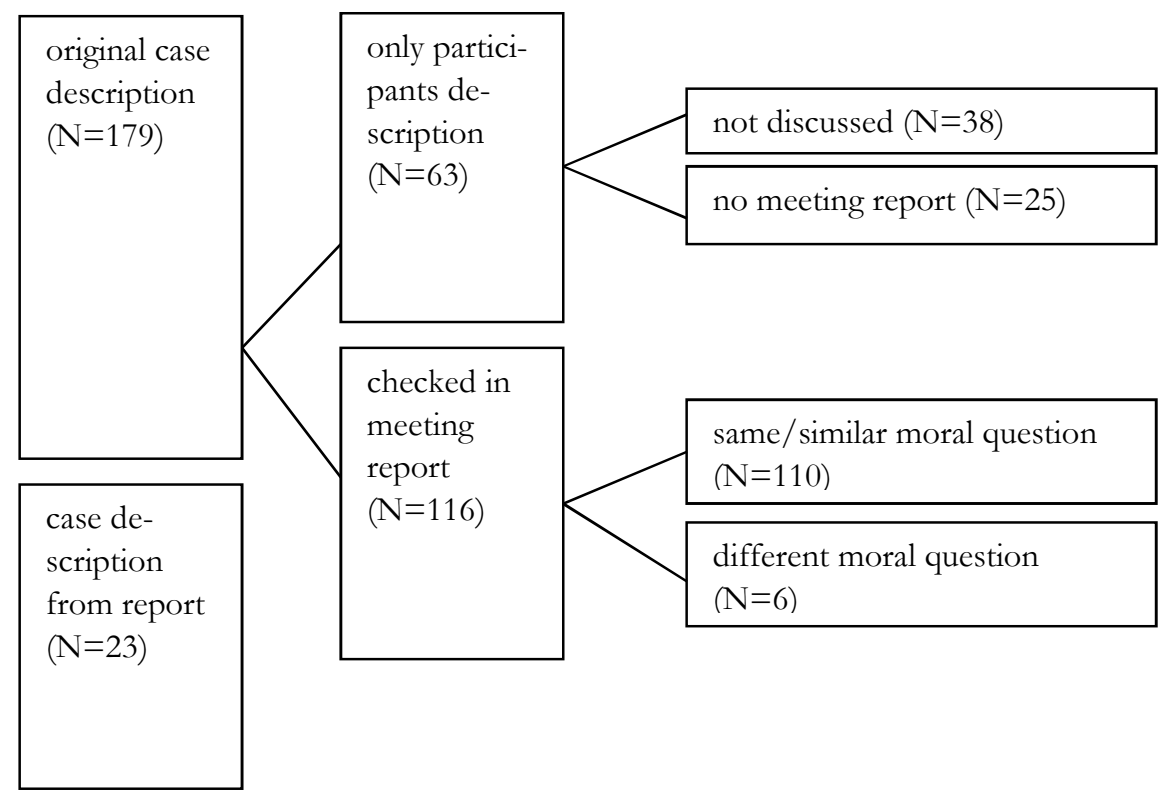

Figure 1: Source case description

During the analysis process we followed an inductive approach in order to be as open as possible to the moral issues discussed. The analysis focused on the content of the case descriptions. ${ }^{21}$ The analysis aimed to identify recurring moral issues (themes) in the case descriptions. This method of analysis is known as conventional qualitative content analysis. $^{22}$ The first author coded the case descriptions with the scope of the issues in mind from the experience as moderator of nearly all MCD sessions. Similar cases were clustered, resulting in categories and subcategories. The structure of themes and subthemes was discussed several times with the second and the fourth author, which led to the merging of some of the main categories into three themes (see figure 2). A number of cases was categorized under more than one label $(\mathrm{N}=44$ under two labels; $N=3$ under three labels).

\section{QUALITY PROCEDURES}

To assess the validity of our study we used the checklist published in the BMJ, 2008. ${ }^{23}$ The 'rock bottom' of the internal validity in qualitative research is considered to be the 'member check' as this procedure helps to eliminate bias. ${ }^{24,25}$ In our study all participants of the MCD sessions received a meeting report. Participants were asked whether they recognized the analysis, and whether it expressed accurately what they had wanted to express. All respondents agreed with the report. During the study process the researcher/first author regularly discussed methodological decisions within the research team. For example, the sampling procedure was discussed, as was the role of the re- 
searcher, the risk of over-identification with the respondents and the proper balance between distance and engagement. Another quality assurance procedure was 'triangulation': we combined a text analysis with information based on participant observations of all MCD meetings. This combination of sources provided us with a larger scope of information, and enabled us to identify discrepancies. The external validity of the study was fostered by giving a description of the context, thus enabling readers to assess the potential transferability of the results to other elderly care settings.

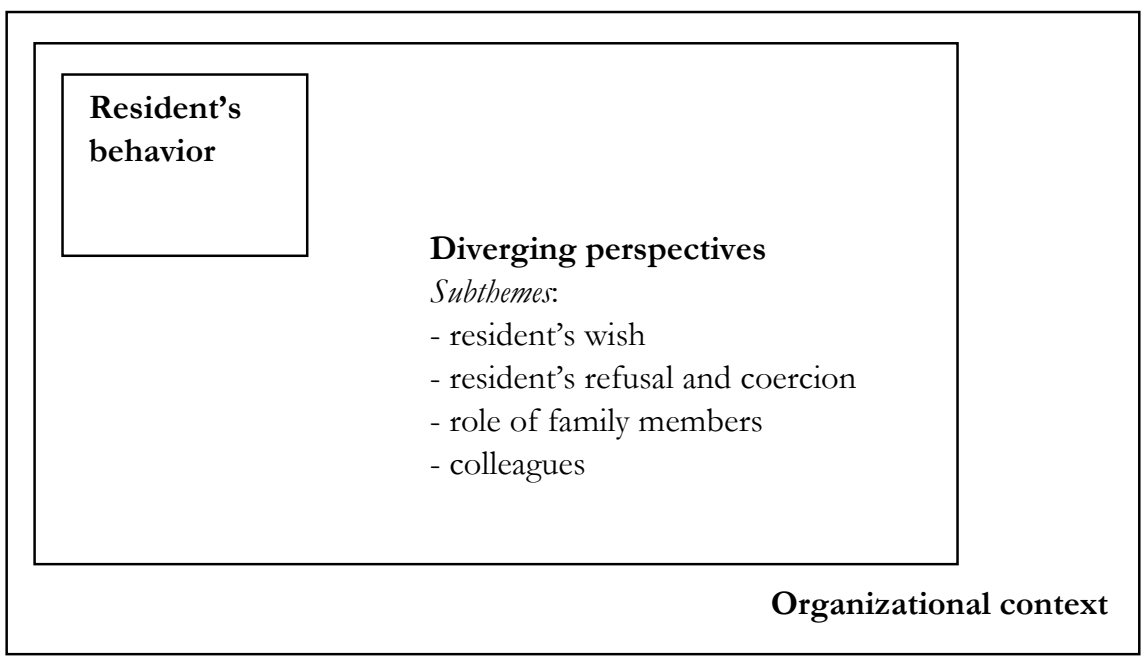

Figure 2: Themes and subthemes

\section{ETHICAL CONSIDERATIONS}

The participants received a letter with an explanation of the study and an invitation to participate. Participants were required to present their cases in an anonymized way in order to protect the privacy of both the residents and the professionals. After informing the participants about the purpose of the study, explicit (verbal) consent was asked for recording the MCD sessions for the purpose of writing the meeting report and for further scientific research. The presented cases and the meeting reports were not shared with others, and were stored in a secure place only accessible to the researcher. The researcher/first author had no hierarchical working relationship with the participants.

\section{RESULTS}

Analysis of the case descriptions showed that moral questions arise in all kinds of situations in daily practice. Most participants in MCD did not frame these questions from an ethical perspective. They did not formulate the case in terms of a conflict between 
values or norms or an ethical dilemma. Instead, they described the situation from a practical perspective and formulated practical questions referring to the gut feelings about a moral problem in the case (for example, referring to "a knot in the stomach").

Most issues (see figure 2) concerned the primary care process, the question being 'what is good care for this or these resident(s)?'. A small number of issues concerned the secondary care process (e.g. problems with distribution of shifts).

We distinguished three different clusters of problems that caregivers encounter. First, caregivers reported confrontation with resident's problematic behavior. Second, caregivers found themselves in a difficult situation when different parties involved in a case had divergent views on what constituted 'good care' in a particular situation. Third, caregivers were confronted with structural factors and limitations within the organizational context. The amount of care that a certain caregiver (or a team) can give or that a resident can get in a certain setting is limited. Below, the clusters of moral issues will be examined in more detail. In table 2 several examples of moral issues are shown.

Table 2: Examples of moral issues

Theme Issues / moral questions

1. Resident's behaviour

- A resident was eating with her hands and burping during dinner. The team asked to what extent it was acceptable for her fellow residents to have to be confronted with her behavior: could she sit at the same table or should she get a table of her own?

- A group of care home residents did not want a fellow resident to take part in an activity because they disliked him. They said that they would quit if he joined them. There was, however, one place vacant and the resident had told the activity therapist that he wanted to join the activity.

- The spouse of a resident had agreed that the nurse would not force her husband to be washed when he started shouting and slapping. However, when she was present when her spouse started behaving inappropriately, she insisted, against the agreement, that the nurse should continue to wash him.

2. Divergent perspectives

- A resident of the care home, who was suffering from diabetes, had gained a lot of weight since his admission one year before, but kept drinking alcoholic

a) Resident's wish beverages and eating sweets.

- A resident wanted to go out for a walk but doing so would place the resident in great risk of falling.

- A resident who owned a small low powered car for which you do not need a driver's license, but unintentionally drove dangerously without regard to the rules of the road.

- A resident insisted on getting speech therapy in the expectation against hope, that this would improve his condition. 
Table 2: Examples of moral issues (continued)

Theme

b) Resident's refusal and coercion

c) Role of family members

d) Colleagues

3. Organizational context
Issues / moral questions

- A resident participated in a mobility training program, but showed no motivation to walk when he was on the ward. Should the caregiver motivate the resident to keep on practicing?

- A resident who set value on remaining physically independent nevertheless asked for help with personal care. Some of the nurses in that team were reluctant to assist the resident because they feared that this would make the resident irreversibly dependent on them.

- A resident, who was 'a bit of a loner'. To what extent should the staff encourage or even push him, to join the other residents in the community room when having diner.

- A resident on a rehabilitation unit, whose condition had not improved despite several months of therapy, became nervous and started acting out because of the constant confrontation with her disabilities. However, the family did see improvement and wanted the therapists to continue treatment.

- A resident in a care home expressed the wish to stay in bed and not participate in activities. Her children requested the nurses to push their mother (the resident) to get out of bed because of their positive experiences with a 'tight' day program in similar situations in the past.

- A resident in the nursing home wished to have unlimited access to a telephone in his room. His daughter requested the staff not to give her father a telephone, because he would then continuously call her.

- A team considered stimulating a resident to stay active and visit day care services, but the day care team working with the resident thought that this particular resident could not participate meaningfullyin the day care programme anymore and would be better off staying on the ward.

- A nurse, on behalf of her team, questioned the physician's decision to start tube-feeding in a resident in the final stage of his illness. The resident died a week later, and the nurses felt that he had needlessly suffered through this treatment.

- An auxiliary nurse presented the question of how to react, when passing a residents' room, hearing her colleague becoming very angry with the resident.

- A nurse questioned whether it was ethically acceptable to ask the son of a resident not to visit his terminally ill mother because the institution was struck by the NORO virus and had responded with a 'no visit' policy.

- The team proposed to move one of the residents from his single room to a four-person room, in order to provide the single room for a terminally ill resident. The resident of the single room, however, resisted the move.

- A resident who was discharged from the hospital too early, in the opinion of the nurses. The question was how to respond to difficulties in offering the amount of care that resident needed.

- A supervisor asked to what extent she should let a nursing student bring her private problems into discussions inside the work environment. 


\section{RESIDENT'S BEHAVIOR}

Behavior that was perceived as problematic by caregivers and/or fellow residents regularly provoked moral questions. One quarter of the cases $(\mathrm{N}=52)$ were about behavioral problems, which were often caused by an underlying disorder, e.g. Alzheimer's disease, Korsakov syndrome, or a psychiatric disorder. A broad spectrum of difficult behaviors was described: residents who were disoriented, suffered from loss of decorum, wandering and 'booking', compulsory behavior, slapping and yelling. Some cases only dealt with a practical or therapeutic questions, focusing not on what to do, but on how to do it properly.

Moral dilemmas that were raised by resident's behavior are various. In the first place, questions related to how behavior affected fellow residents. Caregivers are trained to respond to problematic behavior, but fellow residents are often defenseless victims who need protection. This is not only clear in the case of violence, but also when it comes to loss of decorum. In some cases problematic behavior provoked negative or aggressive reactions from fellow residents. Then the question was whether the resident who was acting out needed protection. In other cases the link with an underlying disorder was less clear or even absent. Also, cases were described, in which the resident's behavior crossed the line of what was considered acceptable to the caregiver. The question then was whether it would be (ethically) justified to interrupt assistance with the personal care when a resident would start acting out.

Often it was not the question of whether or not measures should be taken, but to what extent and to what 'cost' or in what way they should be taken. Especially the use of 'rigorous' measures, for example, physical or chemical restraints, were prominent discussion points. In some cases the caregiver's concern was how to reduce the negative consequences of measures taken. For example, how to give a resident who wants to 'escape' from the ward a sense of freedom without letting him or her go outside. In other cases, a shortage of staff or resources made the situation problematic. For example, when two residents with disturbing behavior have to share a room because there are not enough single rooms available.

\section{DIVERGENT PERSPECTIVES ON GOOD CARE}

The second cluster of moral problems $(\mathrm{N}=138)$ regards dealing with divergent perspectives on what is to be considered 'best' for the resident. Four sub-categories are distinguished: resident's wish, resident's refusal, family members'perspectives, and disagreement among colleagues.

\section{RESIDENTS’ WISH.}

Moral problems may arise when fulfilling a resident's expressed wish has negative consequences for the resident him- or herself or for his or her fellow residents, or when a resident's wish conflicts with the caregiver's professional responsibilities $(\mathrm{N}=30)$.

In some cases it was questioned whether going along with the resident's wish would be the right choice, since his or her personal lifestyle could harm his or her 
health condition or safety. In other cases an underlying (sometimes progressive) disorder like Alzheimer's disease caused professionals to doubt whether it was responsible to fulfill a resident's wish. Equally, the actions of a resident might endanger others.

In other cases the problem was that complying with the resident's wish would cross the line of what was acceptable to the caregiver or would put too much of a (physical) burden on the staff. Two cases expressed the team's awkwardness with an implicit wish of residents to have room and privacy for intimate relationships and sexual contact. In a number of cases the resident's wish was in conflict with agreements documented in the personal care plan. In these cases the case-owner was not part of the (multi-disciplinary) team at the moment the agreement was made. They knew of the agreement but were troubled with the question of whether they should act in conformity with the agreement or should go along with the resident's wish.

\section{RESIDENT'S REFUSAL AND COERCION.}

The refusal of care by the resident also is another source of moral problems $(\mathrm{N}=30)$. It may relate to various aspects of care, such as personal care, taking care of finance, physical independence, participation in activities, eating and drinking, or treatment. Sometimes residents explicitly refused care that was offered to them; in other cases this was less obvious, but the caregiver/case-owner was cencerned that (s)he was being too coercive.

In a number of cases there was a conflict caused by the resident's wish to remain physically independent, on the one hand, and difficulties, on the other, with the resident caring for him- or herself, or for undertaking exercises prescribed by the physiotherapist. These exercises sometimes not only (physically) overstrained the resident, but presented the nurses with physical problems as well. Also, moral questions arose when it came to residents' participation in activities or engaging in social contacts in general.

In some cases, the resident rejected help with taking a shower or putting on clean clothes. These cases were problematic because the lack of personal hygiene could become a nuisance to others (fellow residents, the caregivers or family members). In two cases where the resident refused to eat the case-owner and especially family members were worried about the resident's health. In these cases the resident suffered from Alzheimer's disease but in both cases there was a clear rejection of food. Another type of moral problems concerned the question of whether or not the caregiver should persuade the resident to undergo a medical check or treatment, or to persuade the resident to make use of medical aids such as a hearing aid or elastic compression stockings.

\section{FAMILY MEMBERS' PERSPECTIVES.}

A quarter of the moral problems arise from the triad of resident-family-caregiver $(\mathrm{N}=47)$. There are various possible ways in which the parties (and their perspectives) relate to each other.

The first source of problems is a conflict of perspectives (and sometimes actions) of family members and the professional caregiver(s). In these cases, the perspective of the resident on the matter was mostly unclear or not explicitly mentioned. The case- 
owner's problem focused around whether the behavior or suggestions of the family might not harm the resident's interests. In some other cases, the residents'wishes were more or less evident, and in these cases the case-owner felt he should act as an advocate for the resident.

The second source of problems is a conflict of perspectives between the resident and the relatives. This category of problems partly overlaps with the cases described above, but the perspective of the family adds an extra dimension, making the case more complex or putting more pressure on the case-owner, for example, making the caseowner feel stuck between the perspective of the family and the institution's values, which emphasize the importance of client-centered care in its mission statement. In some cases, following the resident's wishes might be harmful to the relatives.

Participants also described cases where the problem was not caused by a divergence of perspectives on good care for the resident. A small number of cases concerned the (negative) attitude (and behavior) of the relatives towards the staff or the residents. Also, problems were raised where family members disagreed among themselves or fight amongst themselves. The case-owner, in these cases, considered whether it was ethically right to interfere in this. Finally, in a number of cases the case-owner considered whether he or she should also deliver care to the resident's relative (for example, a spouse) or not, because this was outside the boundaries of the work description.

\section{DISAGREEMENT AMONG PROFESSIONALS.}

Moral issues arise or become more complex when professional caregivers do not agree among themselves $(\mathrm{N}=31)$. In these cases the case-owner implicitly or explicitly disapproved of the perspective, the attitude of, or the actions undertaken by his colleague(s). This can be the case between members of different teams, between one of the specialist disciplines and a team, or within a team. In some cases the case-owners explicitly rejected the actions or the attitude of their own colleague(s) and in other cases, the caseowner complained that colleagues did not comply with earlier agreements. In some of the cases, the decision of the physician was questioned Also, cases were described in which the case-owner explicitly advanced the moral question of whether or not they should address such issues and talk to their colleagues about the contested actions or attitudes.

\section{ORGANIZATIONAL CONTEXT}

The third cluster of moral problems is related to the organizational context $(N=59)$. In the first place, existing policies, for example, a 'no visit' policy, sometimes were experienced as a source of moral problems.

In the second place, caregivers are forced to make tough, often tragic decisions because of contextual limits or scarcity of staff or space, further complicating situations that were already (morally or practically) problematic. In some cases, the case-owner was confronted with two residents (or a resident and some volunteers) who required the caregiver's attention at the same time. In other cases, the problems were caused by a 
shortage of single rooms in the nursing home. A number of cases were related to a shortage of staff or cost-cutting. For example, some cases were reported where such resource issues lead to situations in which residents received less attention than was felt to be necessary, where certain activities were put on hold, where cleaning of the rooms was not done properly, or where the reception desk was closed during the evening.

In the third place, the participants described problems that were caused by a mismatch between the care that was needed by a particular resident on the one hand and the possibilities for offering that care on the other hand. For example, cases were raised about circumstances where the resident's condition worsened, requiring a discussion about transferring the resident from the care home to a nursing home. In some of these cases the relatives did not want the resident to be moved, in other cases, the professionals no longer felt able to deliver the required care or felt that the resident's staying in the current setting would not benefit the resident. In a small number of cases the gap between acute care and care home care caused problems.

Finally, in some cases moral problems were not directly related to the primary care process. These problems arose from the social climate in the institution or the attitude of colleagues (e.g. when gossiping) or were related to the position of the case-owner.

\section{I S C USS I O N}

Our study shows clearly that caregivers in elderly care are confronted with a broad range of moral issues in their daily work. These issues can be framed as 'everyday ethical questions.' The moral question only arose very occasionally in the context of end of life decisions. Even in these cases, the core question differs from the typical medical ethical question: participants focused more on communication than on prolonging or abstaining from treatment. Furthermore, no cases on advance directives were described. The everyday ethical issues that were described are characterized by 'multiperspectiveness'. It is not only the perspective of the resident and nurse that are important. In a large number of the cases, the perspectives of family member(s) and other caregivers add to the complexity of the issue. Most issues are not related to moral uncertainty in the mind of one person alone, but to problems in dealing with diverging, and often conflicting, perspectives.

In our MCD project we specifically aimed to refrain from abstract academic concepts and to connect to the experiences of the caregivers by focusing on their moral doubts and questions ('what should I/we do?'). The case descriptions reflect this practical approach. The participants hardly used ethical concepts such as 'autonomy' or 'beneficence' to describe their moral problems. This is in line with the findings of Powers, ${ }^{26}$ who describes that nursing home staff participating in an 'ethics project' found it difficult to recognize and reconceptualize their concerns as etbical issues. Instead they used common frames of reference, 'folk taxonomies', such as 'behavior issues', 'treatment issues' and 'resource issues' to express their concerns. This does not mean that they do not experience moral problems or are insensitive to these issues, but rather that they 
use different labels. This is not merely a difference in concepts. Often, case descriptions touch upon different issues from those discussed in the literature under the heading of autonomy versus beneficence, or autonomy versus justice. If cases do resemble theoretical issues from medical ethics, the presentation tends to be sensitive to complexity and the discussion may lead to different conclusions than those known from the literature.

In the literature there is discussion on what is captured in the concept of a moral issue. Sometimes a moral issue is reduced to a moral dilemma, a situation in which one is forced to choose between two options that both generate negative consequences. ${ }^{27}$ In everyday speech however, the term dilemma refers to all kinds of situations that are perceived as difficult. Also, in the literature a distinction is made between moral questions and other types of questions, such as legal, medical or practical/therapeutic questions. The participants in our study frequently formulated their questions in practical terms (how should I deal with this?). This does, however, not mean that the case does not contain a moral question or questions. As Molewijk ${ }^{28}$ argues, only in the process of deliberation can it become clear whether or not the issue raised concerns a moral question dealing with values. We found that even in the cases which appeared only to be practical, a moral dimension was relevant; in such cases the 'how to' question leads to a moral question (what is right?).

Solum et al. ${ }^{29}$ state that moral problems in elderly care arise when caregivers know what is best for their clients, but do not act accordingly. They further explain that in such situations the care providers often do not experience an ethical problem, but seem to lack the perseverance required to meet the client's needs. In our study, we see the opposite: the caregiver knows what is the (ethically) right thing to do, but is not able to act accordingly. Contextual factors such as understaffing and shortages hinder caregivers' efforts to attend to the values at stake. This is in line with other studies, which found that caregivers experience moral distress when they are not able to act according to what they think is ethically right. ${ }^{30}$ This is especially the case in elderly care, as the professional standards and expectations in society are high while opportunities to realize these standards are missing. ${ }^{31}$ Moral distress can be related to the ethical climate within an institution. A lack of openness and a work environment where caregivers are not stimulated to ask questions cause them to adapt and become routine oriented. ${ }^{32}$ Jakobsen found that caregivers had become frustrated and experienced alienation because of the pressure to act against one's own conscience. Also, personal factors such as a sub-assertive attitude may result in behavior that is incongruent with the caregiver's moral intuition. ${ }^{28}$ Our study also points at another source of moral distress: moral diversity. Some cases addressed unethical behavior of colleagues or behavior motivated by different ethical perspectives. This is stressful since elderly care is based on teamwork, and requires negotiation.

Family members play an important role in the moral problems that caregivers experience. ${ }^{3,7}$ A resident's family is part of his or her life. Family members have known the resident for a long time and went through a lot before the admission of the resident to the institution. Therefore caregivers have to deal not only with the resident but also with family members. The family adds another perspective, and the main challenge lies in negotiating caring responsibilities. ${ }^{1,31}$ A resident's family is often the best guide in 
identifying the values of the resident because of the shared history. Yet, there are situations when the caregiver is better able to identify this, because, for example, (s)he spends more time with the resident, or because in some cases the family projects their perspective onto the resident, and these can be 'colored' by feelings of guilt, mourning, frustration, distrust or idle hope. In addition, caregivers often have to deal with more than one family member, with various perspectives on what is best for the resident.

In a substantial number of cases the source of the moral question lies in the expressed or presumed wish of the resident, manifesting itself in a demand or refusal. These cases reflect, on the one hand, the tension between the societal and institutional emphasis on respect for autonomy, and, on the other, the daily practice where caregivers meet limits of autonomy. Caregivers feel that they have responsibilities in relation to the well-being of individual residents, but also towards fellow residents. In contrast with a cure setting that is organized around the patient-doctor relationship, an elderly care institution is more like a community. ${ }^{8}$ Caregivers have to balance the wishes of the individual resident with the values of other residents. Another aspect of long-term care is the need for narrative integrity. $., 33,34$ Client-centered care means that caregivers have to do more than just what the resident demands. They are responsible for choices being consistent with the resident's narrative history. In this light it is understandable, as Jakobsen $^{32}$ rightly states, that 'although often characterized as a lack of respect for autonomy, defining an action as restraint does not automatically make it wrong' (p. 295) Here we see that the acknowledgement of the complex set of values and moral obligations in practice leads to a reframing of theoretical issues and principles.

\section{LIMITATIONS OF THE STUDY}

The context of this study, the MCD groups, enabled us to gain insight in the perceived ethical issues and internal critique. Critique from outsiders was not included nor did this study provide us with objective information on ethical problems in long-term elderly care.

In our study all cases represented situations that were perceived as burdensome by the care providers. However, it matters who defines an ethical issue as a problem. Other studies have pointed out that not all ethical issues are noticed by caregivers. Nurses may have different perceptions of issues (e.g. the realization of autonomy) from the perceptions of the clients. ${ }^{35,36}$ Moreover, problems experienced by clients or relatives may not be identified by nurses ${ }^{19,33,34}$ This might indicate that our overview of issues, although considerably rich in its variety, possibly shows some deficits.

The willingness to report problems might have been higher in our participants than average. This, we think, did not have an effect on the construction of the overview in a qualitative sense. However, the cases in which the participant judges the perspective or behavior of his/her colleagues as unethical may point at a selection effect of including participants who think of themselves as ethical role models. This might have caused an overrepresentation of cases in which the collaboration between professionals is seen as a problem. Another plausible explanation for these cases is that professionals find it 
easier to discuss what their colleagues do wrong than to discuss their own personal doubts.

\section{CONCLUSIONS AND RECOMMENDATIONS}

Institutions that wish to foster moral reflection and deliberation can use the presented overview as an agenda to structure and guide the attention toward ethical issues among the staff. The three main categories represent different assignments for reflection and deliberation and can be used to enhance the sensitivity for moral issues. The overview indicates that in addition to big issues, attention should be paid to everyday ethics: how to deal with clients whose behavior is experienced as problematic, how to communicate with family and colleagues and how to stay motivated and creative in a context of institutional routines and shortages. For a well-balanced agenda it is necessary to be open to a broad diversity of issues and to involve care providers in the (continuous) process of agenda-setting.

In order to connect with everyday practice, we also recommend a broad definition of the term 'moral issue'. Deliberate effort is then required to extract and articulate moral questions and underlying values from feelings of discomfort and practical questions. ${ }^{37}$ At the same time, it should be acknowledged that issues which seem merely practical at first sight might include important ethical aspects. Moreover, moral reflection should not become isolated from the organizational context and the existing communication structure within the institution

Furthermore, attention should be paid to possible 'blind spots' among caregivers. Openness towards diverse viewpoints is a prerequisite for being able to deal with diverging perspectives. This is difficult, yet necessary for increasing the quality of care. We recommend dealing with divergent perspectives through MCD in a safe environment with various professionals, before inviting other parties, for example family members.

To make MCD successful, bottom-up input should be accompanied by top-down support from the management. Top management has to secure the preconditions, such as time and space. Middle management can play an important role in creating a work environment in which asking questions and considering underlying values becomes part of everyday practice, by stimulating dialogue in the team and acting as role model. 


\section{REFERENCES}

1. Moody, H.R. (1992). Ethics in an ageing society. Baltimore: The John Hopkins University Press.

2. Ludwick, R. \& Silva, M. (2003). Ethics Column: "Ethical Challenges in the Care of Elderly Persons". Online Journal of Issues in Nursing. 9, www.nursingworld.org/MainMenuCategories/ANAMarketplace/ANAPeriodicals/OJIN/TableofCont ents/Volume92004/No1Jan04/EthicalChallenges.aspx

3. Schaffer, MA. (2007). Ethical problems in end-of-life decisions for elderly Norwegians. Nursing Ethics, 14, 242-257

4. Hughes, J.C. (2007). Ethical issues and health care for older people. In R.E. Ashcroft, A. Dawson, H. Draper \& J.R. McMillan (Eds.), Principles of health care ethics (pp. 469-474). West Sussex: John Wiley and Sons

5. Fugger, E., Prazak, B., Hanke, S. \& Wassertheurer, S. (2007). Requirements and ethical issues for sensor-augmented environments in elderly care. Lecture notes in computer science, 4554, 887-893

6. Sharkey, A. \& Sharkey, N. (2010). Granny and the robots: ethical issues in robot care for the elderly. Ethics and Information Technology.

Published online July 4. DOI 10.1007/s10676-010-9234-6

7. Collopy, B., Boyle, P. \& Jennings, B. (1991). New Directions in Nursing Home Ethics. The Hastings Center Report; 21, 1-15

8. Kuczeswski, M.G. (1999). Ethics in long-term care. Are the principles different? Theoretical medicine, 20, 15-29

9. Abma, T.A., A.C. Molewijk \& Widdershoven, G.A.M. (2009). Good Care in Ongoing Dialogue. Improving the Quality of Care Through Moral Deliberation and Responsive Evaluation, Health Care Analysis, 17, 217-235

10. Molewijk AC, Abma T, Stolper M. \& Widdershoven, G. (2008). Teaching ethics in the clinic. The theory and practice of moral case deliberation. Journal of Medical Ethics, 34,120-124

11. Kane, R.A.\& Caplan, A.L. (Eds.) (1990). Everyday ethics: resolving dilemmas in nursing home life. New York: Springer

12. Healy, T.C. (1998). The Complexity of Everyday Ethics in Home Health Care: An Analysis of Social Workers' Decisions Regarding Frail Elders' Autonomy. Social Work in Health Care, 27, 19 - 37

13. Hasselkus, B.R. (1997). Everyday Ethics in Dementia Day Care: Narratives of Crossing the Line. The Gerontologist; 37, 640-649

14. Messikomer, C.M. \& Cirka, C.C. (2008). Managing Everyday Ethics in Assisted Living: A ResearchBased Case Analysis for the Classroom. Gerontology \& Geriatrics Education, 28, 71 - 93

15. Bolmsjö, I. A., Edberg, A.K. \& Sandman, L. (2006). Everyday Ethical problems in dementia care: a teleological model. Nursing Ethics, 13, 340-359

16. Bolmsjö, I. A., Sandman, L. \& Andersson, E. (2006). Everyday Ethics in the care of elderly people. Nursing Ethics, 13, 249-263

17. Elander, G., Drechsler, R.G.N., Persson, K.W. (1993). Ethical dilemmas in long-term care settings; interviews with nurses in Sweden and England. Int J Nurs Stud, 30, 91-97.

18. Enes, S.P.D. \& De Vries, K. (2004). A survey of ethical issues experienced by nurses caring for terminally ill elderly people. Nursing Ethics, 11, 150-164

19. Teeri, S., Leino-Kilpi, H. \& Välimäki, M. (2006). Long-term nursing care of elderly people: identifying ethically problematic experiences among patients, relatives and nurses in Finland. Nursing ethics, 13, 116-29

20. van der Dam, S., Abma, T.A., Molewijk, A.C., Kardol, M.J.M, Schols, J.M.G.A. \& Widdershoven, G.A.M. (2011). Organizing moral case deliberation. Experiences in two Dutch nursing homes. Nursing ethics, 18, 327-340.

21. Lieblich, A., Tuval-Maschiach, R. \& Zilber, T. (Eds). (1998). Narrative research. Reading, analysis and interpretation. Thousand oaks, CA: Sage

22. Hsieh, H.F. \& Shannon, S.E. (2005). Three Approaches to Qualitative Content Analysis. Qual Health Res, 15, 1277-1288

23. Kuper, A., Lingard L. \& Levinson, W. (2008). Critically appraising qualitative research. BMJ, 337, 687692

24. Lincoln, Y., \& Guba, E. (1985). Naturalistic inquiry. New York: Sage.

25. Meadows, L.M. \& Morse, J. (2001). Within-Project Validation. In J. Morse, J. Swanson, and A.J. Kuzel (eds.), Constructing Evidence Within the Qualitative Project. Newbury Park, CA: Sage Publications

26. Powers B.A. (2001). Ethnographic analysis of everyday ethics in the care of nursing home residents with dementia. Nursing research, 50, 332-339 
27. Nussbaum, M.C. (1986) The fragility of goodness. Cambridge: Cambridge University Press.

28. Molewijk, B. (2009). Aan ethiek doen, ethiek laten werken en ethiek organiseren. [doing ethics, making ethics work and organising ethics] In Dilemma's van verpleegkundigen en verzorgenden. [Registered and auxiliary nurses'dilemmas] [In Dutch] CEG: 2009

29. Solum, E.M., Slettebø, A. \& Hauge, S. (2008). Prevention of unethical actions in nursing homes, Nursing ethics, 15, 536-548

30. Pauly, B., Varcoe, C., Storch, J. \& Newton, L. (2009). Registered nurses'persceptions of moral distress and ethical climate. Nursing Ethics 2009, 16, 561-573.

31. Häggström, E. \& Kihlgren, A. (2007). Experiences of caregivers and relatives in public nursing home. Nursing Ethics, 14, 691-701

32. Jakobsen, R. \& Sørlie, V. (2010). Dignity of older people in a nursing home: narratives of care providers. Nursing Ethics, 17, 289-300

33. Abma, T.A. (2010) Herinneringen en dromen van zeggenschap. Cliëntenparticipatie in de ouderenzorg [Memories and dreams of agency. Client participation in elderly care]. Inaugural lecture. Boom/Lemma: Den Haag.

34. Abma, T.A., Bruijn, A., T. Kardol, J. Schols \& Widdershoven, G.A.M. (2011) Responsibilities in elderly care. The narrative of Mr Powell, Bioethics, accepted, October 2010.

35. Leino-Kilpi, H., Välimäki, M., Dassen, T., Gasull, M. Lemonidou, C., Scott, P.A., et al. (2003). Perceptions of autonomy, privacy and informed consent in the care of elderly people in five European countries: comparison and implications for the future. Nursing Ethics, 10, 58-66

36. Rees, J., King, L.\& Schmitz, K. (2009). Nurses' Perceptions of Ethical Issues in the Care of Older People. Nurs Ethics, 16, 436-452

37. Powers B.A. (2000). Everyday ethics of dementia care in nursing homes: A definition and taxonomy. Am J Alzheimers Dis Other Demen, 15, 143 



\title{
Chapter 5
}

\section{Organizing Moral Case Deliberation. Experiences in two Dutch nursing homes}

\author{
S. van der Dam \\ T.A. Abma \\ A.C. Molewijk \\ M.J.M. Kardol \\ J.M.G.A. Schols \\ G.A.M. Widdershoven
}

Published in: Nursing Ethics, 2011, 18(3), 327-340. 


\begin{abstract}
A B S T R A C T
Moral case deliberation (MCD) is a specific form of clinical ethics, aiming to stimulate ethical reflection in daily practice in order to improve the quality of care. This article focuses on the implementation of MCD in nursing homes and the questions how and where to organise MCD. The purpose of this study was to evaluate one way of organizing MCD in two Dutch nursing homes. In both of these nursing homes the MCD groups had a heterogeneous composition and were organised apart from existing institutional communication structures. As part of a naturalistic evaluation systematic observations, interviews and focus groups were completed. The findings indicate that the heterogeneous composition and MCD meetings separately from existing structures have benefits. However, the participants also reported negative experiences. This gives rise to the question whether a mixed MCD group which meets separately is an effective way to embed MCD as an instrument for reflection on moral issues in daily practice. We conclude that there is no single answer to that question. In the end, the two implementation strategies (i.e. within existing communication structures and a mixed MCD group) can be complementary to each other.
\end{abstract}




\section{INTRODUCTION}

Moral dilemmas are part of the day-to-day care in nursing homes. ${ }^{1-5}$ Ethics in nursing homes is not restricted to life and death issues. There are many moral issues concerning the quality of life and care, which we, in line with Kane \& Caplan and Bolmsjö and others, call 'everyday ethics. ${ }^{44,6-7}$ The 'bigger' ethical questions related to life and death (euthanasia, sedation, resuscitation) are often tackled by ethical committees or ethical consultants. The focus is then on the assistance in ethical decision making by experts. A large part of the nursing homes in the Netherlands do not provide these services however. Let alone that the more common moral questions in nursing homes are subject of structural, ethical reflection. Nurses and other health care professionals are not always aware of the ethical dimensions in their work, and may overlook certain moral dilemmas $^{4}$ or experience pressure to avoid issues and adjust to working routines. ${ }^{5}$ At the same time there appears to be a need among health care professionals to reflect on 'everyday ethics'.,8 Recently, in the Netherlands and in Scandinavian countries, initiatives have been started to stimulate ethical reflection, e.g. ethics rounds and moral case deliberation (MCD). ${ }^{9}$ A collective reflection may help to identify moral dilemmas and to increase professionals' moral competence to deal with these issues. ${ }^{4,10-12}$ Other emerging forms to stimulate reflection include experiential learning in care-ethics labs. ${ }^{13}$

\section{IN THE NETHERLANDS}

In the Netherlands a growing number of health care organisations have started implementing MCD in order to support health care professionals in dealing with moral issues and communicating on these issues in a more reflective and dialogical way. ${ }^{10,14-16}$ MCD is not designed as a specialized service, like the ethical committee or ethics consultant, but should be a format that is available for each and everyone within the institution in order to promote reflection on good care.

In MCD health care professionals sit down together to systematically reflect on one of the moral questions from their practice. These questions can be case-specific (e.g. "What should we consider as the morally right thing to do in this specific situation or how should we do it rightly?") or more philosophical or conceptual (e.g. "What is respect?" or "What does understanding mean?"). MCD can have several goals: a) to reflect on the case and improve the quality of care within that case , b) to reflect on what it means to be a good professional and to enhance professional's moral competencies and c) to reflect on institutional or organisational issues and improve the moral quality of care at that level ${ }^{17}$. The task of the MCD facilitator, an ethicist or health care professional trained in ethics, is to foster a sincere and constructive dialogue among the participants, to keep the focus on the moral dimension of the case, to support the joint reasoning process, and to help the group in planning actions in order to improve the quality of care. The facilitator chooses the conversation method that matches with the specific goal of an MCD session which may vary from Socratic conversations to a dilemma method. ${ }^{17}$ 
There are different approaches to MCD: 1) MCD grounded in care ethics, 2) MCD grounded in principlism, and 3) dialogical ethics. ${ }^{11,14,17}$ Our approach, dialogical ethics, is based on the assumption that ethics and morality start with actual experience, not with theories or concepts. This approach to ethics goes back to Aristotle who claimed that (moral) wisdom and (moral) knowledge originate from reflections on and within concrete situations. Dialogical ethics takes this Aristotelian approach to ethics a step further emphasizing the interrelatedness and dialogical nature of human beings and the necessity of intersubjective reflection; moral judgements arise out of dialogue among open-minded people in practice. ${ }^{17}$

Inspired by Gadamer, dialogue is understood as an ongoing, social learning process in which participants develop new, and richer understandings of their practice, what Gadamer called a 'fusion of horizons'. ${ }^{18}$ The outcome of a dialogue cannot be predicted and cannot be reduced to prior positions. It requires openness and engagement to acknowledge the limits of one's own perspective and to change in interactions. ${ }^{19}$

\section{IMPLEMENTING AND ORGANIZING MCD}

The implementation process of MCD brings about questions on how and where MCD should be organised in nursing homes:

- Who should participate in the MCD sessions? With respect to the composition of the MCD groups, it matters whether groups are homogeneous (converging professional background and interests) or heterogeneous (diverging background and interests). The literature on organisational and professional learning indicates that while homogeneity may serve to create an atmosphere of openness and safety, that fosters mutual learning ${ }^{20,21}$, such homogeneity may also create blind spots and group think. ${ }^{22}$ Heterogeneity may help participants to place their own viewpoints in perspective and add new experiences to their own repertoire. ${ }^{23}$

- Where to embed MCD? Innovations often start in niches apart from the formal organisation where they can flourish without the ballast of the dominant culture. ${ }^{24}$ Yet, after some time the innovation, if successful, should be integrated within the institution, becoming part of the formal organisation and communication structure. This is called mainstreaming. It is unknown how this works out for MCD within nursing homes.

\section{STUDY PURPOSE}

The purpose of this study was to evaluate one way of implementing and organizing MCD in two Dutch nursing homes (heterogeneous groups, apart from existing communication structures) and to consider alternative ways. This article reports on participants' positive and negative experiences with a mixed group and on their expectations of alternatives. 


\section{METHOD}

\section{SETTING: MCD IN TWO NURSING HOMES}

The setting of this evaluation study was an MCD project in two nursing homes that started in 2006. The nursing homes were located in the southern part of the Netherlands and were, and remain, part of a larger care consortium. Nursing home A consisted of 8 wards, where approximately 270 residents lived and about 150 staff members worked. Nursing home B consisted of 7 wards, where 180 residents lived and 75 staff members were employed. As is common in Dutch nursing homes ${ }^{25}$ to to ensure that the complex multi-disciplinary (somatic and/or psycho-geriatric) care that the residents require are adequately met, each of these nursing homes employed their own paramedical and psychosocial staff as well as nursing staff and a specially trained nursing home physician. The communication structure in nursing homes features multidisciplinary meetings, evaluating the residents' care plan, as well as disciplinary meetings, in the disciplinary teams and on the wards.

\section{GROUPS}

In the first year of the project, in both nursing homes a project team with members of the university and the institution was installed and a mixed MCD group was composed with internally motivated participants that had different professional backgrounds and came from various wards. This was a deliberate choice. It was expected that this would facilitate the creative and protective environment that innovations need. Besides, representation of as many as possible teams in the MCD groups was considered to foster the dissemination of MCD into the institution. All participants of the MCD groups were involved in the primary care process. Although they were employed by the same institution, some participants did not have regular professional contact with other participants. This was the case in both nursing homes. See table 1 for the composition of the groups.

Both groups met every month in an MCD session for two hours. Participants were asked to bring forward a case from their own daily practice, where they had doubts about what was the morally correct decision to make, each meeting. During the first meetings the cases were (briefly) discussed, in the later meetings the group democratically selected one case and discussed it in depth. The group in nursing home A met eight times and gathered 48 cases in total. The group in nursing home B collected 39 cases in nine sessions. The moral issues that where raised and discussed by the groups included the following types of cases: 1) A resident suffering from Korsakov syndrome does not want to take a shower. Are we allowed to force him to take a shower, and if so when and how often? 2) One of the residents on the ward shouts to the staff and behaves aggressively towards her fellow residents. What constitutes 'good care' for that resident, as taking her to her room would make her isolated and feel lonely, but it would give the other residents some peace and rest. 
Table 1: Composition of the MCD groups and participants evaluation session

\begin{tabular}{llc}
\hline Setting & Participants MCD group & Participant in evaluation \\
\hline Nursing home A (2007) & (auxiliary) nurses (5) & $(3)$ \\
8 MCD's (2 hours) & nurses (2 \& 1 RN) & $(1)$ \\
48 cases & activity therapist & - \\
& speech therapist & $(1)$ \\
& pastor & $(1)$ \\
& occupational therapist & $(1)$ \\
Nursing home B (2008) & nursing home physician & $(5)$ \\
9 MCD's (2 hours) & (auxiliary) nurses (6) & $(1)$ \\
42 cases & nurse (RN) & $(1)$ \\
& physiotherapist & $(1)$ \\
& activity therapist & $(1)$ \\
& pastor & $(1)$ \\
& social worker & - \\
\hline
\end{tabular}

\section{STUDY DESIGN}

This study is part of a larger evaluation study on the implementation of MCD in residential elderly care (two nursing homes and a consortium of care homes). The larger evaluation study can be characterized as a naturalistic evaluation. ${ }^{26,27}$ Typical features of naturalistic evaluation are its emergent design and study of the natural setting. In line with this, our evaluation focused on the experiences of the participants during the implementation process of MCD in their organisation. The aim was not to explain or predict the effects of MCD, but to enhance and reach a holistic understanding of MCD in the residential care setting from the perspective of the insiders.

\section{DATA COLLECTION AND ANALYSis}

Another characteristic of naturalistic evaluation is that different methods of data collection are combined. ${ }^{28}$ In our study, given the focus on the meaning of experiences, the following qualitative research methods (all performed by the first author) were used:

- Semi-structured interviews with middle managers, directors and key-figures of the institutions. Conversations topics included the following: types of ethical issues, organisation of MCD and goals of MCD. The interviews lasted for approximately 45 minutes and were transcribed by the interviewer.

- Participant observation by the MCD facilitator (first author) during the MCD gatherings. The focus was on aspects such as the interaction and communication within the group, their learning trajectory over time. The observations were recorded into field notes.

- Field notes of informal conversations with participants and managers.

- Reports of project team meetings

- Tape recordings of the MCD sessions (parts that were relevant were transcribed) 
- Focus groups with participants of the MCD groups (in total 18 participants). The focus groups took place shortly after the final meeting of the series of MCD sessions. Topics included a general evaluation of the MCD sessions, learning experiences, group processes, content of the moral cases, the specific organisation of the MCD group and views on the future implementation of MCD within their institution. The focus groups lasted about 1,5 hours, were audio recorded and transcribed verbatim afterwards.

For this article only the data from the nursing homes (interviews: $\mathrm{N}=7$; recordings of MCD: $\mathrm{N}=17$ ) were used, as the MCD groups had a comparable heterogeneous composition, in contrast with the more homogeneous MCD groups in the care homes, which do not employ (para)medics.

The process of data collection and analysis was set up in an iterative way. Before the start of the MCD groups, the first author carried out observations on the ward and held semi-structured interviews in order to make an entry into the institution and to explore the issues of the stakeholders involved in the MCD project. Through open coding general categories were formed (e.g. organizing and embedding MCD) to give direction to further data collection and analysis. Organizing and embedding MCD as a theme was discussed within the focus groups. The transcripts of the focus groups were then analysed by means of axial coding, forming new categories and making connections between categories. This process of coding is based on the procedures and techniques used in grounded theory. ${ }^{29}$ The focus group in nursing home A was held at the end of 2007. Due to organisational problems the series of MCD sessions in nursing home B was postponed for a year. In the course of 2008 the transcript of the focus group in nursing home A was analysed. The focus group in nursing home B (end 2008) consisted of an open evaluation as well as a presentation of the analysis of nursing home $\mathrm{A}$ in order to discuss the (preliminary) results further with the participants. From this process we derived the structure in which we present participants' experiences in the results paragraph.

\section{RIGOR OF THE STUDY}

The combination of methods of data collection, known as triangulation, is one of the quality procedures in naturalistic evaluation. Triangulation helps to broaden the scope of data. ${ }^{28}$ In our study the interviews and informal conversations with individuals provided an understanding of personal expectations and (learning) experiences. Participant observations helped to illuminate the group dynamics and mutual learning process of the groups. The focus groups stimulated discussion and yielded information about the future of MCD in the organisations. Other quality procedures included the prolonged engagement in the setting and persistent observation. ${ }^{26}$ The analysis of the interviews was checked with the respondents (member checks) and the coding process was part of discussion within the author team (check coding). ${ }^{30}$ 


\title{
ETHICAL CONSIDERATIONS
}

Cases were anonymised by participants, before presentation in the MCD sessions, in order to protect the privacy of the residents. After informing the participants about the purpose of the study explicit (verbal) consent was asked for recording the MCD sessions, the interviews and focus groups.

\section{RESULTS}

Two features of the mixed MCD groups appeared to be of particular importance: its heterogeneous composition and its disconnectedness from existing communication structures. Participants of the MCD groups experienced both positive and negative aspects, related to both features. In table 2 we present an overview of the experiences of the participants, clustered in main themes (both features) and sub themes.

Table 2: Positive and negative experiences of participants of mixed MCD groups

\begin{tabular}{|c|c|c|}
\hline & Heterogeneous composition & Apart from existing structures \\
\hline+ & $\begin{array}{l}\text { Broadening of horizons } \\
\text { - } \quad \text { greater awareness of each other's moral issues } \\
\text { - } \quad \text { more informal communication about moral issues } \\
\text { - } \quad \text { enriched moral inquiry }\end{array}$ & $\begin{array}{l}\text { Safety and openness } \\
\text { - } \quad \text { safe atmosphere and openness } \\
\text { - } \quad \text { a way to unburden }\end{array}$ \\
\hline- & $\begin{array}{l}\text { Different levels of involvement and moral competence } \\
\text { - } \quad \text { lack of involvement } \\
\text { - } \quad \text { differences in moral competence }\end{array}$ & $\begin{array}{l}\text { Distance from practice } \\
\text { - } \quad \text { lack of direct impact } \\
\text { - } \quad \text { a gap with the rest of the team }\end{array}$ \\
\hline
\end{tabular}

\section{HETEROGENEOUS COMPOSITION OF MCD GROUPS}

\author{
POSITIVE EXPERIENCES: BROADENING OF HORIZONS
}

\section{Greater awareness of each other's moral issues.}

Participants pointed out three ways in which MCD made them become more familiar with each other's daily work and the moral issues that the other participants struggle with.

First, for some participants it was an eye opener that other participants struggled with moral issues at all. One of the auxiliary nurses said:

"I was surprised hearing that the other disciplines also sometimes struggle with problems, because I used to think they just give advice." (auxiliary nurse 2, nursing home A, Focus group)

Second, the kind of moral issues proved to be new to some of the participants. One of the therapists said she had never realised what questions a pastor runs into in his job. 
The pastor, in turn, had always had the idea that ethics is mainly about 'big' issues like end of life decisions. Through the cases of the (auxiliary) nurses he became more sensitive to everyday ethical problems.

Third, it was surprising to some participants how much impact moral issues have on the involved participant. The physician said:

"When I look at the cases I recognise the issues, I know they exist. (...) But I did not always realise that these issues are dilemmas for you (...). I used to think okay these might be nasty situations but they will find a solution." (physician, NH A, Focusgroup)

\section{More informal communication about moral issues.}

As a consequence of becoming more familiar with each other and with each other's work, participants had more open and less superficial contact. Not only during the MCD's, but also in their daily work they talked with each other about (moral) issues. Especially the participants who work on all the wards, for example the social worker or the registered nurse, who said they valued this improved informal communication about moral issues.

"I usually meet $\mathrm{R}$ (physiotherapist) down the corridor. We used to just greet in passing each other but now we really talk. [about moral issues]. Also with $M, J$ and the others I have a more deepened contact when I meet them visiting the ward where they work." (registered nurse, NH B, Focusgroup)

Members of the project team, in a meeting, pointed out that a lack of informal communication on moral issues between care professionals might also be caused by feelings of insecurity.

"Nurses sometimes think that experiencing dilemmas is a sign of not being professional" (pastor, NH A, Project team)

\section{Enriched moral inquiry.}

The exchange of perspectives during the MCD's made participants aware of the existence of other perspectives. Moreover, it made them understand that it is possible to look at moral issues from different angles. Some participants said they had learned to take into account the moral views of other persons and that they had become more open towards perspectives different from their own.

The variety of perspectives was valued by participants since it enhanced the reflection on the case and the moral inquiry undertaken by the group.

"I think the perspectives [of people with different backgrounds] enrich the investigation of the case". (activity therapist, NH B, Focusgroup)

The facilitator regarded the variety of perspectives as especially helpful for getting a more complete picture of the moral issue that was discussed. According to the participants, reflecting on a moral issue on your own or with your own colleagues misses the richness of a wide range of different perspectives. 
"When only auxiliary nurses deliberate or when you only reflect together with your own colleagues, then you will not hear certain perspectives ..." Auxiliary nurse 1: "Yes, then you will go 'round in circles." (social worker, NH B, Focusgroup)

Within a project team meeting a general lack of creativity in finding alternative ways of dealing with a dilemma was brought forward. A broadening of horizons might stimulate this creativity.

"Many times there are different possible solutions. But too often caregivers think there is only one option." (psychologist, NH B, Projectteam)

NeGATIVE EXPERIENCES: DifFERENT LEVELS OF INVOLVEMENT AND MORAL COMPETENCE

\section{Lack of involvement.}

Some participants thought that some cases got little attention, because they were unrecognisable for the majority of the group.

"T thought the cases of the pastor were very interesting. They were new to me, but these cases seemed less appealing to the majority of the group, so they were not chosen for deliberation." (speech therapist, NH A, Focusgroup)

Some of the participants, like the occupational therapist and the speech therapist, supposed that the 'non-nursing' cases were less interesting to the (auxiliary) nurses who work at the ward. The facilitator also observed a tendency to select the more common 'nursing-cases' because they seemed more urgent. The 'non-nursing' cases therefore received less attention. This was seen as a lost chance to further enrich one's horizon of ethical problems and develop one's ethical creativity. The participants appeared to be flexible enough to adjust to this situation by selecting cases that were not too specialised and that would be recognisable to all participants. The speech therapist, for example, said she started bringing cases to the meeting that she thought would be interesting to all participants whereas in a group of her own colleagues she would come up with specific cases, typical for speech therapists, e.g. the question whether or not to continue swallow training.

\section{Differences in moral competence.}

Participants noticed a difference in the ability to talk about moral issues in the group. For those who felt morally competent this sometimes led to frustrations and impatience, for those who felt less competent this resulted in feelings of insecurity. Participant observations illustrated that especially during the first meetings of the MCD series some of the (auxiliary) nurses adopted a 'sitting on the fence' attitude during the first meetings but later on actively took part in the deliberations. In the focus group one of the auxiliary nurses reflected on this and said she had to reassess her view on problems before she could open up to the issues of the other participants and start seeing moral issues in her own practice as well. 
"When I first started I thought where have I ended up? The problems that came to the table, I didn't see what the problem was. I thought: I have to look more carefully at my own practice, it cannot be that we don't have problems. Gradually I started looking at things differently." (auxiliary nurse 2, $\mathrm{NH}$ A, Focusgroup)

\section{ORGANIZING MCD APART FROM EXISTING STRUCTURES}

\section{POSITIVE EXPERIENCES: SAFETY AND OPENNESS}

\section{Safe atmosphere and openness.}

The MCD sessions offered a safe and open atmosphere, in which participants felt that there was room for sharing their experiences and mutual respect for each other's perspectives. This atmosphere was, on the one hand, created by the facilitator who structured the deliberation process and took care that everyone participated actively. On the other hand, safety and openness was caused by the absence of existing communication patterns in which prejudice and gossip are not uncommon.

"In this group the facilitator structured the conversation. That will be difficult on the ward, where there is an existing communication pattern, often with judging and stigmatizing and such ... making it hard to communicate in the way we did." (auxiliary nurse, NH A, Focusgroup)

Two other auxiliary nurses described how these communication patterns on the ward made them feel less free to speak openly to their colleagues or made them hide their emotions when talking about a difficult moral problem. The pastor said that in the MCD group he was less at his guard against the reactions of the others than with his own colleagues. The facilitator caught a glimpse of these communication patterns when she visited the wards. The openness in communication seemed to depend on who was present though.

The positive effect of mixed teams on safety is not exclusive for MCD. One of the managers referred to other projects in which mixed groups were used.

'When you put people from the same team together, there is too much 'bistory'... I have the experience that switching enhances the chances for success" (team manager 1, NH B, Interview)

\section{A way to unburden.}

Since the MCD group was not related to existing communication structures and corresponding responsibilities, the participants felt free from the pressure of having to make a decision. As the pastor in nursing home B put it, without the pressure of having to come to a solution, there is room to acknowledge that it is not always possible to offer what is considered 'good care'. Talking about and learning to deal with feelings of impotence can improve team spirit and awareness of tragic decisions. The pastor in nursing home A referred to the function of the MCD group as a catharsis, a way to relief one's feelings of moral distress: 
"Part of what we did was, according to me, that you could express your thoughts and feelings and discuss them with others. Even though we often didn't reach a solution, it is a relief that you can talk about your problems instead of just struggle with them on your own." (pastor, NH A, Focusgroup)

During the MCD sessions the facilitator observed that the other participants reacted with empathy when the case-owner expressed feelings of distress.

\section{NEGATIVE EXPERIENCES: DISTANCE FROM PRACTICE}

\section{Lack of direct impact.}

The MCD session did not have a direct impact on daily working practice for a number of reasons. First, only one of the cases was chosen for the deliberation, the other cases were not discussed in depth. Second, it was hard to transfer the outcomes of the deliberation to the team of the case-owner. Like the speech therapist put it, she and her colleagues when returning to her own team actually had to start the deliberation process again from scratch.

Most participants needed some time to realise that it is possible and even fruitful to reflect without having to reach a solution or decision. Most participants were frustrated, at least in the beginning, when the session did not end with a conclusion on what to do in the case at hand.

"I wanted to get answers. At the start I found it very frustrating when I did not get an answer. When you bring in a real problem from the ward, you want guidelines or directives on how to deal with this problem. Now I have got used to deliberating without getting an answer. (...) But still, in daily practice decisions have to be made." (auxiliary nurse, NH B, Focusgroup)

\section{A gap with the rest of the team.}

As the participants became more experienced with MCD, paradoxically, it did not become easier to address their own colleagues. Instead they perceived a gap between themselves and their colleagues, who had no experience with MCD. This gap was caused by a number of factors. First of all colleagues did not have a clear picture of MCD and of what is the purpose of deliberating on moral issues. Even when the participants had become experienced they still found it difficult to explain this to their colleagues. Some colleagues, one of the auxiliary nurses in nursing home B said, even sneered at her when she came back from an MCD, asking if she had had a nice "chitchat" with the group.

Secondly, colleagues sometimes had too high or wrong expectations of the MCDs. When they were asked to help formulate a case, they came up with questions that are not suitable for MCD, for example why the board of directors had made a particular top-down decision.

Thirdly, participants adopted an open attitude towards different perspectives than their own, unlike the colleagues in their own team or in the regular multi-disciplinary meetings. The speech therapist referred to the reaction of the physician (not a member 
of the MCD group) at the suggestion to have another look at the case one of the auxiliary nurses brought in.

"I found the physician quite blunt refusing to reconsider the issue again. I thought, bey, we $[M C D$ group] spoke about this issue in a very open way (...) Then you see, we deliberate and we think this way but the other [physician] does not think like this." (speech therapist, NH A, Focusgroup)

One of the location managers was, from the onset, sceptical about the presumed positive effect on the dissemination process of MCD.

"I foresee that the MCD will only benefit the participants of the group." (location manager, NH A, Interview)

\section{FUTURE: EMBEDDING MCD IN EXISTING COMMUNICATION STRUCTURES?}

In the evaluation sessions participants were invited to discuss the future implementation and embedding of MCD in the organisation. In order to close the gap with their colleagues and to make it possible to use MCD as an organisation wide instrument for considering moral issues in daily practice, most participants recommended to implementing MCD in existing communication structures, like the multi-disciplinary meeting or the team meeting.

The participants considered meetings in the existing communication structures as places where moral issues came to the fore in a natural way, but were not discussed in a structured way. They regarded the current communication both quantitatively as well as qualitatively unsatisfying. Participants pointed out two main characteristics of existing communication structures that make communication fall short:

1) It was reported that daily practice was hectic and therefore not offering the ideal circumstances for reflection and deliberation. There was, they felt, not enough time (taken) to reflect and deliberate on moral issues. Especially on the wards there was, according to the (auxiliary) nurses, hardly any time to sit down and discuss things at all.

"On the ward ... you just keep running on and on. In MCD you have the time to really look at a problem." (auxiliary nurse 4, NH A, Focusgroup)

It was reported that the hectic environment of everyday practice made it hard to discuss the issues thoroughly when issues were actually discussed. People often got called away. As a result some issues were left unspoken or were discussed only superficially.

2) Participants reported that decisions on moral issues were often made in a small group. At the level of the nursing team, it was often only the first responsible nurse (who was the central contact for residents' family members) who was involved in solving the problems. This applied both for decision-making on the ward as well as in the multi-disciplinary meeting, where the first responsible nurse represented the 
nursing team. Because the colleagues on the ward were not involved in the (decision making) process, they did not know the considerations and sometimes did not understand the outcomes or did not even implement decisions that were written down in the care plan.

Also, participants questioned the quality of decisions that were taken in a hectic environment or in a small group. As a consequence, when there was not enough time taken to consider the pros and cons of a decision thoroughly, the health care professionals involved often were left with feelings of doubt.

"Even when the problem doesn't disappear ... you can choose this option or that option ... when you have talked about it together, considering the pros and cons, then you can be at peace with what you have chosen to do. (...) Without deliberation, the issue stays in your mind and you'll keep asking yourself have we done the right thing? (physician, NH A, Focusgroup)

A third reason why communication falls short, was pointed out by one of the team managers, in a project team meeting.

"The existing meetings, even the multi-disciplinary team meetings, are very practically oriented. The focus is on outcomes, there is no room to really talk things through." (team manager 2, NH B, Projectteam)

Embedding MCD in existing communication structures would, according to the participants, create more time and tranquillity to reflect, deliberate and deal with moral issues in a better way. Furthermore, the deliberation and decision making process would be enriched when more stakeholders from different backgrounds were involved.

\section{ISCUSSION}

The participants of the MCD groups in two nursing homes experienced both positive and negative aspects, related to the heterogeneous composition of the group and to the organisation of MCD meetings apart from existing communication structures.

The positive aspects are largely similar to those Svantesson et $\mathrm{al}^{21}$ found in their study of nurses' and doctor's experiences with interdisciplinary ethics rounds in Sweden. These ethics rounds were also organised apart from existing communication structures and responsibilities. A difference with the heterogeneous groups in our study was that in the Sweden study only two disciplines, doctors and nurses participated. Participants in the ethics rounds experienced a 'stimulation of broadened thinking', a 'sense of connecting' and 'emotional relief', which is similar to the positive experiences of the participants of the mixed MCD groups in this study. The dialogical approach of performing MCDs seems especially suited to stimulate ethical creativity and create an ethical milieu of reciprocity, solidarity and empathy.,6 This should be valued since Bolmsjö and others ${ }^{4}$ characterized the general ethical milieu in nursing homes as one of 'being in the same world without meeting? 
Existing communication patterns in nursing homes can be characterized by what philosopher Habermas calls 'strategic communication'31, that is communication intended to strengthen one's position and to realize materialist values. In their recent study of nursing homes Jakobsen \& Sorlie also refer to Habermas to point out that system values, like efficiency, money and power, dominate the actions and communication, much to the dissatisfaction of caregivers, who feel that many actions are incongruent with personal as well as cultural values like dignity. ${ }^{5}$ According to Habermas strategic communication is part of the system world, and less constructive for dialogue and communicative action, which is part of the life world. ${ }^{31}$ MCD implies a genuine dialogue among participants so that their mutual understanding is enhanced. Within organisations the conditions for genuine dialogue are hampered by a domination, or even colonization, of the life world by the system world and accompanied strategic behaviour and communication. This may also lead to a focus on outcomes, as is often the case in the multi-disciplinary meetings, leaving no room for considering values and motivation. Organizing MCD outside the usual organisational context helps to create an atmosphere that fosters openness and engagement.

The negative experiences in both our and Svantesson's study ${ }^{21}$ are not so similar. Participants of the MCD groups in our study did not mention 'a sense of unconcern.' They did, however, feel that not each case was of interest to the whole group; cases were adjusted so that each and everyone could relate to the case. This inclusive strategy fostered a process in which all could learn. Svantesson noticed 'a sense of alienation' among some participants. ${ }^{21}$ We saw a different development: MCD participants experienced a connectedness to the participants in the MCD group, but they felt alienation from their team mates and direct colleagues who were not joining the MCD gatherings.

Participants of both the ethics rounds and the MCD groups shared experiences of 'frustration with lack of solutions' and 'resignation to non change' in the sense of a gap with the rest of the team and the lack of time for reflection in current daily practice. This means that intersubjective ethical platforms may create expectations regarding improvements in their daily work and the quality of care. To prevent frustrations these expectations should be discussed, creating realistic expectations among participants. Bolmsjö and others ${ }^{4}$ rightly point out that structural factors also may hamper practice improvements and cannot always be changed rapidly. When trying to manage expectations it also seems important to emphasize that moral dilemmas cannot always be solved. Paradoxically participants in our study did value MCD as a place to unburden, but also wanted to get rid of moral problems. Nussbaum's work on the tragedy of moral dilemmas can be helpful. She states that some dilemmas are tragic, and cannot be dealt with without harming certain values, interests and duties. She argues that it is better to acknowledge the negative consequences of an action or decision, and accompanying feelings of ambiguity, then to surpass them. ${ }^{32}$ The MCD gatherings can offer a platform to acknowledge these negative aspects and feelings that are inherently related to moral dilemmas, and may stimulate reflections on how to deal with these aspects and feelings, (without solving the dilemma) thereby still providing a relief for moral distress.

In our study, the positive aspects of MCD in a mixed group are prominent. Some of the negative aspects, those related to the heterogeneous composition of the group, 
can be put into perspective. The reason why some cases got little attention from the auxiliary nurses may lie in their preference for recognisable cases from fellow auxiliary nurses. A lack of (initially) shared experiences, however, can in fact be a good starting point for dialogue and learning processes. ${ }^{19}$ The differences in experience and ability to talk about moral issues proved to be temporary. The participants who were less familiar with ethical deliberation at the start, developed an open attitude and competencies, like listening and postponing one's initial judgement. The heterogeneous composition of the group enabled the participants to learn from each other. Therefore, different levels of involvement and competence can also be framed as positive aspects. The positive experiences suggest that a mixed MCD group might be an effective way to stimulate ethical reflection and deliberation, especially for gaining experience with MCD in a safe environment.

Organizing MCD apart from existing structures has the advantage of a creative protected niche, but may lead to a situation where the communication pattern does not structurally change, and participants fall back to business as usual when they leave the MCD meeting. There is the risk of MCD becoming an elite group, distant, alienated and isolated from daily practice. These negative aspects resemble the general critique on how ethics committees function. ${ }^{14,15,33}$ This indicates that a stronger connection with daily practice is necessary. Participants therefore recommend to further implement MCD within existing communication structures. In a study of Molewijk et al ${ }^{10}$ participants in an MCD group in a psychiatric hospital also concluded that MCD should take place in the teams in which they actually work. This does not mean that a mixed MCD group is not useful. For pragmatic (reduction of costs, time and staff) and more strategic (creating a protective environment ${ }^{17)}$ reasons it can be useful to start with a small group of enthusiastic participants from different parts of the institution can from which MCD can expand to the teams. The evaluation results rather suggest that combining strategies, synchronically or chronologically, is a promising way of mainstreaming MCD in elderly care.

\section{CONCLUSION}

We conclude that there is not one best way and place where ethical reflection should be organised. Each implementation strategy serves different goals and the use of a specific implementation strategy also depends of the phase of the MCD project in the specific health care institution. In the end, a combination of strategies, combining the positive aspects of a mixed group apart from existing structures and in time utilising the opportunities for moral reflection becoming an integrated part of existing communication structures, seems promising for enhancing the ethical milieu in elderly care. 


\section{REFERENCES}

1. Franklin LL, Ternestedt BM, Nordenfelt L. Views on dignity of elderly nursing home residents. Nursing Ethics 2006; 13(2): 130-146.

2. Teeri S, Leino-Kilpi H, Valimaki M. Long-term nursing care of elderly people: identifying ethically problematic experiences among patients, relatives and nurses in Finland. Nursing Ethics 2006; 13(2): 116-129.

3. Haggstrom E, Kihlgren A. Experiences of caregivers and relatives in public nursing home. Nursing Ethics 2007; 14(5): 691-701.

4. Bolmsjö I Å, Edberg, AK, Sandman, L. Everyday Ethical problems in dementia care: a teleological model. Nursing Ethics 2006;13(4): 240-359

5. Jakobsen R, Sørlie V. Dignity of older people in a nursing home: narratives of care providers. Nursing Ethics 2010; 17(3); 289-300

6. Bolmsjö, I A, Sandman, L., Andersson, E. Everyday ethics in the care of elderly people. Nursing Ethics. 2006;13(4): 249-263

7. Kane RA, Caplan AL. Everyday ethics: resolving dilemmas in nursing home life. New York: Springer, 1990

8. Kardol, M.J.M., Zorg voor zelfstandigheid [care for independance]. Tilburg: Gianotten B.V., 2004

9. Svantesson M, Anderzén-Carlsson A, Thorsén H. et al. Interprofessional ethics rounds concerning dialysis patients: staff's ethical reflections before and after rounds. J Med Ethics 2008;34;407-413

10. Molewijk AC, Abma T, Stolper M. et al. Teaching ethics in the clinic. The theory and practice of moral case deliberation. J Med Ethics 2008;34;120-124

11. Verkerk, MA, Lindemann H., Maekelberghe E. et al. Enhancing Reflection: An Interpersonal Exercise in Ethics Education. Hastings Center Report 2004;34(6): 31-38

12. Abma TA, Widdershoven GAM, Moral deliberations in psychiatric nursing practice, Nursing Ethics 2006;13(5): 546-557

13. Vanlaere L, Coucke T, Gastmans G. Experiential learning of empathy in a care-ethics lab. Nursing Ethics 2010; 17(3); 325-336

14. Steinkamp N, Gordijn B. Ethical case deliberation on the ward. A comparison of four methods. Med Health Care and Philos 2003;6;235-246

15. Molewijk AC, Verkerk M, Milius H. et al. Implementing MCD in a psychiatric hospital: process and outcome. Med Health Care and Philos 2008;1;34-56

16. Molewijk B, Zadelhoff E van, Lendemeijer B, Widdershoven GAM. Implementing moral case deliberation in Dutch health care; improving moral competency of professionals and the quality of care. Bioethica Forum 2008;1(1);57-65

17. Abma TA, Molewijk AC, Widdershoven GAM. Good care in ongoing dialogue. Improving the quality of care through moral deliberation and responsive evaluation. Health care Analysis, 2009

18. Gadamer HG. Wahrheit und Methode. Tübingen: J.C.B. Mohr, 1960

19. Widdershoven GAM, Abma T.A. Hermeneutic ethics between practice and theory. In: Ashcroft R, Dawson A, Draper H, et al, eds. Principles of health care ethics, John Wiley and Sons, 2007

20. Dixon, N.M. The Organizational Learning Cycle: How we learn collectively. London: McCraw-Hill, 1994

21. Svantesson M, Löfmark R, Thorsén H. et al. Learning a way through ethical problems: Swedish nurses'and doctors' experiences from one model of ethics rounds. J Med Ethics 2008;34;399-406

22. Argyris C. Overcoming organizational defenses - Facilitating organizational learning, Allyn and Bacon, Needham Heights, 1990

23. Bodenrieder I. Social Architecture: A prerequisite for organizational learning. Management Report 38. Rotterdam School of Management, Erasmus University, 1998

24. Geels FW. Technological transitions as evolutionary reconfiguration processes: a Multi-level perspective and a case-study. Research Policy, 2002;(31) 1257-1274.

25. Schols JMGA, Crebolder HFJM, Van Weel C. Nursing home and nursing home physician: the Dutch experience. J Am Med Dir Assoc 2004 May-Jun;5(3);207-212

26. Guba, EG and YS Lincoln. Effective evaluation. Beverly Hills, Sage, 1981

27. Rubin, BM. Naturalistic evaluation: Its tenets and application. Studies in art education. 1982;24(1);57-62

28. Greene, JC, Kreider, H and E. Mayer. Combining Qualitative and Quantitative Methods in Social Inquiry (pp. 274-281). In: Somekh, B. and C. Lewin (eds.) Research Methods in the Social Sciences, London: Sage, 2005

29. Strauss A, Corbin J. Basics of Qualitative Research Techniques and Procedures for Developing Grounded Theory (2nd edition). London: Sage Publications, 1998 
30. Meadows, LM, Morse, J. Within-Project Validation, in J. Morse, J.Swanson, and A.J. Kuzel (eds.), Constructing Evidence Within the Qualitative Project. Newbury Park, CA: Sage Publications, 2001

31. Habermas, J. Volume 2: Lifeworld and system: A critique of functionalist reason. Cambridge: Polity Press, 1987

32. Nussbaum MC. The Fragility of Goodness. Oxford: Oxford University Press, 1986

33. Dartel H van. Van ethische commissie naar stuurgroep ethiek. Over de implementatie van moreel beraad in het kwaliteitsbeleid van instellingen voor gezondheidszorg [From ethics committee to steering committee. On the implementation of moral deliberation within the quality policy of health care institutions]. Utrecht: CELAZ/Nederlandse Zorgfederatie, 1998. 


\title{
Chapter 6
}

\section{The discovery of deliberation. From ambiguity to appreciation through the learning process of doing Moral Case Deliberation in Dutch elderly care}

\author{
S. van der Dam \\ J.M.G.A. Schols \\ M.J.M. Kardol \\ A.C. Molewijk \\ G.A.M. Widdershoven \\ T.A. Abma
}




\begin{abstract}
A B S T R A C T
In the field of bioethics a trend can be noticed towards deliberative and collective forms of moral reflection among practitioners. Moral Case Deliberation (MCD) is an example of this development and currently introduced in an increasing number of health care organizations in the Netherlands, including elderly care. The purpose of this article is to evaluate the process of implementation of MCD focusing on the learning experiences of practitioners over time. The article is grounded in a naturalistic evaluation of the implementation of MCD in two elderly care institutions. Methods included interviews, participant observations and focus groups. The results indicate that gaining experience with MCD brought about a learning process in which both the learning of competence for reflection and deliberation (e.g. an exploratory attitude) and experiencing the benefits (e.g. relief of moral distress) were key elements. We conclude that doing ethics is the best way to motivate practitioners to engage in moral deliberations on the work floor. Gaining practical experience should be explicitly stimulated bottomup and facilitated top-down.
\end{abstract}




\section{INTRODUCTION}

The field of bioethics has seen several developments over the past decades, that have deepened and broadened its scope. ${ }^{1}$ Three of these developments together reflect a specialization (or maybe a shift) of bioethics descending from the 'academic ivory towers' into the healthcare practices where bioethics is actually done. One development is the rise of empirical ethics and clinical ethics in order to make ethical theory and principles more relevant for practice, and to acknowledge and build on moral intuitions and experiential knowledge of practitioners. This is illustrated by the move in ethics education from using theoretical textbooks to a focus on real cases from the clinical context. ${ }^{2}$ A second development is the increased attention for everyday ethical issues next to the 'big', controversial or dramatic medical ethical issues, such as euthanasia or withholding treatment. ${ }^{3}$ This has resulted in a new agenda for ethics, including themes like family care, diversity and empowerment. A third development is the rise of more democratic, interactive, dialogical approaches in bioethics. ${ }^{4-6}$ While ethics used to be equated with individual reflection, ethics has now become group work, engaging the work-floor in communal reflections on moral issues. Needless to say that this has had implications for the role of the ethicist; a transition can be noticed from the ethicist as expert to the facilitator of moral deliberations. In the USA it has been suggested to replace ethics consultations, leading to recommendations that may be rejected or considered a mandate, by bioethics mediation. ${ }^{7}$

In the Netherlands these developments have paved the way for the development and expansion of Moral Case Deliberation (MCD) projects in health care institutions, supported by the Dutch government. Explicit attention for moral issues in health care is expected to actively contribute to enhancing the quality of care. ${ }^{8} \mathrm{MCD}$ aims to facilitate the reflection and deliberation on moral issues in the work-place under guidance of a trained facilitator.

Currently MCD is introduced in a broad spectrum of care organizations, including general hospitals and long-term care facilities. The study presented here, involves the introduction of MCD within residential elderly care, where the need for ethics support is not always articulated, and existing support mechanisms do not always match with the everyday questions or the type of workers. ${ }^{9}$ It is the first study that extensively reports on the experiences with MCD in the practice of elderly care. Other forms of ethics support in elderly care have been discussed in the international literature. ${ }^{10-12}$ These studies highlight the design of the intervention. Less attention is given to how the intervention is received in practice and to the developments that take place upon implementation.

The purpose of this article is to evaluate the implementation of MCD within two elderly care institutions and to present lessons learned from organizing this kind of clinical ethics support in elderly care. Key to the learning process that took place when MCD was implemented was the gaining of experience with reflection and deliberation: learning the tricks of the trade and seeing the benefits. 


\section{MCD： FACILITATING A DIALOgICAL LEARNING PROCESS TO IMPROVE QUALITY OF CARE}

In MCD, health care professionals engage in a joint reflection and deliberation about the moral issues they encounter in their daily work. Our approach to MCD is inspired by dialogical ethics and pragmatic hermeneutics in which the source of morality is located in concrete experiences of all involved stakeholders rather than abstract conceptual analysis by external experts. ${ }^{13}$ Starting point for the deliberation is a concrete case, a situation in which a dilemma or a moral question rises, presented by one of the participants. The deliberation is guided by a facilitator (an ethicist or a trained healthcare worker) and structured using a conversation method (e.g. the Dilemmamethod or Socratic dialogue). The role of the facilitator is not that of an expert giving advice, but to facilitate dialogue and investigation into the case and the moral question. S/he supports the joint reasoning process and, when needed, can help the group in planning actions following the outcome of a deliberation, in order to improve the quality of care.

The dialogical process forms the heart of the dialogical-hermeneutic approach to MCD. Depending on the context and goal of the deliberation the emphasis can be more on the development of moral competencies (e.g. developing an exploratory attitude) or on finding a resolution in the case. ${ }^{4}$ What constitutes a good deliberation is a combination of aspects that relate to both content, process and perspectives. First, a good moral deliberation focuses on the moral dimension of care. The quality of the content of the deliberation depends on the formulation of the moral question on which the moral inquiry will be focused. Sometimes this question is clearly formulated beforehand, but often the formulated question is the result of a dialogical process. The focus on moral questions entails that questions of a medical-technical, practical or emotionalpsychological kind are not considered appropriate for MCD. Second, a sincere dialogue is advanced by the efforts of both the participants and the facilitator. Participants need to listen to one another, be open towards the perspectives of the other participants, postpone their own judgements and must let go the drive to convince the other participants. In other words, participants should take on an exploratory attitude. Third, a good deliberation requires the input of a diversity of perspectives. From a democratic point of view all involved perspectives in the case should be represented in the deliberation. Since inviting all involved perspectives in person often is not possible nor desirable, this democratic aspect should be carefully taken care of within the conversation method (e.g. by means of completing a table of all perspectives and their presumed values and norms in relation to the moral question). From a hermeneutic point of view the presence of participants with different professional backgrounds is beneficial for enriching the dialogue. 


\section{DESIGN AND METHODS}

\section{SETTING: INTRODUCTION OF MCD IN TWO ELDERLY CARE IN S T ITUTIONS}

This paper is based on the experiences of various stakeholders in an MCD project in two Dutch elderly care organizations. One organization (ORG 1) participated with two nursing homes (NH A: 270 residents; NH B 180 residents), the other organization (ORG 2), a care home, participated with three locations (a mix of nursing- and assistedliving units, 250 residents). The project was supported by an MCD research team: a $\mathrm{PhD}$-student (first author) and two senior researchers ( $4^{\text {th }} \& 5^{\text {th }}$ author). Apart from some policy development on major ethical issues (euthanasia, do-not-resuscitate orders) the participating institutions had not organized ethics support or systematic reflection and deliberation prior to the MCD project.

The implementation trajectory consisted of four successive, partly overlapping steps, each with different activities. Following the introduction in 2006, in each of the institutions mixed MCD groups ${ }^{14}$ were created, with employees from different wards and disciplines. We deliberately started with motivated participants in order to create an atmosphere of safety and openness, offering room to experiment with MCD. In addition, the mixed composition of the groups, representing as many different disciplines and wards as possible, was expected to foster the dissemination of MCD across the organization. After the first year, NH A withdrew from the project, because of changed organizational priorities. Both in NH B as well as in ORG 2 the two mixed groups that had started simultaneously merged into one group for practical reasons. Over the course of 2008-2009 in NH B and in ORG 2 MCD was implemented on a selection of wards ( 6 in total). The MCD sessions on the wards were preceded by a clinical site visit, talking to the team members and participating in the practical work on the ward, to make the team aware of issues and investigate together with the team what issues needed to be put on the agenda for deliberation. The final step was to train seven representatives from NH B and ORG 2, with prior MCD experience, to become MCD facilitators. In NH B the continuation of MCD was put on hold in 2011 due to budget cuts. The MCD research team is currently involved in the further embedding of MCD in ORG 2, albeit in a more distanced, advisory role.

\section{RESEARCH DESIGN AND DATA COLLECTION}

The first crucial years of the MCD project were accompanied by research activities undertaken by the MCD research team, in close cooperation with stakeholders. Because of the focus of the study on the experiences of the professionals, we concentrated on the stakeholder categories: managers and caregivers. The study design can be characterized as a naturalistic evaluation ${ }^{15}$ with responsive elements, combining the research of a natural setting and an emergent design with the drive to improve practices through the active engagement of stakeholders in dialogical processes. ${ }^{4}$ Several qualitative research 
techniques were used (by the first author) to gather a broad scope of data. First, individual interviews $(\mathrm{N}=16)$ were held with directors, middle managers, (para)medics and nursing assistants. Participants of the MCD groups were not interviewed individually; their expectations and views were collected during the MCD meetings. All interviews were structured using a topic list, including: moral issues experienced, the role of reflection and deliberation in the institution, need for support, possible/desired outcomes of the project, and interviewee's role in the implementation. In addition, two focus groups were organized in the MCD groups in ORG 1, shortly after the last meeting of the series of MCD sessions. The conversation was structured using a topic list, including: the aims of MCD, a general evaluation of the sessions, learning experiences and an exchange of views on the further implementation of MCD. In ORG 2 evaluation was integrated in the MCD sessions as a continuous process.

Participant observation was performed in a number of ways and settings. Before the start of the mixed MCD groups the first author visited various wards in order to explore the work setting of the participants through informal conversations and participant observations. The impressions from the exploratory visits were recorded in a logbook. During the project this logbook was a file for field notes (describing events, scenes and conversations shortly after occurrence) and a reflexive journal ${ }^{16}$ to document memos (personal reflections, methodological considerations and analytic notions). The clinical site visits and project group meetings were recorded and provided written reports. Participant observation was also performed during the MCD sessions, in total 47 sessions of 2 hours each. Memos were written in the logbook immediately after the session. All MCD sessions were recorded and resumed in minutes that were sent to all participants.

\section{DATA ANALYSIS}

The analysis process followed an inductive approach. It consisted of re-reading and coding of the MCD reports, field notes, memos and transcripts of the interviews and focus groups. We used a common coding procedure: thematic content analysis. First, a quick reading of the material produced a set of 'sensitizing concepts'17 that sketched the contours of the learning process that had taken place during the project. Using the sensitizing concepts, the first author made a close reading of the material. This resulted in the construction of a more finely meshed code tree and a document with relevant text passages. Both were discussed with the second and third author, leading to relabeling or merging some of the codes. Although the categories were constructed by the research team, and a process of coding inevitably includes some interpreting, every attempt was made to keep the content of the themes as close as possible to the respondents' statements. Exact quotes from interviews, focus groups and MCD sessions were used to illustrate the constructed codes. 


\section{QUALITY PROCEDURES AND ETHICAL CONSIDERATIONS}

We used several procedures to warrant the reliability and validity. First, we applied 'member checks'16, 18, 19 to verify our interpretations from the interviews and focus groups with the participants. Second, considering the method of sampling, we deliberately included interviewees who were thought to be less supportive towards MCD, reflecting the range of opinions. Third, we applied 'data-triangulation' using several methods of data collection. Using different sources of information and a variety of methods decreases bias and allows the researcher to approach the research subject from various perspectives, providing a richer account of reality. ${ }^{19},{ }^{20}$ Fourth, the collection and analysis of the data were regularly discussed within the research team. Co-checking of the preliminary code-structure was done to reduce bias from the first author. Fifth, the credibility of our study was established through prolonged engagement and persistent observation. ${ }^{16,18}$ Prolonged engagement enabled the researcher to become familiar with the organization culture, build trust-relations with stakeholders and to lessen the impact of temporary distortions, like budget cuts, to the project. Persistent observation made it possible to reconsider early interpretations and reflect the complexity of the social reality that was studied. In order to be transparent about the design and the way the study was conducted, we made use of the Coreq checklist ${ }^{21}$ for reporting on qualitative research.

During the entire project particular care was taken to inform stakeholders about the project and research activities through written material and through presentations. Participation in the MCD groups, co-operation of team members in clinical site visits, focus groups and interviews was voluntary. The cases that were brought to the MCD sessions were anonymized for protection of the privacy of both residents and professionals. Participants gave their consent for audio recording the MCD sessions.

\section{RESULTS}

\section{THE PROCESS OF DISCOVERING MORAL DELIBERATION}

The implementation of MCD brought about a learning process in which gaining experience with MCD played a crucial role. Before the start of the MCD groups there was ambiguity towards MCD. Notions of reluctance were expressed in the interviews, but equally, interviewees expressed hopes and expectations. When the mixed MCD groups had started, the participants became experienced with MCD. Initially they struggled with a number of aspects related to the setting of the groups and the systematic and thorough way of investigating a case. After some time, participants developed their competence in reflection and deliberation, and they discovered the benefits of this for both their own professional development and for their caring relationships with the residents. In the next part, we will highlight the different elements in the process of discovering deliberation. 


\section{Ambiguity TOWARDS MCD}

\section{RELUCTANCE AND PREJUDICE}

The reluctance expressed by interviewees relates to a number of doubts: Do we really need MCD? Where does MCD take us? Is MCD appropriate for nursing staff? Is there enough time for MCD?

The first source of reluctance was caused by doubts about the usefulness of MCD. These doubts were expressed mainly by the nursing staff. Some nurses and care assistants said they did not experience moral problems (or frame their problems as moral problems) and therefore did not experience a need for MCD. Three different causes for this were described by interviewees. First, MCD was perceived as a tool for solving problems and mediation only in case of (persisting) conflicts within the team and therefore not necessary in a team with good inter-personal relationhips.

"I can imagine MCD would be beneficial when a team is really divided ... but I don't have that experience, being in a team that is like a safe and warm nest." (Interview, care assistant, Care Home)

Another cause was the 'primary medical-technical' approach to experienced problems. The quote below illustrates a situation where the care assistant and her colleagues lost sight of the moral dimension (taking-over versus stimulating self-help) by reducing the discussion whether or not to use the patient lift, to a medical-technical advice from the physiotherapist.

"I could have made clear to the physiotherapist why I had a different opinion [use the standing aid to preserve a sense of independence, $S v d D]$, but hey, in the end she's the expert and therefore I followed her advice." (Interview, care assistant, $\mathrm{CH}$ )

A third reason why some of the nursing staff did not experience moral problems was because they strongly valued the agreements recorded in the resident's personal care plan. They said they trusted that once agreements have been made or when the family (as the resident's representative) has given consent, further deliberation is unnecessary.

The second source of reluctance towards MCD for some of the interviewees was that they were not sure of the benefits. In general, according to most interviewees, employees had 'cold feet' towards any new project that is introduced to them. A middle manager of the care home organization labeled this as 'a culture of only believe it when you see it'. Some interviewees had their doubts about the (political) impact of MCD. As a care assistant questioned: would MCD be able to convey the message that staff shortages are a problem to the higher political levels, where she felt the solution for this problem lay. Finally, there were doubts about the benefits of MCD for the quality of care for the resident. The location manager of nursing home A was skeptical about the motives for participating in MCD. In his view, professional caregivers, especially physicians, too often follow their own standards and do not have enough focus on the individual resident. He was afraid they would 'highjack' MCD for their own profit and lose sight of his goal: a better quality of care for residents. 
A third source of reluctance was the concern that MCD would not be appropriate for nurses and care assistants, either because of learning style and work routines, or because of the limited communication between the ward team and the multidisciplinary team (MDT). Most interviewees typified nurses and care assistants as taskoriented: hard-working employees who put a lot of effort in the (physical) caring for the residents. Reflection and deliberation was not believed to match very well with this hands-on orientation, as the quote of a middle manager illustrates:

"Care assistants are often action-oriented. They find it difficult to spend their time with other activities than with 'bands-on' jobs. (...) And when they have some spare time they take the resident out for a walk... that seems easier than to sit down for a while and have a chat." (Interview, middle manager, $\mathrm{CH}$ )

The focus on physical care sometimes seemed to make nurses and care assistants less inclined to explore and investigate moral issues or to put a lot of effort in reflection and deliberation. A coordinator-care assistant explained that the tough physical work sometimes left the team washed out, with no energy to discuss (moral) issues in depth.

"Sometimes they [care assistants] say: Please, not now, we have been working hard enough'. From their faces you can tell that they'd rather not deliberate on the issue. And when I then choose the lesser of two evils and provide a solution they are happy." (Interview, coordinator care assistant, NH B)

MCD's appropriateness was also doubted because of the perceived distance between the ward team providing the basic care and the MDT, which discusses the resident's individual care plan. Dialogue between the nurses and care assistants on the ward and the (para-)medical staff was not optimal because the ward team was only represented by the 'first responsible nurse'. In practice, some care assistants had developed alternative strategies that, according to them, worked just as well as dialogue.

'We use reporting in the daily care report... look, when the doctor says this and we don't agree ... well, then we will report every day, three times a day .. and then finally the doctor will have to give it a thought ... Well, and sometimes we are right ..." (Interview, care assistant, NH B)

On the other hand, also physicians used strategies that avoided dialogue, by giving their 'doctor's orders' to the team without further explanation

A fourth source of reluctance consisted of the percieved impediment of staff shortages and a heavy workload for MCD. In contrast to the other notions of reluctance, time constraints were also seen as problematic by the participants of the MCD groups. However, they were convinced that taking the time to reflect and deliberate was necessary. They doubted whether, in the future, the management would give enough support in the form of time and back-up cover to participate in MCD. Without this, investing in MCD would result in giving less attention to the resident, and reduced quality of care.

"MCD costs working-time. And if my hours are not replaced ... then it reduces the time spent on a resident. Because when I'm here, I'm not with the resident." (Focusgroup, activity therapist, NH B) 


\section{HOPES AND EXPECTATIONS}

Despite the visible reluctance and prejudice about MCD, several interviewees, especially managers and candidate MCD participants, expressed their hopes and expectations that the implementation of MCD would lead to relieve of moral distress and would raise awareness of moral issues.

MCD was expected to help relieve moral distress through offering a place where you can share frustrations and emotions. Especially when you're involved in tragic issues where choices always carry negative consequences, or when caregivers know what is good care but are unable to provide it, for example because of contextual constraints. According to a ward manager, talking about this in MCD might help to prevent frustration and distress.

"When you come to work every day and have the feeling you should give a 100\% to the residents and in practice you only get to, say $60 \%, \ldots$. And when there is no occasion to talk about this, or you can't find a way to deal with it (...) you will become frustrated. I think that sharing this together, those dilemmas ... in MCD, will help to relieve stress." (Interview, ward manager NH B)

According to the respondents, discussing issues that in daily practice are easily left unaddressed might also help prevent them from escalating into conflicts. According to one of the activity therapists, sharing and discussing issues instead of ignoring them, would lead to better ways of working together within the team. In addition, because of its structured conversation methods, it was expected that MCD could be used to guide and enhance spontaneous reflection.

It was also expected that MCD would make the caregivers more aware of moral issues. A care home middle manager expected that MCD would lead to reflection on one's own behavior, relating it to alternative ways of acting and therefore potentially changing behavior. Several interviewees referred to being imprisoned in existing ways of thinking and routines. MCD, they hoped, could trigger caregivers to examine an issue from a different, new point of view. MCD therefore was believed to prevent routine ways of working, as the manager of one of the nursing homes said:

"I think the value of MCD can be that it makes them [nurses] consciously consider their daily actions, a very simple example .... the nurse pours fifteen cups of coffee, all with milk and sugar ... No one is asked how they like their coffee, ... in fact, the nurse doesn't even ask whether the resident wants coffee in the first place, they just put it at the table in front of them and say cheers!'” (Interview, Manager, NH B)

One of the middle managers of the care home organization regarded MCD as a way to counterbalance the emphasis on efficiency, directives and the technical aspects of giving care. In MCD, she expected, space can be given to question one's attitude. In addition to this, as some of the managers expected, MCD could be helpful to better connect to the view and mission statement of the organization. In the deliberation on issues, attention could be paid to the (core) values of the institution and how they relate to the values of resident and care givers. 


\section{DOING MCD: LEARNING THE TRICKS OF THE TRADE}

Although the participants of the MCD groups were motivated, the first sessions were not a matter of 'plain sailing'. Participants expressed initial difficulties with different aspects of MCD concerning, for example, the setting and method used. Also, because the mixed groups were composed of participants from different ward teams and disciplines, it took some time to get to know each other and to create the safe atmosphere that some of the participants needed to be able to open up and to publicly show their doubts, insecurities and vulnerability. The most important challenges for participants were: grasping the moral dimension, engaging in a dialogue and valuing the input of various perspectives.

\section{GRASPING THE MORAL DIMENSION}

Most participants were not fully aware of the moral issues in their daily practice or found it hard to grasp the moral dimension in the difficult situations they experienced. All MCD participants were asked to write down a case for every meeting. Some participants initially thought moral issues in their work were limited to the 'difficult' residents on the ward. One of the nurses in the care home confessed she had not written a case for the coming MCD session, because she felt she had 'run out of moral issues. Over time it became easier to write a case description. Through the presentation of the cases participants practiced articulating their dilemmas, both on paper and verbally. This resulted in more succinct descriptions of the cases.

Working through a case in a systematic and thorough way was considered hard work. During the first sessions it took a lot of effort to reach consensus on the formulation of the moral question to form the starting point of the deliberation. The facilitator (first author) also observed participants' struggle with putting themselves in the place of the involved perspectives and their values and norms regarding the case. As participants became used to the conversation method and the guidance of the facilitator, they acknowledged it helped the group to focus on the core problem, as one of the physicians said:

"When we went deeper into the case, we often came to the insight that the question we wanted to deliberate on was different than the one we started off with. We realized that that was the real problem." (Focusgroup, nursing home physician, NH A)

For some participants it was a challenge to think beyond existing agreements and policies. For example, when a resident wanted to go out for a walk, but the institution's policy, for reasons of insurance, prohibited volunteers to accompany residents outside of the institution's grounds.

\section{ENGAGING IN A DIALOGUE}

The facilitator sometimes had to pull the words from the group. At the same time, participants often had to be slowed down as they found it hard to postpone their own judgments and were eager to give their solution. Participants had to be trained to ask themselves and the other participants questions. In practicing deliberation they learned 
to listen to each other, to postpone their own judgments and to ask supplementary questions. They developed a more exploratory attitude.

"MCD makes you realize that it's necessary to listen to each other... one thinks this, the other thinks that. On the ward, often it becomes a yes/no discussion. MCD makes you look at things differently ... before, I used to make a judgment, now I've learned to ask 'is that so?' I've discovered that often there is more than one truth." (Focusgroup, care assistant, NH B)

\section{VALUING THE INPUT OF VARIOUS PERSPECTIVES}

Reading each other's cases and discussing them in the sessions gave participants more insight in the issues their colleagues struggled with.

"A buge advantage of the MCD group was that the different disciplines learned to look at each other differently... So not only, what is my vision, what do I regard important, but that you learn to take more account of the other's view." (Focusgroup, nurse, NH A)

According to the participants, this better understanding also promoted a more open attitude and a better working climate. They became more interested in their colleagues, more understanding towards different points of view.

\section{DOING MCD: EXPERIENCING THE BENEFITS}

When the participants became more experienced, they saw the benefits of a thorough moral investigation including multiple perspectives for promoting careful decision making and effective communication with resident, family and colleagues.

\section{BETTER QUALITY OF CARE}

The joint deliberation enriched the investigation of the issue that was discussed. Participants believed this positively influenced the quality of care. This was not achievable without sharing their viewpoints. One of the participants described how she discovered what the joint deliberation added to her personal reflections:

"Reading the case at home, preparing the meeting, you don't think it through ... During the $M C D, \ldots$ together, you go a lot deeper. You cannot deliberate like that sitting alone at home." (MCD, care assistant, $\mathrm{CH})$

A thorough and joint moral investigation also offered participants some 'peace of mind' and confidence in the option that was chosen. For example, in the following case: a resident of the care home had told the nursing staff she wished to stay in bed, but her family recognized their mother's behavior from hospital admissions earlier in her life, and urged the staff to stimulate their mother to get up and to be active.

"I felt less uneasy talking her out of bed, and later in the day, exactly like her children had predicted, she was smiling." (MCD, coordinator-care assistant, $\mathrm{CH}$ )

When all perspectives have been considered and when the pros and cons have been weighed this reassures the team in their choices. As one of the participating physicians suggested, "Without a thorough deliberation issues stay in your mind". 


\section{COMPLIANCE AND EFFECTIVE COMMUNICATION}

According to participants it would be easier to communicate the outcome when it was based on a thorough moral investigation. First, participants presumed, this would lead to a better 'compliance' by the nursing staff. In the present situation decisions are often made by a small group of people and assigned to the rest of the team. As one of the nursing home physicians knew from experience, this contained the risk that nurses on the ward who disagree with the decision, tend to do what they see fit. Thorough deliberation would help the team to understand the reasoning behind the decision and act accordingly. Second, participants believed this would lead to more effective communication with resident and family. When caregivers are able to explain their own considerations and make clear that the decision was not based on an individual viewpoint, but upon a joint deliberation, it might make it easier for them to bear the negative consequences of tragic decisions.

\section{RELIEVE OF MORAL DISTRESS}

Discussing moral issues in the MCD group felt helpful to relieve moral distress.

"To acknowledge that there is no completely satisfactory solution, to acknowledge feelings of powerlessness, because we can't always offer what we ideally want ... If we could talk about this in our teams, ... and concentrate on what we can offer ... that would be positive for the atmosphere in our teams." (Focusgroup, pastor, NH B)

The insight that there is not always a solution that makes the problem disappear was new to some participants. Sharing thoughts and feelings in MCD helped them to 'unburden'. In addition, it stimulated participants' creativity to find alternative ways for dealing with dilemmas.

\section{DOING REFLECTION INSTEAD OF TALKING ABOUT IT}

It was broadly shared that doing MCD was essential in being able to appreciate the true value of reflection and deliberation (and MCD as a means to this). Upon the first introduction of MCD to the participating institutions, several employees were enthusiastic, but a lot of them also had 'cold feet' towards MCD. A much-heard critique was that MCD was considered 'vague', 'elusive' and 'not-concrete'. Even for the participants who volunteered in the MCD groups it was difficult to imagine what MCD exactly was and what benefits it might have. But once the participants had started with the MCD sessions this vagueness disappeared and they discovered that deliberation may be extensive but, in fact, also very concrete. A middle manager experienced this when he joined an MCD session especially organized to make the managers acquainted with MCD.

'Well, it's ... like the nurses put it, it's a bit vague ... Once you're actually doing MCD, you see it's not vague. (...) When you are dealing with an issue in MCD ... then it's a lot more concrete than you could imagine." (Interview, middle manager, $\mathrm{CH}$ )

Doing MCD is an essential step, according to participants, towards appreciation of reflection and deliberation. In contrast with the care-technical courses that are common 
in elderly care, MCD cannot be learned from a book or simply transferred to colleagues.

\section{I S C USSION}

\section{LEARNING BY DOING}

Implementation of MCD within the involved elderly care institutions brought about a learning process. The main insight that the learning process provided was that the actual experience of MCD, actually doing it, was crucial. Gaining experience with MCD proved most prejudices wrong and some notions of reluctance proved all the more reason to engage in MCD.

The expressed doubts concerning the necessity of MCD and the initial struggles of the participants to find and describe cases from their daily practice reflect a poor awareness of the moral dimensions of care. This contains the risk of reducing care to the execution of technical acts and interventions when caregivers do not acquire and develop an attitude of empathy. ${ }^{11}$ Several authors found that moral issues, especially the less spectacular, more mundane issues, are easily overlooked and stay unrecognized. ${ }^{3,}$, 12, 22 External factors such as work environment and a lack of time and resources also impede the ability of caregivers to recognize or identify ethical challenges. ${ }^{23}$ Our findings indicate that practicing with reflection and deliberation (e.g. writing and presenting cases, formulating a question) within the safe environment of MCD made it easier for participants to grasp the moral dimension of care. Participation in MCD deepened the awareness of moral issues by providing the opportunity for greater insight into the participants' own values and norms but also in those of the perspectives involved in a case and in the issues of their colleagues. Also, MCD provided the opportunity to develop moral competencies such as listening to each other and postponing their own judgment. In this sense MCD aimed at slowing down the thinking process, offering an environment to exercise in posing 'slow questions' as Kunneman ${ }^{24}$ calls the questions on the moral and existential aspects of our lives.

Research on the quality of deliberative democracy (DD) provides four criteria that can be used to assess the quality of deliberative sessions: 1) equal participation, 2) respect for the opinion of others, 3) the adoption of a societal instead of personal perspective, and 4) reasoned justification of ideas. ${ }^{5}$ Our findings indicate these criteria, except the adoption of a societal perspective also apply to MCD in health care organizations. Equal participation, respect for the opinion of others and reasoned justification relate to the process of DD. In MCD the quality of the outcomes strongly depends on the quality of the process of the deliberation. The learning process we described, reflects the interrelatedness of the elements that together constitute a good deliberation: content, process and perspectives. When caregivers with different professional backgrounds and educational levels are stimulated to deliberate on each other's moral issues together, as happens in MCD in mixed groups, they are enabled to learn from each 
other and dialogue in daily practice is stimulated. ${ }^{14}$ In MCD routines are questioned and superficial assumptions are critically reflected upon. Participants think that awareness, an inclusive approach towards all perspectives involved in a case, a thorough analysis and clear communication are beneficial for the quality of care.

The initial expressed doubts about the appropriateness of MCD for nurses and care assistants illustrate a culture in which dialogue is not common and in which nurses and care assistants can easily become silenced. Howe ${ }^{25}$ pointed at the risks of such a culture and stressed the importance of an inclusive approach to dealing with ethical issues, giving 'all care providers more opportunities to share their ethical concerns with others'. Arguments to actively involve aides are amongst others that they provide bottom-up information from their close relation with the resident (which is of indispensable value in decision making) and that it is beneficial for increasing 'esprit de corps' and a 'sense of shared responsibility'. ${ }^{25}$

Next to the elements of the learning process that directly relate to the process and outcome of deliberation, our research also point at the significance of an additional element of MCD: the relieve of moral distress felt by the participants. This is important because it both motivates them to engage in deliberation and thereby protects them from the negative and long-lasting effects of moral distress, leading to desensitization to the moral dimensions of care or even leaving a profession. ${ }^{26}$

\section{LIMITATIONS OF THE STUDY}

Our study (inevitably) has some imperfections that should be mentioned here. First, the study covers a specific context. Our results cannot be extrapolated to any elderly care institution right away. However, by giving a rich description of the context and a detailed account of the learning process we describe, we aim to enable readers to decide in what way and to what extent results are transferable to their own context. This is called naturalistic generalization ${ }^{18,27}$. Second, our study focused on participants that 'stayed on board'. In addition to participants who quit because they changed jobs, a small number of participants (mostly from facility services) withdrew because they did not feel a 'click' with MCD. Presumably these participants did not recognize the moral issues in their work or felt that MCD should be about resident care issues and considered their own issues less relevant. This focus may have coloured our findings through an overrepresentation of the positive experiences with MCD. Finally, our study covers a relatively short time span of 2,5 years; we focused on the first and second project phase. After our data collection for the current study had finished, in the care home MCD was implemented in more teams and the role of facilitator was transferred to the newly trained team coordinators. We suggest further research into the long-term learning processes when MCD becomes integrated in existing practice. We expect that this mainstreaming of MCD will make the benefits for others than the professional, for example the resident and his family, more visible. 


\section{IMPLICATIONS FOR IMPLEMENTING MCD}

Despite these limitations, we believe our study provides a number of insights relevant to those involved in implementing MCD in the future.

First, the learning process was not a linear and predefined process with a pre-set destination. Over time the intensity, duration and impact varied with the gaining of experience being the accelerator. The role of developing competencies and experiencing benefits also shows that the learning process is a motivational process. The benefits of MCD are therefore not an endpoint to the implementation but are part of the process. The discovery of deliberation is not a final destination but it offers the starting point for dialogue, inclusion of the moral dimensions, more effective communication on moral issues and improvement of the quality of care.

Second, letting employees experience MCD seems to be a more effective strategy for implementation than talking about it. In line with Weidema et $\mathrm{al}^{28}$ we conclude that MCD needs ' bottom-up' enactment. Using ideological arguments to promote MCD might even be contra-productive because it might amplify the initial association of MCD with heaviness and trivial discussions about details. ${ }^{28}$ This is in line with the pragmatic hermeneutic theoretical inspirations of MCD: MCD should not become a goal in itself or be presented as a fixed dogmatic ideal.

Third, the expected spontaneous diffusion of MCD through the entire institution following the success of the mixed MCD groups did not happen. Probably because of the lack of experience with MCD, colleagues of the participants did not automatically adopt MCD. Gaining experience may be even a more important factor for them. In terms of Rogers' work on the diffusion of innovations ${ }^{29}$ these employees come behind the 'innovators' and 'early adopters'. Linked to experience, we think a certain 'take-off run' is needed. Therefore, enough time should be invested in making it possible for the majority of the employees to experience MCD, for more than one session.

Fourth, given that adopting MCD did not happen spontaneously, top-down supportive elements may be necessary for a successful implementation and continuation of MCD. This comes with the risk of creating resistance. However, resistance seems inevitable when changing (nursing) practice and changes in the social and cultural sphere generally bring on more resistance than technological change. ${ }^{30}$ It is therefore important to create time and space in the process of implementing MCD, to deal with resistance. In our study the researcher facilitator acted as a 'change agent', but not in an authoritarian way. Full support of the management appeared to play an important role throughout the project. Along the way the (middle) managers who had taken part in MCD sessions, developed a sense of ownership of the innovation, again stressing the importance of practical experience.

\section{CONCLUSION}

Moral reflection and deliberation are necessary in residential elderly care. Poor awareness of moral issues and ambiguous attitudes towards MCD make bottom-up stimula- 
tion and top-down facilitation needed. Participation in MCD is a crucial factor and an accelerator in the implementation process. In gaining experience, in other words doing MCD, participants develop competencies for reflection and deliberation, experience the benefits and therefore become internally motivated. The implementation of MCD in elderly care and other health care organizations seems a promising pathway for the integration of bioethics in everyday practice. 


\section{REFERENCES}

1. Jonsen AR. A history of bioethics as discipline and discourse. In: Jecker NS, Jonsen AR and Pearlman RA, (eds.). Bioethics An introduction to the history, methods and practice. second ed. Sudbury MA: Jones and Bartlett publishers, 2007, p. 3-16.

2. Agich GJ. Clinical ethics: a role theoretic look. Soc Sci Med. 1990; 30: 389-99.

3. Kane RA and Caplan AL. Everyday ethics : resolving dilemmas in nursing home life. New York: Springer Pub. Co., 1990, p.xvii, 331 p.

4. Abma TA, Molewijk B and Widdershoven GA. Good care in ongoing dialogue. Improving the quality of care through moral deliberation and responsive evaluation. Health Care Anal. 2009; 17: 217-35.

5. De Vries R, Stanczyk A, Wall IF, Uhlmann R, Damschroder LJ and Kim SY. Assessing the quality of democratic deliberation: a case study of public deliberation on the ethics of surrogate consent for research. Soc Sci Med. 2010; 70: 1896-903.

6. Irvine R, Kerridge I and McPhee J. Towards a dialogical ethics of interprofessionalism. J Postgrad Med. 2004; 50: 278-80.

7. Fiester A. The failure of the consult model: why "mediation" should replace "consultation". Am J Bioeth. 2007; 7: 31-2.

8. Ministry of Health Welfare and Sport. Agenda ethiek en gezondheid 2006 [Agenda ethics and health 2006]. 2005.

9. Dauwerse L, Van der Dam S and Abma TA. Morality in the mundane: specific needs for ethics support in elderly care. Nursing ethics. 2012.

10. Bolmsjo IA, Edberg AK and Sandman L. Everyday ethical problems in dementia care: a teleological model. Nursing ethics. 2006; 13: 340-59.

11. Vanlaere L, Coucke T and Gastmans C. Experiential learning of empathy in a care-ethics lab. Nursing ethics. 2010; 17: 325-36.

12. Powers BA. Everyday ethics of dementia care in nursing homes: a definition and taxonomy. American Journal Alzheimers disease other dementias. 2000; 15.

13. Widdershoven GAM and Molewijk AC. Philosophical foundations of clinical ethics. A hermeneutic perspective. In: Schildmann J, Gordon JS and Vollmann J, (eds.). Clinical ethics consultation. Theories and methods, implementation, evaluation. Surrey: Ashgate, 2010, p. 37-52.

14. van der Dam S, Abma TA, Molewijk AC, Kardol MJM, Schols JMGA and Widdershoven GAM. Organizing moral case deliberation experiences in two Dutch nursing homes. Nursing ethics. 2011; 18: 327-40.

15. Rubin BM. Naturalistic evaluation: its tenets and application. Studies in art education. 1982; 24: 57-62.

16. Erlandson DA. Doing naturalistic inquiry : a guide to methods. Newbury Park, Calif.: Sage, 1993, p.xxi, 198 p.

17. Bowen GA. Grounded theory and sensitizing concepts. International Journal of qualitative methods. 2006; 5

18. Lincoln Y and Guba E. Naturalistic inquiry. New York: Sage, 1985.

19. Meadows LM and Morse J. Within-project validation. In: Morse J, Swanson J and Kuzel AJ, (eds.). Constructing evidence within the qualitative project. Newbury Park, CA: Sage, 2001.

20. Greene JC, Kreider, H. \& Mayer, E. . Combining Qualitative and Quantitative Methods in Social Inquiry In: Somekh BCL, (ed.). Research Methods in the Social Sciences. London: Sage, 2005, p. 274-81.

21. Tong A, Sainsbury P and Craig J. Consolidated criteria for reporting qualitative research (COREQ): a 32-item checklist for interviews and focus groups. Int J Qual Health Care. 2007; 19: 349-57.

22. Austin W. The ethics of everyday practice: healthcare environments as moral communities. ANS Adv Nurs Sci. 2007; 30: 81-8.

23. Solum EM, Slettebo A and Hauge S. Prevention of unethical actions in nursing homes. Nursing ethics. 2008; 15: 536-48.

24. Kunneman H. Voorbij het dikke ik. 3 ed. Amsterdam: Humanistics University Press, 2005.

25. Howe EG. All Careproviders Need More Opportunities to Share their Ethical Concerns with Others. J Clin Ethic. 2010; 21: 179-88.

26. Hamric AB. Empirical research on moral distress: issues, challenges, and opportunities. HEC forum : an interdisciplinary journal on hospitals' ethical and legal issues. 2012; 24: 39-49.

27. Abma TA and Stake RE. Responsive evaluation: Roots and evolution. . In: Greene JC and Abma TA, (eds.). Responsive evaluation: New directions for evaluation. San Fransisco: Jossey-Bass, 2001, p. 7-22.

28. Weidema FC, Molewijk AC, Widdershoven GA and Abma TA. Enacting Ethics: Bottom-up Involvement in Implementing Moral Case Deliberation. Health Care Anal. 2011.

29. Rogers EM. Diffusion of innovations. 5th ed. New York: Free Press, 2003, p.xxi, 551 p.

30. Curtis E and White P. Resistance to change. Nursing Management. 2002; 8: 15-20. 


\section{Chapter 7}

General discussion 
The main goal of this thesis was to explore the field of ethics support in institutional elderly care, to investigate the specific needs for ethic support in Dutch elderly care institutions and to evaluate one specific form of ethics support in Dutch elderly care institutions: moral case deliberation (MCD). In MCD, health care professionals meet to reflect and deliberate on ethical questions and dilemmas they experience in their work. In a dialogue, structured by a conversation method and under the guidance of a facilitator, participants analyze a concrete case by exploring the perspectives, values and norms of the stakeholders involved in the case and the participants present in the deliberation.

Internationally, ethics support in elderly care has been developed since the 1980s. In the Netherlands, but also in several other western countries, elderly care is under pressure of demographic developments (greying of the population, increased life expectancy) and political and societal choices (budget cuts, lowering of educational levels, bureaucratization) which have led to societal unrest and concerns about the quality of care in elderly care. ${ }^{1-3}$ Problems in elderly care became subject of media coverage and public discussion. One way to improve the quality of care is to pay explicit attention to the ethical dimension of the care that is provided. ${ }^{4}$ During the past decade the development of ethics support was put on the political agenda in the Netherlands and the number of institutions that have started implementing ethics support initiatives has increased rapidly over the years.

An international overview of the variety of ethics support types and the developments over the past decades was not available yet. Since institutional elderly care is different from acute care it was important to investigate what the characteristics of elderly care (the type of care, kind of ethical issues and characteristics of health care professionals) mean for the specific needs for ethics support. In the Netherlands one specific kind of ethics support, MCD, has emerged during the past decade and is now widely implemented in Dutch health care institutions. This kind of ethics support, MCD, was evaluated in the context of moral case deliberation projects in two Dutch elderly care organizations.

This final chapter discusses our main findings and reflects on the limitations of the study. Finally, future directions for practice and research are presented.

\section{MAIN FINDINGS}

\section{ELDERLY CARE: EVERYDAY ETHICAL ISSUES IN ABUNDANCE}

Residential elderly care is full of ethical issues. Our analysis of the cases $(N=202)$ that were presented by participants of mixed MCD groups, within the context of the MCD projects, showed that issues that play on the work floor are mostly everyday ethical issues. ${ }^{5}$ The term 'everyday ethics' was coined by Kane \& Caplan in 1990.6 Everyday ethical issues arise in the context of daily practice, the routines and encounters with residents and relatives. These issues are less obvious than the 'big' and dramatic issues surrounding decisions at the end of life -the traditional focus of bio-ethics ${ }^{7}$ - and may easily stay unrecognized. 6 , 8 Participants formulated the problematic situations in the 
case descriptions in practical terms, not in terms of conflicting values, norms or principles. Powers ${ }^{8}$ labeled the common frames of reference that participants in an ethics project used as 'folk taxonomies'.

In our study, we distinguished three domains of ethical issues (see fig 1): resident's behavior, divergent perspectives on good care and the organizational context. ${ }^{5}$

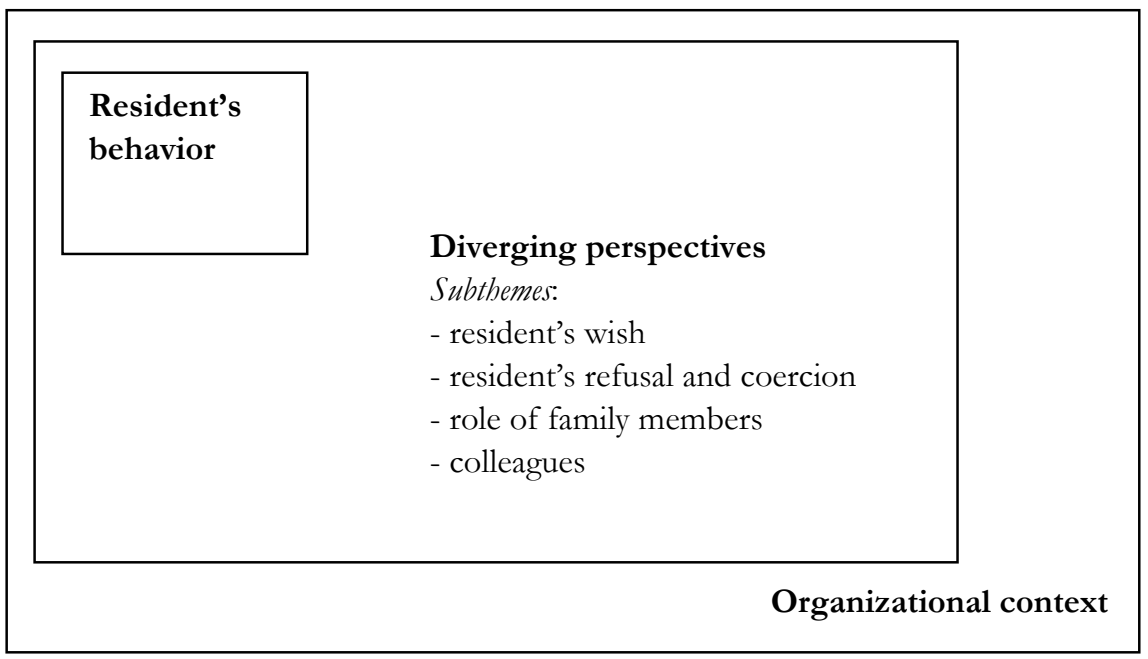

Figure 1: Domaines of ethical issues

The first domain contains situations where problematic or aggressive behavior of residents raised questions on the protection of fellow residents, the extent of aggressive behavior being acceptable to professionals, and the measures to be taken.

The second domain contains situations in which divergent perspectives on good care gave rise to ethical questions in a number of ways. Firstly, a resident's wishes might have negative consequences for fellow residents or conflict with the professional's perspective on good care. Secondly, ethical questions arose when a resident refused care and the professional struggled with the dilemma whether or not to use persuasion or even coercion in order to provide the necessary help, improve the resident's physical condition or protect fellow residents from the negative consequences of nonintervention. Thirdly, family members' perspective(s) gave rise to ethical questions, for example when a professional felt stuck between conflicting perspectives of the resident and their family, or was confronted with disagreements among family members or with family members who needed professional help themselves. In the fourth place, ethical questions arose from conflicting perspectives among colleagues or disapproval of their attitude or actions. This also gave rise to the ethical question whether or not to address these divergent perspectives, attitude or behavior.

The third domain contains situations in which the organizational context, with existing policies, limited resources and limited options for care, raised questions such as on where priority should be put or whether a resident should be transferred or not. 


\section{MULTIPLICITY OF PERSPECTIVES AS A SOURCE FOR MORAL DISTRESS}

The everyday ethical issues presented by the participants of the MCD groups, reflect the complexity of a multiplicity of perspectives in elderly care. Unlike in acute care, which is organized around the individual patient, in elderly care divergent perspectives are common because residents are living together, care is based on teamwork and family members often play an important role in resident's lives. Our research pointed out that this moral diversity in perspectives can be a source for moral distress. ${ }^{5}$ In a recent study, overviewing the empirical research on moral distress, Hamric ${ }^{9}$ gives examples of root causes of moral distress that extend beyond the institutional constraints and power hierarchies that Jameton, who first defined the concept of moral distress in 1984, ${ }^{10}$ focused on in his initial definition. Moral distress may also be caused by factors internal to the caregiver, e.g. perceived powerlessness, or by external factors in the situation, e.g. a lack of administrative support, or by the clinical situation, e.g. futile treatment. ${ }^{9}$ Our findings add an extra source of moral distress to the spectrum of root causes that have been identified in the literature, namely having to deal with divergent perspectives on care situations.

Handling this multiplicity of perspectives is extra complex in a situation where there is no (legal) rule or absolute norm of goodness, or hierarchy of positions. Care givers involved may feel that they will never be able to do good or find a compromise. Then dialogue is needed to express feelings and emotions, and to explore underlying values and find mutual understanding. If a conversational space for communal dialogue about various and sometimes conflicting perspectives is not available - as is often the case -, care givers have to individually deal with the emotionally challenging situation, eventually leading to moral distress.

\section{NEEDS FOR ETHICS SUPPORT, ALBEIT NOT UNCONDITIONALLY}

The availability of ethics support in Dutch elderly care is still limited ${ }^{11}$, although the abundance of everyday ethical issues in elderly care and these issues being a source for moral distress suggest a large need for ethics support in elderly care. Our mixed methods study among board members of elderly care institutions and experts from the field, in the Netherlands, indeed indicated that there is a (strong) need for ethics support. ${ }^{11}$ This need was also articulated by managers and healthcare professionals in the context of the MCD projects. It was expected that MCD would make caregivers more aware of ethical issues and that this would help to relieve moral distress through offering a place where you can share frustrations and emotions. Also, discussing issues that in daily practice are easily left unaddressed might help prevent them from escalating into conflicts. Furthermore, MCD might prevent routine ways of working by triggering caregivers to examine an issue from a different, new point of view. Finally, MCD was regarded as a way to counterbalance the emphasis on efficiency, directives and the technical aspects of giving care. ${ }^{12}$

However, in elderly care practice this need for ethics support is not unconditionally and not felt by everyone. ${ }^{11}, 12$ When we started implementing MCD in the participating organizations it became clear that not everyone experienced ethical problems nor expressed a need for support to practice ethical reflection and deliberation. From the 
interviews before the start of the MCD groups, we identified four sources of reluctance. In the first place there were doubts about the usefulness of MCD. MCD as a tool for problem solving and mediation might be superfluous in a team with good relations and only useful in case of (persisting) conflicts. A primary medical-technical approach to experienced problems made caregivers strongly rely on medical-technical advice from (para)medical staff. Also, a strong reliance on earlier made agreements in the care plan, decreased the need for further reflection and deliberation. In the second place, reluctance was caused by uncertainty about or even distrust of the benefits of MCD both for the professionals and for the quality of care from the perspective of the resident. In the third place, reluctance was induced by doubts about the appropriateness of MCD for nurses and care assistants, both because of their hands-on orientation and focus on physical care, and because of the strategies in practice that functioned as an alternative for dialogue, such as multidisciplinary team meetings. In the fourth place, organizational constraints (staff shortages, heavy workload) and uncertainty about the management's commitment to support investment in MCD (providing time and back-up cover), gave rise to reluctance.

\section{THE DISCOVERY OF DELIBERATION: THE CRUCIAL ROLE OF DOING MCD}

The need for ethical reflection and deliberation, and the value of MCD as a means for this, became articulated during the learning process that started upon implementation of MCD in the participating institutions. Practical experience in the mixed MCD groups appeared crucial for the appreciation of MCD, for two reasons: participants developed moral competencies and experienced benefits of reflection and deliberation. Writing and presenting cases and discussing them in systematic way, using a conversation method helped participants to grasp the moral dimension of care. They also learned to engage in a dialogue (listen to each other, postpone judgment, develop exploratory attitude) and to value the input of various perspectives (increased insight, understanding and interest in other perspectives). Participants experienced benefits of MCD for the quality of care (thorough investigation, confidence in chosen option), for communication (acting upon agreements, better able to explain the reasoning behind decisions), and for relief of moral distress.

The learning process during the experience of MCD can be understood further in terms of the criteria for assessing the quality of democratic deliberation developed by De Vries et al. ${ }^{13}$ The first two criteria 'equal participation' and 'respect for the opinion of others' closely relate to what participants in MCD learned with respect to 'engaging in a dialogue' and 'valuing the input of various perspectives'. The fourth criterion, 'reasoned justification of ideas', applies to the systematic and thorough moral investigation within MCD. The third criterion, 'adoption of a societal instead of personal perspective', seems less relevant for MCD.

\section{ORGANIZING MCD, THE PROS AND CONS OF MIXED GROUPS}

The MCD projects started with mixed groups of intrinsically motivated participants from different teams and professional backgrounds. It was expected that a group of voluntary participants, who deliberate outside of existing communication patterns that 
are often dominated by strategic action, would create an atmosphere of safety and openness. Also, it was expected that representation of as many teams and disciplines in the mixed groups would foster dissemination through the institution. The mixed composition might also offer a laboratory to deal with a multiplicity of perspectives on good care.

Participants of the MCD groups experienced both positive and negative sides to the heterogeneous composition of the group and the organization apart from existing structures. ${ }^{14}$ A broadening of horizons made participants more aware of each other's moral issues and perspectives on good care, stimulated communication on moral issues and enriched the moral enquiry undertaken. The mixed groups provided a safe and open atmosphere and offered a way to unburden feelings and emotions. Negative experiences related to a lack of involvement when cases were not recognizable for all participants and differences in moral competence, causing either frustrations and impatience or feelings of insecurity. Participants also experienced a lack of impact and a (growing) gap with the rest of their own team. Restoring of connections with team members was felt as a requirement to actually realize practice improvements.

\section{MAINSTREAMING REFLECTION AND DELIBERATION}

In our projects we started with mixed groups, for the above mentioned reasons. For the future, participants suggested implementation of MCD in existing communication structures in order to create time to reflect and deliberate and generate widely supported decisions. ${ }^{14}$ This is in line with what board members and experts from the field suggested: ethics support in elderly care should be integrated in daily activities and take the actual experiences of nurses as a starting point rather than introducing distanced and formalized services or innovations that are imposed on nurses to improve their work. ${ }^{11}$

Institutional elderly care is different from acute care. Not only is being a resident in elderly care different from being a patient in hospital (longer residency, often until death), ${ }^{15-17}$ there are also differences concerning the kind of issues (everyday ethical issues), 5, 8, 18 the kind of health care workers (lower educated), and resources. ${ }^{19}, 20$ Given the specific context, ethics support in elderly care should focus on developing the professionals, through raising awareness and sensitivity towards ethical issues and through stimulating reflection and mutual learning rather than making them dependent on external ethical expertise and advice. Creativity in dealing with issues that do not request acute decisions requires a positive and open ethical climate in which a dynamic of questioning and evaluation exists. Role models can play an important role in creating an environment in which reflection and deliberation on ethical issues and good care are integrated in the daily work. ${ }^{21}$ As Ash $^{22}$ states: ethical everyday practice demands an organizational culture which invites and requires critical thinking and questioning (p. 207).

The expected spontaneous dissemination did not happen, participants of the mixed MCD groups even experienced a (growing) gap and disconnection with others. ${ }^{14}$ This lack of spontaneous dissemination, combined with the crucial role of gaining experience for the acceptance of MCD, indicate that mainstreaming ethics, making reflection 
and deliberation become part of everyday practice, requires top-down implementation strategies next to bottom-up involvement. This is in line with what Weidema et al ${ }^{23}$ found when implementing MCD in psychiatry. Top-down support and steering was reinforced by the presence of key persons during MCD sessions and by firmly stating management regulations such as compulsory attendance. ${ }^{23}$

\section{HOW CAN MCD MEET THE SPECIFIC NEEDS FOR ETHICS SUPPORT IN ELDERLY CARE?}

In elderly care there is a need, although not always articulated, to recognize and reflect on everyday ethical issues. These issues may be experienced as problematic situations but also may stay hidden in daily routines. Health care workers need to learn to grasp the moral dimension of care in everyday practice. They also need to learn how to engage in a dialogue on ethical issues: to ask each other questions, reconsider their own perspective and develop an exploratory attitude. Finally, they need to acknowledge that several perspectives can be involved in a case and will have to learn to deal with a multiplicity of perspectives in practice.

MCD can meet those needs in a number of ways. In the first place, MCD can offer a recognizable space within the institution where the moral dimension of care is made explicit and where employees are enabled to deliberate on their ethical issues. Tronto ${ }^{24}$ states that such 'well-conceived space' must be built in, in order for care organizations to be highly deliberate and explicit about how to best meet the needs of the people who they serve (p. 169). MCD can offer safety and openness for health care professionals to engage in a dialogue and to acquire the competence needed for this. The guidance of a facilitator and the use of a conversation method help to structure the conversation and to keep the focus on the moral dimension. In the second place, MCD strongly connects to what is going on at the work floor by taking the experiences of health care professionals as a starting point, and by giving voice to care givers, including nursing aids, who often feel not recognized and unheard. The moral knowledge of care givers, a practical understanding of experienced people who know what is good in concrete situations, is what Aristotle called phronesis. ${ }^{25}$ According to Singer et al, ${ }^{26}$ ethics support should aim at developing the skills of care workers in order to create a workforce that is able to address common ethical issues without the assistance of a clinical ethicist. MCD is an example of an ethics support form that is especially suited for developing care worker's phronesis.

Of course, MCD is not a panacea for every problem in elderly care. Although MCD can contribute to a culture change in care organizations, it is not simply a tool to achieve a more open and ethical climate. Other things, such as role models and leadership are necessary too. Furthermore, MCD cannot be used to compensate for deteriorating conditions for providing good care, such as budget cuts.

\section{INTERNATIONAL DEVELOPMENTS IN ETHICS SUPPORT IN ELDERLY CARE}

The development of MCD in the Netherlands should be placed in the wider context of the international developments in ethics support in elderly care. Ethics support (services) in health care institutions originated in the USA in the 1970s, when hospitals 
began to form clinical ethics committees(CECs), influenced by the publication of journal articles and the New Jersey Supreme Court decision in the Karen Quinlan case in $1976^{27}$. About a decade later elderly care followed the example of hospitals.

Our review of the literature on ethics support in elderly care institutions showed that since then, next to the traditional CEC other forms of ethics support have been developed. Based on this review, we identified four main categories of ethics support types: 'institutional bodies' (CEC and ethics consultation); 'frameworks'; 'educational programs and MCD'; and, 'written documents and policies'. ${ }^{20}$ Ethics support often serves several goals and can be targeted at more than one level. Various ethics support mechanisms can exist together in one institution. Figure 2 displays the different accents of the distinguished types of ethics support but also shows their interconnectedness.

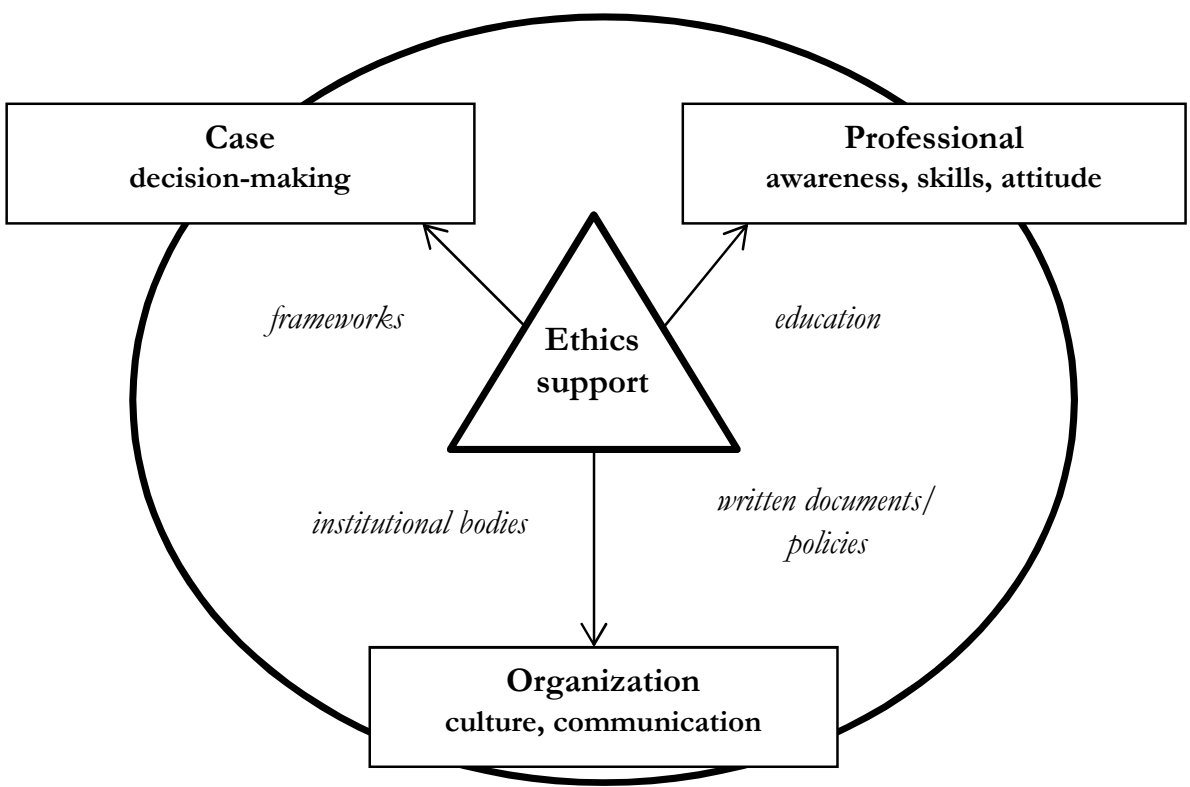

Figure 2: Interrelated elements in ethics support

Over the past decades a number of developments have taken place in ethics support in elderly care. Critique on traditional CECs for being distant from the work floor, ${ }^{28}$ the emergence of more deliberative forms of ethics support ${ }^{29-31}$ and a greater account of the specific context of elderly care ${ }^{11}$ have led to the development of new types of ethics support that are more integrative, outreaching and pro-active than the traditional clinical ethics committee. A greater focus is put on the development of health care professionals, making use of their own concrete experiences and stimulating interdisciplinary dialogue. ${ }^{32}$ Another, related, development is that the attention for everyday ethical issues, that arise within the daily encounters with residents and their families, ${ }^{11}$ has increased. These everyday ethical issues are less obvious and more difficult to rec- 
ognize than more dramatic issues, ${ }^{6,8}$ e.g. decisions regarding the end of life, that are traditionally brought to the CEC. ${ }^{19}$ Ethics support has also become more interwoven with the institutional context through transforming committees into decentralized network structures, integration with quality assurance and the development of a more holistic perception of ethics, including organizational ethical issues. ${ }^{20}$

\section{LIMITATIONS OF THE STUDY}

This study has some limitations that need to be taken into account when considering the results.

First, both the investigation on the needs for ethics support and the evaluation of MCD took place within the Dutch context of institutional elderly care. Although we reflected on our results from an international perspective, making use of the literature on comparable forms of ethics support in other countries, it was not possible to directly compare empirical data between different countries. As previous research on the perception of ethical concepts revealed both differences between groups within the same county and differences between countries, ${ }^{34}$ it is expected that replication of our study in other countries would also lead to (partly) different findings. The context descriptions of our findings may enable readers to assess which lessons from our study may also be relevant for their own context.

Second, the evaluation of the implementation of MCD was limited to two institutional elderly care organizations. By giving a rich description of the context and a detailed account of the results, we aimed to enable readers to judge in what way and to what extent our results can be transferred to other contexts. This is called naturalistic generalization ${ }^{35}$, 36. Logically this might be easier for Dutch readers than it will be for readers from other countries.

Third, the evaluation of the implementation process only covers the first two phases of the MCD project, the introduction phase and the phase of gaining experience in mixed MCD groups. After these phases, in the care home organization and one nursing home the project continued with expanding MCD to ward teams and the training of MCD participants to become facilitators. For a successful embedding and mainstreaming (MCD becoming a natural part of everyday practice) of MCD the latter phases are also crucial, because in these stages the employees that come behind the 'innovators' and 'early adopters' ${ }^{37}$ are actively engaged in MCD for the first time.

Fourth, the patient's perspective, or in the case of elderly care, the perspectives of the residents and their family were not included in the research. This inevitably caused a one-sided focus that is not completely in accordance with the multiplicity of perspectives in elderly care practice. In addition, we did not investigate what the effects of the implementation of MCD were on the residents and their families.

Fifth, the content of the deliberations, as we presented in the overview of issues based on the case descriptions of MCD participants, may reflect a number of selectioneffects and may therefore not cover the full spectrum of moral issues that arise in the context of elderly care. In the first place, health care professionals may have a different perception of issues than residents and their families ${ }^{39,40}$ or they might fail to identify 
residents' and their families' issues and perspectives. ${ }^{41,}{ }^{42}$ In the second place, the overview may contain an overrepresentation of cases in which the collaboration between professionals is seen as a problem when the pioneering MCD participants think of themselves as ethical role models. Another plausible explanation for these cases is that professionals find it easier to discuss what their colleagues do wrong than to discuss their own personal doubts.

\section{FUTURE DIRECTIONS AND CHALLENGES}

\section{EDUCATION AND PRACTICE}

Since the learning process of developing competencies for reflection and deliberation and discovering the benefits of MCD is crucial for the acceptation of MCD in practice, it is recommended that future health care professionals already gain experience with MCD during their education. The classroom can provide a safe environment for student to practice with ethical reflection and deliberation. Our findings indicate that (future) health care professionals need training to develop competencies for engaging in a dialogue and conducting systematic and thorough moral investigations of cases. When students practice listening, postponing judgments and asking questions, they develop an exploratory attitude that will help them in their future communication with colleagues. When students learn to recognize the moral dimension of care they will be better able to address issues that otherwise may stay hidden in daily routines.

The recent initiatives for the reintroduction of higher educated nurses in elderly care $^{43}$ are promising. In addition to the role these nurses can play in leadership, improving expertise and the integration of science and practice through stimulation of evidence-based nursing, they should play a role in the integration of ethics support in daily practice. In the stimulation of an open ethical climate in the institution, they can function as role models. Higher educated nurses may also play a role in bridging the gap between the lower educated nurses in the ward teams and the higher educated (para)medical staff. Higher educated nurses should not take over reflection and deliberation from lower educated nurses, but play a role in the mutual support that health care professionals of various disciplines and educational levels can offer to each other. MCD can contribute to inter-professional communication processes because through deliberation participants get to know each other and gain insight in each other's perspectives.

Considering the concrete learning style of, in particular, nursing aides, it is recommended to combine forms of ethics support that focus on reflection and deliberation with other forms of ethics support. Especially interactive forms of ethics support that focus on raising awareness, making use of role play, can be a good preparation for getting engaged in MCD. In the Netherlands, initiatives have been developed that bring educational theatre to health care organizations. The scenes displayed by the actors require active interference of the audience in order to construct how good care should be performed, together. A Belgian initiative, the sTimul care ethics lab, invites care professionals to step into the shoes of care receivers, and offers a program of experiencing what it means to receive care or to provide care, combined with reflection of 
these experiences, in a lab-like situation outside of the professional's own work environment. ${ }^{44}$

Although our MCD projects had an inclusive approach, aiming to involve employees throughout the institution, our research also revealed a tendency to think that MCD should primarily be used within the primary care process and that especially care assistants and nurses need to further develop competencies for reflection and deliberation. It remains a challenge to create an institution-wide culture that is supportive to reflection and deliberation. Involvement of the management should not be limited to providing support and resources, managers should also actively engage in deliberation and should actively stimulate dialogue institution-wide, in order to prevent that MCD becomes a closed circuit at the work floor.

Another challenge is how residents and their relatives can be actively involved in deliberations. Up till now their perspectives were included in an indirect way. In the light of the learning process and the educational function of the deliberations in the context of the implementation project this can be justified. But in case of prospective deliberations, for example in order to decide on aspects of the future care plan of a resident, it might be, motivated by ethical and political considerations, ${ }^{38}$ appropriate to include residents or family members in the deliberations. Preferably these residents and family members should be actually involved in the case at hand. Weidema et al ${ }^{38}$ show that the presence of clients may initially be experienced as a challenge by professionals, who feel reluctant to express their vulnerabilities in the company of clients and family. Yet, when mutual trust is build up all may experience the benefits of such mixed group composition.

Experiences with involvement of residents and their families, but also several other topics should be subject of exchange of experiences and knowledge between care organizations. Development of a national network for clinical ethics support can be a good forum for sharing best practices. In addition it might be informative to not only share success stories, but also the experiences on what did not work well in practice.

Finally, societal and political attention for the ethical dimension of elderly care is necessary. Budgets cuts and increased emphasis on efficiency should not turn MCD into a 'palliative' tool: a measure to learn health care professionals to deal with tragic situations in which good care cannot be provided because of limited resources and organizational constraints.

\section{RESEARCH}

Future research is needed on the mainstreaming of ethics support in practice. Publications on the design and implementation of ethics support dominate the literature. More insight is needed on the role(s) that ethics support can play in the process of caring. Not only in the primary care process, but also in the secondary process (management, facility services), where also organizational ethical issues arise. And, not only in the importance for health care professionals, but also research is needed on what ethics support can mean for residents and their families. With respect to MCD it would be interesting to follow how MCD will be used in practice after the implementation phase: will MCD become a permanent educational instrument, or will the use of MCD shift 
towards using it as a decision making tool? And, if and how will MCD become integrated in the regular communication structures?

Future research is needed to systematically investigate the way(s) in which MCD has an effect on care givers and on the care for residents. Next to qualitative studies, quantitative research into the effects of MCD in practice is needed. One issue to be addressed is moral distress. Much empirical research has been conducted on moral distress but very few studies investigate (educational) interventions that may reduce moral distress ${ }^{9}$. Hamric ${ }^{9}$ provides some useful hints for future research of moral distress, which may also apply to intervention studies on MCD: research requires 'stable and sensitive measures in order to determine whether an intervention has been effective in decreasing moral distress'. Currently a revision of the moral distress scale (MDS-R) is tested in the USA. The MDS-R may provide a useful instrument to measure the effects of interventions on moral distress. Multi-site studies are required since the levels of moral distress that health care professionals experience are associated with the environment in which they work ${ }^{9}$. In doing such research, it cannot be excluded that implementation of MCD might provoke feelings of moral distress or might raise levels of experienced moral distress. This might be the case with health care professionals who's awareness of moral issues and the existence of a multiplicity of perspectives on these issues are triggered by participation in MCD. Thus, results of quantitative studies require careful consideration, and need to be complemented with qualitative data in order to evaluate the effects of MCD in a balanced way.

With respect to the theoretical underpinnings of our approach to MCD, it would be interesting to explore the central concept of 'fusion of horizons' in practice. When asked, participants in MCD often indicate that their original opinion on the subject of the case did not change during the deliberation, although they report an increased insight in their own perspective and that of the other's (involved in the case or participating in the deliberation). More research is needed into the dialogical process that takes place during deliberations, but also what happens in the follow up. Do participants really try to understand perspectives different from their own and how do they do that? Do participants take over (part of) each other's perspectives? Do the resolution or alternatives to the issue at hand reflect a fusion of several perspectives?

In the Netherlands, since the 1980's initiatives have been developed to substitute nursing home care to the (care) home situation, in order to achieve a reduction of costs and reach a larger population. Also, this should reinforce home care to meet the wish of most elderly people to stay in their own home as long as possible. ${ }^{45}$ This policy development continues until today. ${ }^{46}$ Implementation of ethics support forms such as MCD may be easier to organize in an institutional setting, where all employees work in the same location and care processes are organized in units. Research is needed into the possibilities to organize ethics support in home care, where health care workers operate on their own and have little contact with their colleagues.

Finally, ethics support (and MCD) in elderly care is relatively new and still developing. As the above directions and challenges for the future point out, there is still a lot of work to do in order to further develop and implement ethics support and moral case deliberation ... let's roll up our sleeves! 


\section{REFERENCES}

1. Klaver K and Baart A. Attentiveness in care: towards a theoretical framework. Nursing ethics. 2011; 18: 686-93.

2. Jakobsen R and Sorlie V. Dignity of older people in a nursing home: narratives of care providers. Nursing ethics. 2010; 17: 289-300.

3. Haggstrom $\mathrm{E}$ and Kihlgren A. Experiences of caregivers and relatives in public nursing homes. Nursing ethics. 2007; 14: 691-701.

4. Ethiek in de zorgopleidingen en zorginstellingen. Hoofdstuk 6 uit: Signalering ethiek en gezondheid, 2005 [Ethics in the care education and the health care institutions Chapter 6 from: Agenda ethics and health care 2005]. Zoetermeer: CEG [Center for Ethics and Health], 2005.

5. van der Dam S, Abma TA, Kardol MJ and Widdershoven GA. "Here's My Dilemma". Moral Case Deliberation as a Platform for Discussing Everyday Ethics in Elderly Care. Health Care Anal. 2012; 20: 250-67.

6. Kane RA and Caplan AL. Everyday ethics : resolving dilemmas in nursing home life. New York: Springer Pub. Co., 1990, p.xvii, 331 p.

7. Moody HR. Ethics in an ageing society. Baltimore, MD: The John Hopkins University Press, 1992.

8. Powers BA. Ethnographic analysis of everyday ethics in the care of nursing home residents with dementia: a taxonomy. Nurs Res. 2001; 50: 332-9.

9. Hamric AB. Empirical research on moral distress: issues, challenges, and opportunities. HEC forum : an interdisciplinary journal on hospitals' ethical and legal issues. 2012; 24: 39-49.

10. Jameton A. Nursing practice: The ethical issues. . Englewood Cliffs: Prentice-Hall, 1984.

11. Dauwerse L, Van der Dam S and Abma TA. Morality in the mundane: specific needs for ethics support in elderly care. Nursing ethics. 2012.

12. Dam van der $\mathrm{S}$. The discovery of deliberation. From ambiguity to appreciation through the learning process of doing Moral Case Deliberation in Dutch elderly care. . 2012; submitted.

13. De Vries R, Stanczyk A, Wall IF, Uhlmann R, Damschroder LJ and Kim SY. Assessing the quality of democratic deliberation: a case study of public deliberation on the ethics of surrogate consent for research. Soc Sci Med. 2010; 70: 1896-903.

14. van der Dam SS, Abma TA, Molewijk AC, Kardol MJ, Schols JM and Widdershoven GA. Organizing moral case deliberation experiences in two Dutch nursing homes. Nursing ethics. 2011; 18: 327-40.

15. Collopy B, Boyle P and Jennings B. New directions in nursing home ethics. Hastings Cent Rep. 1991; 21: S1-15.

16. Whiteneck MR. Integrating ethics with quality assurance in long term care. QRB Qual Rev Bull. 1988; 14: $138-43$.

17. Schneider RL and Kropf NP. The admission process in nursing homes: a clinical model for ethical decision-making. Journal of Long Term Home Health Care. 1996; 15: 39-46.

18. Bolmsjo IA, Sandman L and Andersson E. Everyday ethics in the care of elderly people. Nurs Ethics. 2006; 13: 249-63.

19. Kelly $\mathrm{C}$ and Lazaroff A. Learning to pay attention. An ethics study group refocuses on issues affecting long-term care residents' daily lives. Health Prog. 1993; 74: 40-3, 52.

20. Dam van der S, Molewijk AC, Widdershoven GAM and Abma TA. Ethics support in institutional elderly care: a review of the literature. SUBMITTED. 2012.

21. Miller JF. Opportunities and obstacles for good work in nursing. Nursing ethics. 2006; 13: 471-87.

22. Ash A. Ethics and the street-level bureaucrat: implementing policy to protect elders from abuse. Ethics and Social Welfare. 2010; 4: 202-9.

23. Weidema FC, Molewijk AC, Widdershoven GA and Abma TA. Enacting Ethics: Bottom-up Involvement in Implementing Moral Case Deliberation. Health Care Anal. 2011.

24. Tronto JC. Creating caring institutions:politics, plurality, and purpose. Ethics and Social Welfare. 2010; 4: 158-71.

25. Widdershoven GAM and Molewijk AC. Philosophical foundations of clinical ethics. A hermeneutic perspective. In: Schildmann J, Gordon JS and Vollmann J, (eds.). Clinical ethics consultation Theories and methods, implementation, evaluation. Surrey: Ashgate, 2010, p. 37-52.

26. Singer PA, Pellegrino ED and Siegler M. Clinical ethics revisited. BMC Med Ethics. 2001; 2: E1.

27. McCarrick PM. Ethics Committees in hospitals. Scope Note 3. Washington DC: National Reference Centerfor Bioethics Literature Kennedy Institute of Ethics, 1992.

28. Thompson MA and Thompson JM. Ethics committees in nursing homes: a qualitative research study. HEC Forum. 1990; 2: 315-27.

29. Program clarifies ethical issues in care of the dying patient. Health Prog. 1984; 65: 16-8. 
30. Abma TA, Molewijk B and Widdershoven GA. Good care in ongoing dialogue. Improving the quality of care through moral deliberation and responsive evaluation. Health Care Anal. 2009; 17: 217-35.

31. Irvine R, Kerridge I and McPhee J. Towards a dialogical ethics of interprofessionalism. J Postgrad Med. 2004; 50: 278-80.

32. Doucet H. Ethical deliberation in multiprofessional health care teams. Ottawa: University of Ottawa Press, 2001.

33. Dartel van JN. Van ethische commissie naar stuurgroep ethiek? [From ethics committee to steering committee]. Utrecht: CELAZ/Nederlandse Zorgfederatie, 1998.

34. Leino-Kilpi H, Valimaki M, Dassen T, et al. Perceptions of autonomy, privacy and informed consent in the care of elderly people in five European countries: general overview. Nursing ethics. 2003; 10: 18-27.

35. Abma TA and Stake RE. Responsive evaluation: Roots and evolution. . In: Greene JC and Abma TA, (eds.). Responsive evaluation: New directions for evaluation. San Fransisco: Jossey-Bass, 2001, p. 7-22.

36. Lincoln Y and Guba E. Naturalistic inquiry. New York: Sage, 1985.

37. Rogers EM. Diffusion of innovations. 5th ed. New York: Free Press, 2003, p.xxi, 551 p.

38. Weidema FC, Abma TA, Widdershoven GA and Molewijk AC. Client participation in moral case deliberation: a precarious relational balance. HEC forum : an interdisciplinary journal on hospitals' ethical and legal issues. 2011; 23: 207-24.

39. Leino-Kilpi H, Valimaki M, Dassen T, et al. Perceptions of autonomy, privacy and informed consent in the care of elderly people in five European countries: comparison and implications for the future. Nursing ethics. 2003; 10: 58-66.

40. Rees J, King L and Schmitz K. Nurses' perceptions of ethical issues in the care of older people. Nursing ethics. 2009; 16: 436-52.

41. Abma T, Bruijn A, Kardol T, Schols J and Widdershoven G. Responsibilities in elderly care: Mr Powell's narrative of duty and relations. Bioethics. 2012; 26: 22-31.

42. Teeri S, Leino-Kilpi $\mathrm{H}$ and Valimaki M. Long-term nursing care of elderly people: identifying ethically problematic experiences among patients, relatives and nurses in Finland. Nursing ethics. 2006; 13: 11629.

43. State Secretary of Health Care WaS. Letter to House of Representatives, MEVA/BO-3102550. In: Ministry of Health Care Was, (ed.). The Hague2012.

44. Vanlaere L, Coucke T and Gastmans C. Experiential learning of empathy in a care-ethics lab. Nursing ethics. 2010; 17: 325-36.

45. Schols JMGA and Wierik te MJM. Verpleeghuiszorg buiten de muren: dagbehandeling, consultatie en substitutieprojecten [extramural nursing home care: daycare, consultation and substitution projects]. Ned Tijdschr Geneeskd. 1993; 137: 2717-22.

46. Preventie bij ouderen: focus op zelfredzaamheid. Publicatienr. 2009/07 [Prevention in the elderly: focus on functioning in daily life. Publication no. 2009/07]. Den Haag [The Hague]: Gezondheidsraad [Health Council of the Netherlands], 2009. 
Summary 
In the Netherlands, about $4,5 \%$ of the 2,6 million people over the age of 65 live in a residential institution for elderly care, either a care home (for assistance with ADL and social activities) or a nursing home (for more intensive or complex care and treatment). Daily care in care homes and nursing homes is provided by nurses and nursing aides.

The importance of ethics support in elderly care has been stressed in the literature. Professionals in elderly care have to deal with conflicting interests, difficult behavior, limited resources and social problems between residents who did not choose to live together, causing feelings of moral distress. In the Netherlands, the Ministry of Health, Welfare and Sport acknowledged that 'making explicit the ethical aspects of working in health care - from nursing assistant to manager - will make an important contribution to the quality of care and a respectful treatment of patients or clients'. Moral case deliberation (MCD) was presented by the Ministry as an 'instrument that can be used to recognize dilemmas and to notice the underlying values', in order to improve the quality of care.

This thesis consists of two parts. Part 1 deals with ethics support in elderly care in general, part 2 concentrates on the evaluation of an MCD project in two Dutch elderly care organizations.

\section{PART 1}

The first part of this thesis (chapters 2 and 3) explored the field of ethics support in elderly care from an international perspective and investigated the specific needs for ethics support in elderly care in the Dutch context.s

\section{CHAPTER 1}

This chapter provides a general introduction to the thesis. It describes the background and developments of ethics support and MCD and it presents the main research question of the thesis.

Ethics support, often delivered through clinical ethics support services (CESS), aims to support health care professionals in their provision of high quality care and in dealing with ethical problems in daily practice. In institutional elderly care, clinical ethics supports services have started in the 1970s. In the Netherlands, the most popular type of ethics support is the Clinical ethics committee (CEC), but other ethics support forms have also been developed. Today, in the Netherlands $15 \%$ of the elderly care organizations do not have any form of ethics support. The past decade the Dutch government has supported the development and implementation of MCD in care organizations in order to improve the quality of care. This thesis places the developments with respect to MCD and ethics support in Dutch elderly care in an international perspective.

The main research question was: What are the needs for ethics support in residential elderly care, and how can MCD meet those needs and provide a space for care workers to address ethical issues and emotional challenges to realize good care? 


\section{CHAPTER 2}

This chapter presents an overview of the ethics support mechanisms that have been developed internationally. A review of the literature was performed in three electronic databases (Pubmed, CINAHL/PsycINFO, Ethxweb). Sixty papers were included in the review. The ethics support mechanisms are classified in four categories: institutional bodies (ethics committee and consultation team); frameworks; educational programs and moral case deliberation; and, written documents and policies. For each category the goals, methods and ways of organizing are described. Ethics support often serves several goals and can be targeted at more than one level: the case, the professional or the organization.

Over the past decades a number of changes have taken place in the development of ethics support in elderly care. Considering the goals, ethics support has become more outreaching and pro-active, aiming to qualify professionals and to integrate ethics in daily decision making processes. The spectrum of methods in ethics support has become more diverse and better adapted to the concrete learning style of the nursing staff and more focused on everyday ethical issues. Ethics support has become less centrally organized and more connected to the organizational context. Clarity on the theoretical underpinnings of ethics support and transparency about design, data collection and analysis of empirical research are needed in the future in order to assess and compare the actual contribution of each kind of ethics support service to the quality of care in elderly care.

\section{CHAPTER 3}

This chapter systematically investigates the specific needs for ethics support in elderly care using a mixed-methods design. The findings of two surveys, two focus groups and 17 interviews demonstrate that the availability of ethics support is limited in the Netherlands. There is a need for ethics support, albeit not unconditionally. The kinds of ethical issues that health care professionals experience and the characteristics of these caregivers create a specific need for ethics support in elderly care. Advice-based forms of ethics support are less appropriate as they are removed from practice. Instead, ethics support should be integrated in daily practice and tailored to the often mundane and easily overlooked moral issues that arise in long-term care. Attention should also be given to the concrete learning styles of nurses who favor experiential learning. Traditional ethics support, such as the CEC, does not match well with these learning styles and the need for collective learning. Raising awareness and developing a climate of openness and dialogue are the most suitable ways to deal with the mundane moral issues in elderly care. 


\section{PART 2}

The second part (chapters 4 to 6 ) evaluated one specific form of ethics support, MCD, which was implemented in two Dutch elderly care organizations. In MCD, health care professionals meet to reflect and deliberate on ethical questions and dilemmas they experience in their own work. Starting point for the deliberation is a concrete case, in which at least the case-presenter, but sometimes the whole group, is involved. In a dialogue, structured by a conversation method and under the guidance of a facilitator, participants analyze the case by exploring the perspectives, values and norms of the stakeholders involved in the case and the participants present in the deliberation. Our MCD projects are based on a dialogical-hermeneutical approach which focuses on concrete experiences and is based on the assumption that ethics and morality start with actual experience, not with theories or concepts. The role of the ethicist or trained moderator in MCD is that of a facilitator, not an expert or consultant.

\section{CHAPTER 4}

This chapter presents an overview of the ethical issues that were brought forward by participants of the MCD projects in two Dutch elderly care organizations. The overview was inductively derived from all case descriptions $(N=202)$ provided by participants of seven mixed MCD groups, consisting of care providers from various professional backgrounds, from nursing assistant to physician. Analysis of the case descriptions pointed out that health care professionals in elderly care confront a wide variety of mainly everyday ethical issues. We distinguished three main categories: 'resident's behavior', 'divergent perspectives on good care' and 'organizational context'. Our research pointed out that the moral diversity in perspectives can be a source for moral distress. The presented overview can be used as an initial framework for agenda setting when institutions wish to stimulate ethical reflection and deliberation. In order to create commitment and tune in on the specific issues arising in a certain context it is important that an agenda is constructed bottom-up and open to a variety of ethical issues. In addition, organizing reflection and deliberation requires effort to identify moral questions in practice whilst at the same time maintaining the connection with the organizational context and existing communication structures. Such connection is needed to prevent ad hoc solutions, and to learn from and translate cases into policy measures.

\section{CHAPTER 5}

This chapter focuses on the implementation of MCD in nursing homes and the questions how and where to organize MCD. The purpose of this study was to evaluate one way of organizing MCD in two Dutch nursing homes. In both of these nursing homes the MCD groups had a heterogeneous composition and were organized apart from existing institutional communication structures. As part of a naturalistic evaluation systematic observations, interviews and focus groups were completed. The findings 
indicate that the heterogeneous composition and MCD meetings separately from existing structures have benefits (e.g. a broadening of horizons, enriched moral inquiry, and safety and openness). However, the participants also reported negative experiences (e.g. differences in involvement and competence, distance from practice, and a gap with the rest of the team). This gives rise to the question whether a mixed MCD group which meets separately is an effective way to embed MCD as an instrument for reflection on moral issues in daily practice. A successful implementation may require a start of MCD in the protected environment of a mixed group of enthusiastic pioneers, it certainly requires support from the management and an investment of enough time and money to give professionals throughout the institution the chance of gaining experience with $\mathrm{MCD}$, and to integrate MCD in existing communication structures.

\section{CHAPTER 6}

This chapter aims to evaluate the process of implementation of MCD focusing on the learning experiences of care workers over time. The article is grounded in a naturalistic evaluation of the implementation of MCD in two elderly care institutions. Methods included interviews, participant observations and focus groups. Before the start of the MCD groups there was ambiguity towards ethical reflection and deliberation. Next to hopes and expectations, relating to an expected and wished-for increase of moral awareness and relief of moral distress, employees expressed doubts about the usefulness and benefits of MCD. Staff also questioned the appropriateness of MCD for nurses and care assistants, and they perceived organizational impediments. Gaining experience with MCD brought about a learning process in which both the learning of competence for ethical reflection and deliberation (e.g. an exploratory attitude) and experiencing the benefits (e.g. relief of moral distress) were key elements. We conclude that doing ethics is the best way to intrinsically motivate practitioners to engage in moral deliberations on the work floor. Gaining practical experience should be explicitly stimulated bottom-up and facilitated top-down.

\section{CHAPTER 7}

This chapter discusses the main findings of the above described studies. With respect to the main research question, we conclude that MCD can meet the specific needs for ethics support in elderly care in a number of ways. In the first place, MCD can offer a recognizable space within the institution where the moral dimension of care is made explicit and where employees are enabled to deliberate on their ethical issues. MCD can offer safety and openness for health care professionals to engage in a dialogue and to acquire the competence needed for this. MCD creates a conversational space to address a multiplicity of perspectives on good care, to explore underlying values and to create mutual understanding. It also gives voice to care givers and nursing aids, who often feel that their perspective is left out. Furthermore, MCD might prevent routine ways of working by triggering caregivers to examine an ethical issue from a different, new point 
of view. The guidance of a facilitator and the use of a conversation method help to structure the conversation and to keep the focus on the moral dimension. In the second place, MCD strongly connects to what is going on at the work floor by taking the experiences of health care professionals as a starting point and aiming at the development of health care worker's phronesis.

Our findings offer future directions and challenges for practice and research. With respect to education and practice it is important that health care professionals already become trained in engaging in reflection and deliberation during their education. Practicing MCD at school may strengthen the moral competence of students. Considering the concrete learning style of, in particular, nursing aides, it is recommended to combine forms of ethics support that focus on ethical reflection and deliberation with other interactive and embodied forms of ethics support, such as simulations where care workers are actually experiencing themselves what it means to be a resident and dependent on the care of others.

However, MCD should not exclusively focus on care assistants and nurses, but should involve all layers and stakeholders of the organization to create a more ethicallyresponsive culture within the institution. In addition, the residents and their families should be more actively involved in deliberation to exemplify the meaning of ethical issues from their perspectives. Further and future research is needed with respect to what MCD can mean for professionals who work in the secondary care processes and for residents and their families. Also, future research is needed to systematically investigate the way(s) in which MCD has an effect on moral distress of staff and the wellbeing of residents and their families. In the light of the developments regarding extramuralisation elderly care, research is needed into the possibilities to organize ethics support in home care. 
Samenvatting 
Momenteel wonen in Nederland ongeveer 2,6 miljoen 65-plussers. Ongeveer 4,5\% van hen woont in een residentiële instelling voor ouderenzorg, ofwel een verzorgingshuis (voor hulp bij ADL en sociale activiteiten) of een verpleeghuis (voor meer intensieve of complexe zorg en behandeling). De dagelijkse zorg in verzorgings- en verpleeghuizen wordt geleverd door verzorgenden en verpleegkundigen.

Het belang van ethiekondersteuning in de ouderenzorg wordt onderstreept in de literatuur. Professionals in de ouderenzorg hebben te maken met tegenstrijdige belangen, beperkte middelen, 'lastig' gedrag en sociale problemen tussen bewoners onderling. Dergelijke lastige situaties kunnen morele stress en emotionele problemen veroorzaken. Het Ministerie van Volksgezondheid, Welzijn en Sport (VWS) erkent dat 'het expliciet maken van de ethische aspecten van het werken in de zorg in alle lagen van de organisatie- van ziekenverzorgenden tot en met manager -een belangrijke bijdrage levert aan de kwaliteit van het handelen, en aan een respectvolle bejegening van patiënten en cliënten.' Moreel Beraad (MB) wordt door het Ministerie gezien als 'een voorbeeld van een instrument dat ingezet kan worden om die verschillende dilemma's te erkennen en de onderliggende waarden te benoemen. Op die manier kunnen zorgverleners, managers en andere betrokkenen binnen kaders ethisch reflecteren op een onderwerp als bejegening van patiënten en cliënten. Het nut en de noodzaak om binnen instellingen met elkaar in gesprek te gaan over meer en minder dagelijkse morele dilemma's blijken in de praktijk aanwezig.'

Dit proefschrift bestaat uit twee delen. Deel 1 gaat over ethiekondersteuning in de ouderenzorg in het algemeen, deel 2 richt zich op de evaluatie van een MB project in twee Nederlandse ouderenzorg organisaties.

\section{DEEL 1}

Het eerste deel van dit proefschrift (hoofdstukken 2 en 3) gaat in op ethiekondersteuning in de ouderenzorg vanuit een internationaal perspectief en de specifieke behoeften aan ethiekondersteuning in de ouderenzorg in de Nederlandse context.

\section{HOOFDST K 1}

Dit hoofdstuk geeft een algemene inleiding op het proefschrift. Het beschrijft de achtergrond en ontwikkeling van ethiekondersteuning en MB en sluit af met de centrale onderzoeksvraag van dit proefschrift.

Ethiekondersteuning heeft tot doel professionals in de gezondheidszorg te ondersteunen in het aanbieden van kwalitatief hoogwaardige zorg en in het omgaan met ethische problemen in de dagelijkse praktijk. In de institutionele ouderenzorg, is ethiekondersteuning ontstaan in de jaren zeventig. De meest populaire vorm hiervan in Nederland is de ethische commissie (EC), maar in de loop van de tijd zijn ook andere vormen van ethiekondersteuning ontwikkeld. Vandaag de dag, heeft ongeveer 15\% van de ouderenzorg instellingen in Nederland geen enkele vorm van ethiekondersteuning. 
Het afgelopen decennium heeft het Ministerie van VWS de ontwikkeling en implementatie van MB in zorgorganisaties gesteund om de kwaliteit van de zorg te verbeteren. Dit proefschrift plaatst de ontwikkelingen met betrekking tot MB en ethiekondersteuning in de Nederlandse ouderenzorg in een internationaal perspectief.

De centrale onderzoeksvraag luidt: Wat zijn de behoeften aan ethiekondersteuning in de residentiële ouderenzorg, en hoe kan MB aan deze behoeften tegemoet komen en ruimte bieden aan hulpverleners om ethische kwesties en emotionele problemen aan te pakken teneinde goede zorg te realiseren?

\section{HOOFDSTU 2}

Dit hoofdstuk geeft een overzicht van de vormen van ethiekondersteuning die internationaal zijn ontwikkeld. Een literatuurstudie (review) werd uitgevoerd in drie elektronische databases (Pubmed, CINAHL / PsycINFO, Ethxweb). Zestig publicaties werden opgenomen in de review. De vormen van ethiekondersteuning zijn ingedeeld in vier categorieën: 'institutionele organen' (ethische commissie en consult team); 'stappenplannen'; 'educatieve programma's en MB', en, 'protocollen en beleid'. Voor elke categorie zijn de doelen, methoden en organisatiewijzen beschreven. Ethiekondersteuning dient meestal verschillende doelen en richt zich op meerdere niveaus: de casus, de professional of de organisatie.

In de afgelopen decennia heeft een aantal veranderingen plaatsgevonden in de ontwikkeling van ethiekondersteuning in de ouderenzorg. Ten aanzien van de doelstellingen is ethiekondersteuning meer outreachend en pro-actief geworden, om zorgverleners beter te kwalificeren en om ethiek te integreren in de dagelijkse praktijk. Het spectrum van methoden in de ethiekondersteuning is diverser geworden en beter afgestemd op de concrete leerstijl van het verplegend personeel en meer gericht op de alledaagse ethische kwesties. Ethiekondersteuning wordt minder vaak centraal georganiseerd en meer verbonden met de organisatorische context. Helderheid over de theoretische achtergronden van ethiekondersteuning en transparantie over het design, data verzameling en analyse van empirisch onderzoek is nodig om in de toekomst te kunnen beoordelen en vergelijken wat de daadwerkelijke bijdrage van elke vorm van ethiekondersteuning is aan de kwaliteit van de ouderenzorg.

\section{HOOFDSTU 3}

Dit hoofdstuk gaat in op de specifieke behoeften aan ethiekondersteuning in de ouderenzorg, die zijn onderzocht met behulp van een mixed-methods design. De bevindingen van twee verschillende enquêtes, twee focusgroepen en 17 interviews tonen onder meer aan dat de beschikbaarheid van ethiekondersteuning beperkt is in Nederland. Er is weliswaar behoefte aan ethiekondersteuning, zij het niet onvoorwaardelijk. De typen ethische kwesties waarmee zorgverleners worden geconfronteerd in hun werk en de kenmerken van deze zorgverleners, creëren een specifieke behoefte aan ondersteuning in de ouderenzorg. Vormen van ethiekondersteuning die gebaseerd zijn op advies van 
experts, zijn minder geschikt vanwege de afstand tot de dagelijkse praktijk. In plaats daarvan moet de ethiekondersteuning worden geïntegreerd in die dagelijkse praktijk en toegerust zijn op de vaak alledaagse ethische kwesties, die talrijk zijn in de ouderenzorg, maar ook gemakkelijk over het hoofd worden gezien. Ook moet aandacht worden besteed aan de concrete leerstijlen van zorgverleners die doorgaans vooral door ervaring leren. Traditionele vormen van ethiekondersteuning, zoals de ethische commissie, sluiten niet goed aan bij deze leerstijl en de behoefte aan collectief leren. Bewustwording en het ontwikkelen van een klimaat van openheid en dialoog zijn de meest geschikte manieren om het omgaan met alledaagse ethische kwesties in de ouderenzorg te bevorderen.

\section{DEEL 2}

Het tweede deel van dit proefschrift (hoofdstukken 4 tot en met 6) betreft de evaluatie van de implementatie van één specifieke vorm van ethiekondersteuning, Moreel Beraad (MB), in twee Nederlandse ouderenzorg organisaties. Een MB is een bijeenkomst waarin zorgverleners op een systematische manier gezamenlijk reflecteren op ethische vragen en dilemma's die zij ervaren in hun eigen werk. Uitgangspunt voor het MB is een concrete casus, waarbij ten minste de casus-inbrenger, maar soms ook de hele groep, betrokken is. In een dialoog, onder leiding van een gespreksleider en gestructureerd met behulp van een gespreksmethode, analyseren de deelnemers de casus. Ze verkennen de perspectieven, waarden en normen van de stakeholders die betrokken zijn bij de casus en van de aanwezige deelnemers aan het MB. Onze MB projecten zijn gebaseerd op een dialogische-hermeneutische benadering die uitgaat van concrete ervaringen en de veronderstelling dat ethiek en moraal beginnen met de werkelijke ervaring, en niet met theorieën of concepten. De rol van de ethicus of getrainde gespreksleider in het MB is die van een facilitator, niet die een expert of consultant.

\section{HOOFDSTU 4}

Dit hoofdstuk geeft een overzicht van de ethische kwesties die naar voren werden gebracht door de deelnemers van de MB projecten in twee Nederlandse ouderenzorg organisaties. Het overzicht is op een inductieve manier verkregen uit alle casusbeschrijvingen $(\mathrm{N}=202)$ die door de deelnemers van de zeven gemengde MB groepen, bestaande uit zorgverleners met verschillende professionele achtergronden (van verzorgende tot arts) zijn aangeleverd. De analyse van de casusbeschrijvingen wijst uit dat zorgverleners in de ouderenzorg een breed scala aan voornamelijk alledaagse ethische kwesties tegenkomen. We onderscheiden drie domeinen: 'gedrag van de bewoner', 'uiteenlopende perspectieven op goede zorg', en 'de organisatorische context'. Uit ons onderzoek blijkt dat morele diversiteit een bron van morele stress kan zijn. Het gepresenteerde overzicht kan worden gebruikt als een kader bij het agenderen van ethische reflectie en overleg in instellingen die dit willen stimuleren. Voor het genereren van 
betrokkenheid en afstemming op de specifieke problemen die zich in een bepaalde context voordoen, is het belangrijk dat een dergelijke agenda bottom-up in de organisatie wordt geconstrueerd en open staat voor een verscheidenheid aan ethische kwesties. Daarnaast vergt het organiseren van reflectie en overleg inspanning om morele vraagstukken in de dagelijkse praktijk te herkennen, terwijl tegelijkertijd de verbinding moet worden gezocht met de organisatorische context en de bestaande communicatiestructuren. Dit is nodig om ad hoc oplossingen te voorkomen, en om te leren van casussen en deze te vertalen in beleid.

\section{HOOFDSTU 5}

Dit hoofdstuk evalueert de implementatie van MB in twee Nederlandse verpleeghuizen met als centrale vragen hoe en waar MB te organiseren. In beide verpleeghuizen hadden de MB groepen een heterogene samenstelling en werden zij georganiseerd buiten de bestaande institutionele communicatiestructuren. Als onderdeel van een naturalistische evaluatie werden observaties, interviews en focusgroepen uitgevoerd. De bevindingen wijzen erop dat de heterogene samenstelling en het organiseren van MB bijeenkomsten buiten bestaande communicatiestructuren voordelen hebben (zoals een horizon verbreding, verrijking van het morele onderzoek, en veiligheid en openheid). Echter, de deelnemers ervoeren ook nadelen hiervan (zoals verschillen in betrokkenheid en competentie, afstand tot de praktijk, en een kloof met de rest van het team). Dit geeft aanleiding tot de vraag of een gemengde MB groep die los van bestaande communicatiestructuren wordt georganiseerd, voldoet als manier om MB in te bedden als instrument voor reflectie op ethische kwesties in de dagelijkse praktijk. De beschermende omgeving van een gemengde groep van enthousiaste pioniers mag dan een stimulans vormen voor een succesvolle implementatie van $\mathrm{MB}$, onontbeerlijk zijn de steun van het management en het vrijmaken van voldoende tijd en geld om professionals binnen de instelling de kans te geven om ervaring op te doen met MB en ethische reflectie te integreren in bestaande communicatiestructuren.

\section{HOOFDSTUK 6}

In dit hoofdstuk wordt het implementatieproces van MB geëvalueerd met een focus op de leerervaringen van de deelnemers door de tijd heen. Het hoofdstuk is gebaseerd op een naturalistische evaluatie van de MB projecten in beide ouderenzorg organisaties, met interviews, participerende observaties en focusgroepen als onderzoeksmethoden. Voor de start van de MB groepen was er sprake van ambivalentie ten opzichte van ethische reflectie en overleg. Naast hoop en verwachtingen ten aanzien van morele bewustwording en verminderen van morele stress, uitten medewerkers ook twijfels over het nut en de meerwaarde van MB. Er werden vraagtekens geplaatst bij de geschiktheid van $\mathrm{MB}$ voor verzorgenden en men zag organisatorische belemmeringen. Het opdoen van ervaring met MB leidde tot een leerproces waarin zowel het ontwikkelen van competenties voor ethische reflectie en overleg (bijvoorbeeld een onderzoekende houding) 
als het ervaren van de voordelen (bijv. verlichting van morele stress) kernelementen waren. De conclusie is dat het doen van ethiek de beste manier is om medewerkers intrinsiek te motiveren om deel te nemen aan MB op de werkvloer. Het opdoen van praktijkervaring met MB zou expliciet bottom-up moeten worden gestimuleerd en topdown gefaciliteerd.

\section{HOOFDST K 7}

In dit hoofdstuk worden de belangrijkste bevindingen van de hierboven beschreven studies op een rij gezet. Met betrekking tot de centrale onderzoeksvraag, kunnen we concluderen dat $\mathrm{MB}$ op verschillende manieren tegemoet kan komen aan de specifieke behoeften voor ethiekondersteuning in de ouderenzorg. In de eerste plaats, kan MB herkenbare ruimte bieden binnen zorginstellingen, waar de morele dimensie van de zorg expliciet benoemd wordt en waar werknemers in staat worden gesteld om te reflecteren en delibereren over hun ethische kwesties. MB kan veiligheid en openheid bieden zodat zorgprofessionals in dialoog kunnen gaan en de daarvoor benodigde competenties kunnen ontwikkelen. MB zorgt voor ruimte om met elkaar te spreken over de perspectieven op goede zorg, om de onderliggende waarden te verkennen en om wederzijds begrip te creëren. MB geeft ook een stem aan verzorgenden, wiens perspectief soms niet gehoord wordt. Bovendien kan door MB routinematig werken worden voorkomen, doordat zorgverleners worden uitgedaagd om ethische kwesties vanuit andere, nieuwe perspectieven te verkennen. Begeleiding door een gespreksleider en het hanteren van een gespreksmethode helpen om het beraad te structureren en om de focus op de morele dimensie te houden. In de tweede plaats, is MB sterk verbonden met wat er gaande is op de werkvloer doordat MB de ervaringen van de zorgverleners als uitgangspunt neemt en het ontwikkelen van phronesis bij de zorgverleners zelf tot doel heeft.

Onze bevindingen bieden handreikingen voor toekomstige ontwikkelingen voor zowel praktijk als onderzoek. Met betrekking tot educatie en praktijk is het van belang dat professionals in de gezondheidszorg al tijdens hun opleiding worden getraind in reflectie en overleg. Oefenen met MB in onderwijssituaties kan bijdragen aan het ontwikkelen van morele competenties van studenten. Gezien de concrete leerstijl van, in het bijzonder verzorgenden, is het raadzaam om vormen van ethiekondersteuning die zich richten op ethische reflectie en overleg te combineren met andere interactieve en belichaamde vormen van ethiekondersteuning, zoals simulaties waarbij zorgpverleners zelf ervaren wat het betekent om een bewoner te zijn en afhankelijk van de zorg van anderen.

Er moet echter voor gewaakt worden dat MB zich niet uitsluitend richt op verzorgenden, maar op alle lagen en belanghebbenden in de organisatie, zodat een meer ethisch-responsieve cultuur tot stand wordt gebracht binnen de instelling. Daarnaast zouden bewoners en hun familieleden actiever betrokken moeten worden bij overleg om ethische vraagstukken vanuit hun perspectief te illustreren. Toekomstig onderzoek is nodig met betrekking tot wat MB kan betekenen voor medewerkers die werkzaam zijn in het secundaire zorgproces en voor de bewoners en hun families. Ook is verder 
onderzoek nodig om systematisch in beeld te brengen op welke manier (en) MB effect heeft op het ervaren van morele stress door medewerkers en op het welzijn van de bewoners en hun familie. In het licht van de ontwikkelingen op het gebied van extramuralisering van de ouderenzorg, is onderzoek nodig naar de mogelijkheden om ethiekondersteuning in de thuiszorg te organiseren. 



\section{Dankwoord}

Het is volbracht!

Op deze plaats wil ik graag de mensen bedanken die gedurende de rit aan mijn zijde stonden. Soms dichtbij, soms meer op afstand, ... zonder jullie steun was ik niet zover gekomen ...

Allereerst, veel dank voor Tineke Abma. Nadat je eind 2009 had meegeschreven aan een nieuwe versie van mijn eerste artikel, werd je in januari 2010 officieel als begeleider betrokken bij mijn promotietraject. Ik had de handdoek destijds bijna in de ring gegooid, maar jij dacht vol enthousiasme mee over de rode draad van mijn proefschrift. Je woorden in de eerste mail na ons gesprek, "beste sandra, zie goede mogelijkheden, tot snel, tineke", vormden het begin van de weg omhoog naar het eindresultaat. Bedankt Tineke, voor het inspireren, coachen en meeschrijven!

Guy Widdershoven, jou wil ik bedanken voor je jarenlange betrokkenheid en vertrouwen vanaf het begin. Je snelle en rake commentaar op conceptteksten waren heel welkom. Je praktische insteek, "niet teveel vragen stellen, ga 't maar gewoon doen", heeft veel opgeleverd.

Tinie Kardol, bedankt voor de kans die je me hebt gegeven om in Vughterstede aan de slag te gaan met moreel beraad. Ik heb jouw, door de praktijk gevoede, kritische blik en persoonlijke touch ('t gebakje bij de eerste begeleidingscommissie na Marinus' geboorte) altijd zeer gewaardeerd.

Bert Molewijk, jouw bevlogenheid en gedrevenheid waren heel inspirerend. Je pionierswerk in de praktijk en het onderzoek naar moreel beraad is bewonderenswaardig. Toen je me in 2006 op mijn verjaardag belde om te vertellen dat ik was aangenomen, gaf je me een geweldige kans om jarenlang deel uit te kunnen maken van een inspirerende Moreel Beraadclub.

Jos Schols, ook jij bedankt voor de kans die je me gegeven hebt om in Vivre het moreel beraad op te starten. Ook al stopten de projecten eerder dan voorzien, je bleef altijd betrokken bij mijn promotietraject, onder meer als medeauteur. Je wervelende enthousiasme en supersnelle commentaar waren heel behulpzaam.

Op deze plek wil ik ook de deelnemers aan de moreel beraadgroepen en alle anderen die bij de moreel beraad projecten en het onderzoek betrokken waren, bedanken voor hun inspanningen, enthousiasme en openheid.

Mijn collega's van de vakgroep Metamedica in Maastricht bedank ik omdat zij mij een echte thuisbasis bleven bieden nadat veel van mijn collega's in 2009 met Guy en Tineke naar Amsterdam waren vertrokken. In het bijzonder wil ik noemen: Antina de Jong, Yolanda Turksema, Anna Wolters, Els Geelen, Claudia Pitz, Lineke van Hal, Rob Hou- 
tepen, Bèr Crouzen en Angelique Heijnen. Ook wil ik hier enkele oud-collega's noemen, met wie ik contact ben blijven houden: Sandra Reijntjens, Albine Moser en Yvonne Goertz.

David Townend, dank voor je interesse in mijn artikelen en de hulp bij 't Engels.

Wil Botden, jij bent een belangrijke steun en klankbord geweest toen ik in 2008 mijn promotie weer op de rails moest krijgen en in de jaren daarna ging nadenken over het leven na de promotie (dat uiteindelijk 2 jaar voor afronding van het boekje al begon ...).

Hilde en Anita, jullie heb ik leren kennen tijdens onze eerste CaRe course. De afgelopen jaren hebben we regelmatig tijdens een etentje ons promotie- en persoonlijk lief en leed gedeeld. Wat mij betreft zetten we deze traditie voort!

Mijn moreel beraad collega's, eerst aan de UM (ik denk ook aan oud-collega Saskia Ranson) en later het VUMC zijn onmisbaar geweest voor mijn vorming, zowel persoonlijk als op werkgebied. Margreet Stolper, Arnold van Elteren, Linda Dauwerse, Froukje Weidema en Karin Pasman, ontzettend bedankt!

Bijna tweeënhalf jaar geleden solliciteerde ik bij de afdeling Beleidsinformatie \& onderzoek van de gemeente Eindhoven, een kans die ik niet kon laten liggen. Het was niet altijd makkelijk deze baan te combineren met het werken aan mijn proefschrift. Teamleider Carla waarschuwde destijds (uit eigen ervaring) dat het zwaar zou worden. Helaas kan ze nu niet meer meedelen in de vreugde dat het gelukt is. Ik heb veel gehad aan de belangstelling, het meeleven en meevieren van mijn collega's: Eveline, Hein-Willem, Freek, Marij, Harry, Jan, Kees, Cecilia, Marja, Jeanine en Ingrid.

En dan, last but not least, mijn vriendinnen, vrienden en mijn thuisfront. Lieve Margriet, Linda, Henriëtte, Katja, Loes, Anneke, Nynke, Eppie, André \& Suzanne, Michel \& Samantha, Jeroen \& Yvonne, Marieke, Judith, Steffie, Marlies en Sigrid, veel dank voor jullie belangstelling, plezierige afleiding en onmisbare steun! Laten we weer eens afspreken!

De laatste regels zijn voor mijn naasten. Mijn moeder, luisterend oor en praktische steun. Altijd vol praktijkverhalen uit het verzorgingshuis waar je werkt. Jaren geleden was moreel beraad 'ver van je bed', maar laatst zat je als trotse 'mem' tussen je collega's toen ik in jullie huis een presentatie over moreel beraad hield, we zullen 't ook in de toekomst nog vaak over die dagelijkse kwesties hebben! Ook mijn schoonouders hebben mijn promotieperikelen altijd met interesse gevolgd. Voortaan zal er meer tijd zijn om jullie te bezoeken!

Lieve Johannes, wat heb je veel met me te verduren gehad, altijd maar werken en geen tijd om de was op te vouwen, de administratie weg te werken of de vaatwasser in te ruimen. Dank voor je uithoudingsvermogen! Tussen de werkbeslommeringen door heeft onze liefde iets prachtigs voortgebracht: Marinus. Kleine schat, nu hoeft mama niet meer altijd te werken!. En tot slot, onze kleinste spruit, nog in mijn buik. Zonder dat je 't wist heb je met je getrappel de laatste loodjes lichter gemaakt. Lieverds, ik ben klaar en laten we daar samen van genieten! 


\section{Curriculum Vitae}

Sandra van der Dam kwam op 26 april 1974 ter wereld in Oudehorne (gemeente Heerenveen). Zij behaalde haar VWO diploma in 1992 aan de Rijksscholengemeenschap in Heerenveen. Daarna studeerde ze tot 1996 Sociaal Pedagogische Hulpverlening aan de Christelijke Hogeschool Noord Nederland (CHN) in Leeuwarden. Vervolgens ging ze in Amsterdam, aan de UvA, Sociologie van Verzorging en Beleid studeren, waar ze in 2000 afstudeerde. In 2001 werd Sandra aangesteld als junior medewerker binnen het programma Lokaal Zorgbeleid van het Nederlands Instituut voor Zorg \& Welzijn (NIZW, nu Vilans) in Utrecht. Van 2004 tot 2006 werkte ze als onderzoeker bij het Instituut voor Onderzoek naar Verslaving \& leefwijzen (IVO, Rotterdam) aan een etnografisch onderzoek naar harddruggebruikers in Heerlen. In 2006 begon ze als aio aan haar onderzoek naar 'moreel beraad in de ouderenzorg' aan de Universiteit Maastricht (UM), bij de vakgroep Metamedica (Health Ethics \& Society, HES) en de onderzoeksschool Caphri. Vanaf 2010 combineerde ze haar promotie onderzoek met haar baan als beleidsonderzoeker/adviseur bij de gemeente Eindhoven.

Sandra woont samen met Johannes Hofman. In 2009 kregen ze een zoon, Marinus. 